Portland State University

PDXScholar

6-1996

\title{
The Leadership of African American Women Constructing Realities, Shifting Paradigms
}

Gloria Murphy Gostnell

Portland State University

Follow this and additional works at: https://pdxscholar.library.pdx.edu/open_access_etds

Part of the Educational Assessment, Evaluation, and Research Commons, and the Educational Leadership Commons

Let us know how access to this document benefits you.

\section{Recommended Citation}

Gostnell, Gloria Murphy, "The Leadership of African American Women Constructing Realities, Shifting Paradigms" (1996). Dissertations and Theses. Paper 2695.

https://doi.org/10.15760/etd.2691

This Dissertation is brought to you for free and open access. It has been accepted for inclusion in Dissertations and Theses by an authorized administrator of PDXScholar. Please contact us if we can make this document more accessible: pdxscholar@pdx.edu. 
THE LEADERSHIP OF AFRICAN AMERICAN WOMEN: CONSTRUCTING REALITIES, SHIFTING PARADIGMS

by

GLORIA MURPHY GOSTNELL

A dissertation submitted in partial fulfillment of the requirements for the degree of

\author{
DOCTOR OF EDUCATION \\ in \\ EDUCATIONAL LEADERSHIP: \\ ADMINISTRATION
}

Portland State University

01996 
The abstract and dissertation of Gloria Murphy Gostnell for the Doctor of Education in Educational Leadership: Administration were presented June 5, 1996, and accepted by the dissertation committee and the doctoral program. COMMITTEE APPROVALS:

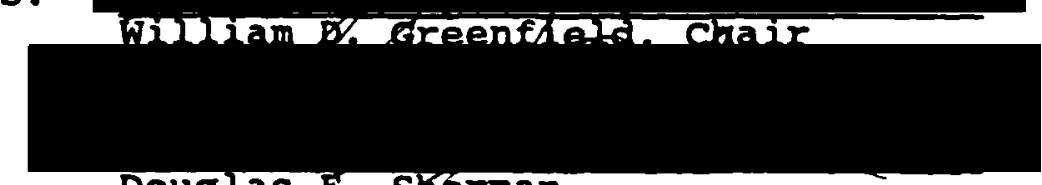

Douglas F. SKerman

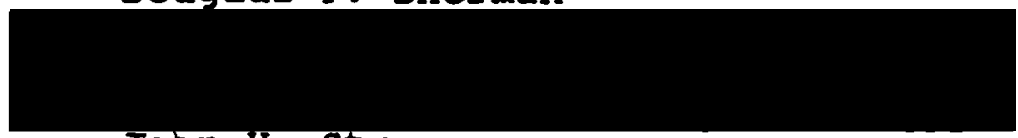

Joan H. Strouse

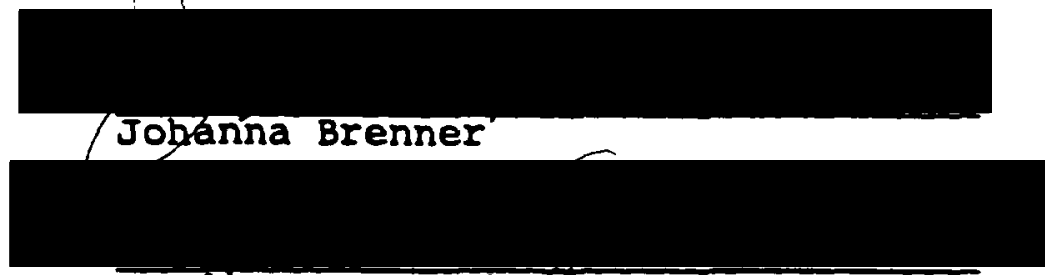

Candice $\bar{L}$. Goucher

Representative of the office of Graduate studies

DOCTORAL PROGRAM APPROVAL:

Robert B. Everhart, Dean

School of Education

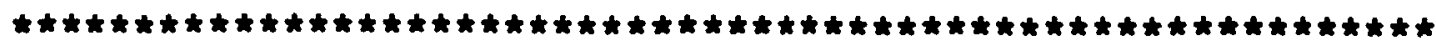

ACCEPTED FOR PORTLAND STATE UNIVERSITY BY THE LIBRARY

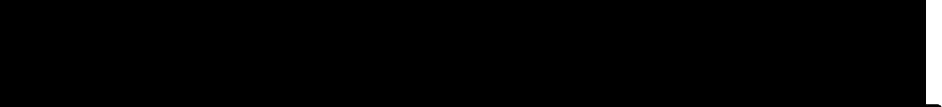

on Hlengest 199 


\section{ABSTRACT}

An abstract of the dissertation of Gloria Murphy Gostnell for the Doctor of Education in Educational Leadership: Administration presented June 5, 1996.

Title: The Leadership of African American Women: Constructing Realities, Shifting Paradigms

The purpose of this qualitative study was to learn more about leadership from the perspectives, norms, and values of a selected group of African American women leaders. I sought to develop a more inclusive view of the realities of leadership, and a better understanding of the impact of the interlocking status of race, gender, and social class on the practice, pursuit, and perceptions of leadership by these women.

This study is grounded in a Black women's standpoint, and places Black women's experiences at the center of analysis. In answer to the question "How do we know the world?," the standpoint suggests that Black women know the world as survivors and not as victims, as mothers, and as "other mothers." In answer to the question "What is the nature of reality?," Black women's standpoint embraces a reality that is defined by complexity and contradiction, 
by an acknowledgment that racism is a constant that must not become an excuse for giving in or giving up: that reality is self, internally defined. In answer to the question "How do Black women gain knowledge about the world?," the standpoint suggests that knowledge is gained through real life experience, by paying attention to the past and to the present, to the margins and to the center, to the pieces and to the whole, and by listening and responding to our own and each other's authentic voices (Collins, 1990).

of the seven women selected for the study, four are positional leaders: a high school principal, a senior level community college administrator, a state legislator, and the executive director of a large philanthropic foundation. Also participating were three non-positional leaders who work within their communities in different roles described in the study. I interviewed each respondent using a modified open interview schedule. Interviews lasted between one-and-a-half and three-and-ahalf hours.

Common themes emerging from the interviews included: (a) development of psychological and emotional resilience, (b) experiences of racism and sexism, (c) cultivation of a spiritual or religious life, (d) construction of a positive sense of self, and (e) a construct of connected leadership. 


\section{DEDICATION}

To my parents Augustine Murphy and the late Henderson Murphy, for the constancy of both their love and their high expectations. To my grandmother the late Mabel Dotson, and my aunt Nola Johnson who throughout my childhood also showed me that I was special in their eyes. And to my sister Loretta Young, my first friend who shared the secrets of my childhood. 


\section{ACKNOWLEDGEMENTS}

I would like to thank members of my Dissertation Committee for their help in seeing this work to fruition: my Chair, Dr. William Greenfield, Dr. Joan Strouse, Dr. Doug Sherman, Dr. Johanna Brenner, and Graduate office Representative, Dr. Candace Goucher.

The members of my women's dissertation group provided critical feedback, encouragement, and nourishment at crucial times during the development of the study. Thank you Penny Poplin-Gosetti, Leslie Rennie-Hill, and Lorna Kern.

The women in my Black women's reading group, my sister-friends, have served as both my real life models and my cheering section for the past five years, reflecting back to me the need to insert the voices of Black women into the dialogue wherever they are absent. Beverly, Avel, Emily, Karen, Rachael, my thanks for your ongoing presence in my life.

Our children Allyson, Jonathan, Nicole and Karla have taught, and continue to teach, me much about mothering and "other mothering," and I am a wiser, happier and more humble person because they share this journey with me. 
This study would not have been possible without the generosity of the women who opened their homes, offices, and hearts to me. They examined painful parts of their lives and trusted me with their confidences. With modesty, they described their leadership, and admitted that they are still "becoming." They participated in the study in order to help me to better understand their lives as African-American women leaders, and in the process to proclaim that "we are here, and we're not going away." I am very grateful for the ways in which they have enriched my life and furthered my understanding.

Finally, I wish to thank my friend and partner Dr. David R. Gostnell, whose loving encouragement and patience during my years of conducting this study, even now amazes me.

Pati sluys read through and edited several drafts of this study, providing indispensable assistance in preparation of the final document. I am grateful for her expertise and continual good humor. 
TABLE OF CONTENTS

PAGE

ACKNOWLEDGEMENTS. . . . . . . . . . . . . . . . . ii

CHAPTER

I INTRODUCTION . . . . . . . . . . . . 1

statement of Purpose . . . . . . . 5

Study Participants

Background of the study. . . . . . . 9

Power of the Paradigm. . . . . . . . 12

Importance of the study. . . . . . . 17

The Interview. . . . . . . . . . 18

Summary. . . . . . . . . . . 18

II IITERATURE REVIEW. . . . . . . . . . . . 20

Leadership Theory. . . . . . . . . 21

Traditional Theories of Leadership

Emergent Leadership Theories

Women and Leadership . . . . . . 30

Black Women's Leadership: What is Known?

Non-Positional Leadership

Dimensions of African American Women's

Experience .. . . . . . . . . . 42

Black Women: Family and Work

Black Women and Controlling Images 
Black Women and the Construction of

Self............. 52

Black Women Moving From silence to Speech

Black Women and Community

Black Women and Resiliency

Black Women and the Politics of Location

Summary of Chapter II. . . . . . . 61

III RESEARCH DESIGN AND METHODOLOGY. . . . . . 62

Purpose of the study and Basic Assumptions. . . . . . . . . . 62

Basic Assumptions of the Study Definition of Terms

Constructed Knowledge and Theoretical

Paradigms . . . . . . . . . . . 64

Critical Theory

Feminist Theory/Constructed

Knowledge

Black Women's Standpoint

Afro-Centric Feminist Epistemology:

A Paradigm

Locating Myself as Researcher . . . 76

Research Questions. . . . . . . 77

Development of Interview

Instrument

Respondents

Data collection

Interview Schedule Analysis of the Data

Limitations

Summary, Chapter III. . . . . . 86

IV THE RESPONDENTS SPEAK. . . . . . . . . . 87

Demographics . . . . . . . . . 88

Family

Siblings

Marital Status/Significant

Relationships 
Children

Community

Education

Social Class

Profiles............. 90

Paula's story

Kim's Story

Jean's Story

Audrey's Story

Betty's Story

Carla's story

Katy's story

summary. . . . . . . . . . 126

V DATA AND ANALYSIS. . . . . . . . . . . 128

Socio-Historical Influences. . . . . 129

Locating Myself as Researcher. . . . 130

Results. . . . . . . . . . 131

Resilience . . . . . . . . 133

Relevance of Resiliency Research to the Study of African American Women Leaders

Childhood/Family and Community . . . 136

Summary of this Section

Construction of Identity . . . . . . 142

Reading as a Primary Influence

Identity as struggle and Definition

Mentors and Friends

silence and Voice

Religion/Spirituality

Connectedness with Others

The Reality of Racism and Sexism

The Leadership of Black Women. . . . 169

Betty. . . . . . . . . . . 171

Carla. . . . . . . . . . 173

Kim. . . . . . . . . . . 175 
Jean . . . . . . . . . . . . 178

Paula. . . . . . . . . . . . 180

Audrey . . . . . . . . . . . . 181

Summary. . . . . . . . . . . . 186

VI DISCUSSION, CONCLUSIONS AND
RECOMMENDATIONS. • . . . . . . . . . . . 188

Restatement of Purpose of Study. . . . 189

Review of Research Questions. . . . 190

Emergent Themes. . . . . . . . . 190

Resiliency

Racism and Sexism

Reading as Primary Influence

Construction of a Positive Sense of Self

Methodological Discussion

Thoughts on Developing Leadership Potential in African American

Girls

On a Beginning Theory of Black Women's

Leadership: A Paradigm of Connected

Leadership... . . . . . . . . 202

Discussion . . . . . . . . . . 205

Summary. . . . . . . . . . . . 207

Limitations. . . . . . . . . . 208

Recommendations for Educational Policy

Foundations, and Administrative

studies. . . . . . . . . . . 209

REFERENCES. • . . . . . . . . . . . . . . . . 212

APPENDIX
A
LETTER TO PARTICIPANTS . . . . . . . 224
B PARTICIPANT PROFILES . . . . . . . . 226
C INTERVIEW SCHEDULES AND PROBES . . . . 229 
viii

D RESEARCH NOTE. . . . . . . . . . 234 


\section{CHAPTER I}

\section{INTRODUCTION}

The days of looking for leaders with the right endorsements and the right credentials as defined by an established elite are over. The leaders of the future will not come riding out of the sunset on white chargers--heroes without heroism. Many will instead be ordinary people with extraordinary commitments. Their styles will be different. Their accents will be different and so will their color and complexion. What most will have in common, however, is the commitment to a civil society. (Joseph, 1994, p. 5)

Joseph's (1994) concern about the kind of leadership needed in the coming "uncertain century" (Morse, 1994) is one that is shared by many. Especially during this present season of local and national elections, one is aware of the rhetorical and pallid nature of the debate that frames political electioneering, and of the superficial and tentative discussions surrounding the meaning and tasks of leadership. The absence of substantive and critical debate on the subject of leadership is not limited to political arenas alone, but is also noted in other organizational settings, including pre-collegiate and higher education, the for-profit and voluntary sectors, in all areas of the media, and elsewhere. For the most part when discussions on leadership are heard, they are rooted in an assumed view 
of leadership that traditionally has not considered the voices or the leadership of women or of men of color.

Paradigms positing leadership as hierarchical, and/or as charismatic, as precious, as primarily white and male, continue to dominate commonly held notions of leadership, and in many cases to shape the realities of day-to-day leadership practice. However, some (Joseph, 1994 ; Morse, 1994) argue that a radically changed social, political, and economic landscape emerging nationally and internationally, demands a reconstructed view of leadership that challenges not only commonly held conceptions of who leads, but the very nature of leadership itself.

Said simply, our concept of leadership must change. Our world is so complex, interdependent, and interrelated that the old paradigm of singular leadership will not and cannot work. Just as the world moved from the industrial revolution to the technological, there must be a leadership revolution... The new model reinvents what Edmund Burke called "platoons of democracy" in every household, neighborhood, and organization. (Morse, 1994, p. 2)

Morse (1994) and Joseph (1994) suggested that the demands of the 21 st Century will require cadres of "citizen leaders" whose concern for the common good engages them in work with others with whom they can solve even the most intractable of human problems. Their vision is one of dispersed leadership, and synergistic communities home to people of diverse and complementary 
skills, experiences, and ways of viewing the world. While Morse and Joseph saw the activity of groups as a critical component for social problem solving, they also championed the contributions of individual leaders who are capable of integrating information from a variety of sources, and of articulating this information in ways accessible to all. Cleveland (cited in Morse, 1994, p. 3) referred to the special strength of this kind of leader as one who provides a "synoptic view from a single integrative mind." While there is discussion in many academic circles about the importance of educating "culturally competent" students who will be equipped to negotiate the demands of the rapidly paced "global village" of the future, little has been written about the diversity of leadership needed to meet the challenges of building and thriving in such a world. Leadership narrowly defined, cannot provide the breadth of experience needed to creatively and substantively address the complex educational, economic, and social issues facing our nation and other nations around the globe. Only in reframing commonly accepted ideas about the nature of leadership, and challenging well-worn assumptions about who leads, can we begin to nurture, identify, and utilize a leadership pool that spans gender, race, social class, and position.

While some believe that there is a "leadership vacuum" in the United States, Joseph (1994) asserted that 
this is not so. Rather, he claimed that we have been "looking in the wrong places" for evidence of effective leadership and that leaders can be found in every community, and furthermore, that others are "in waiting," poised to assume leadership roles as the need and opportunities arise. He further asserted that the narrow focus of traditional conceptions of leadership has failed to identify those who diverge by race or ethnicity, gender, or social class, from commonly defined leadership profiles and that a "leadership vacuum" is due more to a matter of definition than of fact. In addition, because the informal participatory leadership style adopted by some leaders, particularly non-positional leaders (community leaders, etc.) challenges established definitions of legitimate leadership behavior, it is often not recognized or acknowledged as leadership.

Joseph (1994) reminded us that a thriving global community of the third millennium will require leadership that is diverse, flexible, and capable of communicating across the boundaries of race, class, nationality, gender, and other difference.

According to the World Development Forum, if our world were a village of 1,000 people, there would be 564 Asians, 210 Europeans, 86 Africans, 80 South Americans, and 60 North Americans. In the village would be 300 Christians (183, Catholics, 84 Protestants, 33 orthodox), 175 Muslims, 128 Hindus, 55 Buddhists, 47 Animists, 85 from other religious groups, and 201 atheists. Of these people, 60 would control half the total income, 500 would be hungry, 600 
would live in shantytowns, and 700 would be illiterate. (p. 6)

This study addresses the implications for educational and other leadership development in a pluralistic, multinational community, by focusing upon the lives and leadership of one group of leaders whose experiences are presently not represented in the literature--African American women.

\section{Statement of Purpose}

The purpose of this study was to learn more about the dimensions of African American women's leadership, and in so doing to add to the literature a perspective on leadership presently absent. By increasing the visibility of Black women as subjects and as producers of knowledge, I hoped to extend the ways in which leadership is conceived, and to challenge traditional assumptions about who leads and the nature of leadership. In examining the leadership of African American women I sought to broaden the conceptual parameters of leadership models, and to encourage the study and subsequent inclusion of the leadership experiences of others not presently represented in the literature, especially the experiences of people of color.

The study examines the interlocking status of race, gender and class on the pursuit and perceptions of leadership by Black women and develops a richly textured, 
multidimensional picture of their lives. In explicating a new leadership paradigm, it was important for me to develop portraits of respondents as complex and fully human individuals. In order to do this, I explored their life histories as well as their work and leadership, and also the tensions and the connections between their personal lives and professional endeavors.

\section{Study Participants}

The seven African American women participants relate their stories and define their leadership roles in ways that are distinctly personal. And yet, woven throughout each transcript are common themes: experiences of struggle and accomplishment, of self-doubt and selfconfidence, of success and disappointment, of the continuing search for self-definition. of the seven participants, four are positional leaders: a high school principal, a senior level community college administrator, a state legislator, and the executive director of a major philanthropic foundation. Also participating were three non-positional leaders who work prominently within their communities in a variety of ways, which are described later in the study.

Joseph (1994) and Morse (1994) asserted that the demands of leadership in the coming decades will require vast cadres of "ordinary people" to provide the multiple perspectives, energy, and comritments to the common good 
needed to analyze and solve interlocking economic, social, and political problems. Participants in this study all play a significant leadership role in their communities, and each has a public presence that generates multiple and competing demands on her time and energies. However, with one exception, they are not nationally known figures (although several have received national recognition in the area of their leadership), and each is a selfproclaimed "ordinary" person. Having accepted the mantle of "leader" respondents have developed strategies to help them to remain connected to the people they lead, as is seen in Chapter $\mathrm{V}$.

Hull, Scott, and Smith (1982) argued that in order to capture the breadth, depth, and texture of African American women's lives, it is important to illuminate the everyday acts of Black women as mothers, workers, and community members. Historically, Black women's leadership has evolved and been nurtured within the context of their communities and families. It is therefore germane to a study of African American women's leadership to locate the broader context of both their individual and their common history.

Only through exploring the experience of "ordinary" Black women whose "unexceptional" actions enabled us and the race to survive, will we be able to begin to develop an overview and an analytical framework for understanding the lives of Afro-American Women. (p. xxii) 
It is interesting to note that most respondents describe their paths to leadership as a circuitous one, and as not always eagerly embarked upon. Indeed, all expressed some combination of ambivalence and/or reluctance to "being out front" as a leader. In most cases they stepped in or stepped up to their leader's role when there was a need for them to do so. Typically, the respondents recalled their paths to leadership as being the results of a series of fortuitous circumstances, rather than a systematic design. African American poet Audre Lorde (cited in White, 1990) captured the circumstances which thrust several of the respondents into their leadership role: "Sometimes we are blessed with being able to choose the time and the arena and the manner of our revolution, but more usually we must do battle where we are standing" (p. 36). Respondents in most cases typify Greenleaf's (1994) ideal of the "servant-leader" whose leadership develops as a consequence of her wish to serve, rather than as a "leader-servant" who wants to become a leader but does not necessarily consider leadership as an act of service.

In my original dissertation proposal it was my intent to interview women of color in educational administration. However, after leaving the principalship, and being impressed by the work of African American women in a variety of leadership roles, I became aware that exploring 
the question of African American women's leadership across a variety of experiences and professions was a more fruitful study for investigating the parameters of leadership. While the numbers are too small to develop a theory based on the data, certain trends appear in the study which I believe are important ones, and worthy of further exploration and application in the area of leadership theory. These are discussed in Chapter v.

\section{Background of the study}

A few years ago as a doctoral student in Educational Leadership and Policy Development, I became uncomfortably aware of the discrepancies between most descriptions in the literature of organizational reality and the dimensions of leadership practice, and my own lived experience as an African American woman working as an elementary school principal. It was not that I found the information "wrong" or unhelpful; my coursework was often stimulating and challenging, and I learned a great deal. Rather, I found the traditional literature incomplete and practically silent on the issues which were most problematic, most enduring, and most characteristic of my day-to-day experiences as an educational leader. In other words, I could not find ways in which traditional leadership theories and descriptions of organizational reality correlated (Harding, 1986, p. 86) with my own 
leadership experience as a school leader, as an African American, or as a woman. One example of this was how rarely the subject of interpersonal relationships was alluded to in the literature. Typically a school leader's days are dominated by both informal and formal meetings with students, parents, teachers, etc., many of which are of a sensitive nature and involve negotiation or mediation and seemingly endless hours of communication. This major part of a school leader's reality was not discussed in the literature. A second, and in my judgment a more serious omission, was the failure of the traditional literature to address the ways in which the social and cultural contexts of institutions reflect the larger society, and are therefore, inherently a part of the mix of a leader's reality. Specifically absent from the purview of traditional leadership literature was any mention of the impact of racism, sexism, classism, and other privilege on the society at large, and by extension, on social structures within institutions, and by further extension upon the tasks of leadership.

The failure to locate my own leadership experiences in the literature exemplifies what feminist sociologist Dorothy Smith (1987) referred to as a "fault line"--by which she described that juncture where women's voices are muted, and their experiences neutralized and subsumed in the research process, under the guise of universal 
experience. In her own work as a sociologist, Smith found that her perspectives, concerns and experiences--her world view--as a woman led her to interpretations of reality that differed from that of her male colleagues, leaving her with feelings of professional invisibility. These experiences propelled her to develop a sociological paradigm that included women's experiences and "the everyday world as problematic," which gives weight to the day-to-day life experiences of women as legitimate areas of scholarly concern.

This study began with my attempt to better understand the nature of the limitations of the traditional leadership literature, and with a wish to expand the parameters of my own understanding of what constitutes true leadership. It has led me to a body of literature by and about women and minority men which casts a larger net and a more critical eye on the dimensions of leadership practice. In addition, I have gained a greater understanding of the variety of human experience that is captured when one uses multiple lenses to define, cultivate, and view the world of leadership.

In the following section I discuss the power of the paradigm, and some ways in which paradigms work to maintain hierarchies of privilege. I investigate the role of theoretical constructs in shaping, and often 
determining the ways in which leadership is viewed and perpetuated.

Power of the Paradigm

A paradigm is a world view, a general perspective, a way of breaking down the complexity of the real world. As such, paradigms are deeply embedded in the socialization of adherents and practitioners: paradigms tell them what is important, legitimate, and reasonable. Paradigms are also normative, telling the practitioner what to do without the necessity of long existential or epistemological consideration. But it is this aspect of paradigms that constitutes both their strength and their weakness--their strength in that it makes action possible, their weakness in that the very reason for action is hidden in the unquestioned assumptions of the paradigm. (Patton cited in Lincoln \& Guba, 1985, p. 15)

The paradigm, as "a basic set of beliefs that guide action" (Denzin \& Lincoln, 1994, p. 99), illuminates the world view of the researcher, prescribes the relationship between the investigator and that which or whom is investigated, declares the areas or topics deemed worthy of investigation, and finally, declares that which is judged to be "true." Paradigmatic "truth" then, like the traveler's destination, is rooted in the point of departure (framing the question), the path taken (method of investigation), and the impressions of the most salient parts of the journey (analysis of the data). The paradigm, as a human construction, is definitionally limited by the experiences, world view, blind spots, etc. of the investigator. 
often framed by the positivist paradigm, traditional leadership literature does not address the implications of the social and cultural context of leadership. In operationally nullifying the importance of all but the most rational and quantifiable aspects of human behavior, the positivist paradigm fosters the construction of a decidedly limited view of reality, and a narrow, homogenized view of leadership.

Among areas unexamined by this "scientific" construction of reality are the texture and meaning of individual and group human behavior, and the symbolic meaning of experiences that moderate, among other things, how we as humans know what we know. In addition, because positivist approaches fail to explore the role of extant social hierarchies and socio-political realities, race, class, and gender are not seen to be of researchable significance. In the positivist paradigm, race and gender are subsumed under a theoretical invisibility, and they are not included as part of the research design or of the questions posed:

Work within the positivist tradition, within the tradition of "normal" science, argues for noncontroversial, detached "truths" that remain impervious to larger equity, issues, social realities, and social problems. Allegiance to such "truths" under the guise of scientific rigor, or value free inquiry, of universal certainty and control, of propositions and explanations free from cultural or historical bias, and/or preoccupation with "hard" data, has virtually excluded discourse relative to such issues as the under representation of 
race/ethnic minorities - . (Yeakey, Johnston, \& Adkison, 1986, p. 113)

In the positivist paradigm, philosophical, theoretical and methodological assumptions of objectivity, homogeneity and consensus definitionally exclude attention to race and gender (Yeakey et al., 1986, p. 115) and preclude the discussion and investigation of leadership by those not already in the leadership "loop," historically those who are white and male. Operationally, the research foci and institutional practices reinforcing these paradigmatic assumptions have resulted in an exclusionary way of thinking about, promoting, and practicing leadership. Bachrach and Baratz (cited in Yeakey et al., 1986 , p. 113) remind us in a related context that nondecisions as well as decisions structure the discourse, the taken-for-granted reality, and the perpetuation of unexamined ideas about "right" institutional practices including "appropriate" leadership. In not including the topics of race, gender, and class as part of leadership conversations, hierarchies of privilege, and de facto exclusionary practices are reinforced.

Gosetti and Rusch (1995) illustrated ways in which academic leadership discourse and, by extension, the practice of leadership are shaped by "gatekeepers" in higher education who perpetuate the status quo in direct and enduring ways. In their broad review of the current leadership literature including textbooks for professors 
and students, professional journals, and national policy board publications, they find the continued promotion of a "privileged" viewpoint of leadership that is dominated today, as it has been in the past, by white males with the longest history and the greatest access to the academy.
A review of educational divisions of major publishing houses found few texts on leadership, the principalship, the superintendent, the professoriate, or educational leadership written by women or other marginalized groups. Those written by women tend to focus specifically on women. Those few texts that include content about women, equity, or diversity usually add a special chapter which highlights the inclusion of women and minorities as problematic. Rarely is any attention given to balancing perspectives and voices of white males with perspectives and voices that have traditionally been silenced or marginalized. (p. 24)

Gosetti and Rusch (1995) spoke of privilege as an advantage not consciously held or acknowledged; rather it is the unearned, socially sanctioned status awarded by virtue of the race, gender, or social status conferred at birth. They referred to McIntosh's definition of privilege:

Privilege, from a broader perspective, exists as an invisible and frequently taken-for-granted collection of unearned advantages and assets which are conferred by virtue of our group membership. These advantages and assets not only give us choices and opportunities, and a degree of control over our own lives that others might not have, but they also grant us dominance and permission to control. (p. 17)

Challenges to traditional social scientific theory raised by critical theorists (Foster, 1984; Greenfield, 1988; Kincheloe McLaren, 1994) and feminist theorists 
(Gilligan, 1979; Olesen, 1994; Schmuck, 1980, 1982;

Shakeshaft, 1982) have expanded the leadership discourse and legitimized the view that multiple realities, previously unreported in the literature, exist both for researchers and for those whose lives they study. Although generally not yet a part of the mainstream leadership literature, this growing body of research illustrates clearly that no single theoretical construct can sufficiently capture the whole range of human experience, and that leadership is the legitimate enterprise of women, and men of color as well as others who have traditionally not been seen as leaders. It is remarkable not that there are multiple ways of experiencing the world, but rather that a single world view, dictated and perpetuated by a privileged elite, has so thoroughly dominated ideas about leadership and about the dimensions of knowledge, truth, and reality.

The contribution of this more critical (post positivist) and inclusive (feminist) literature has expanded our understanding about the dimensions of leadership. Although its contribution should not be minimized, with rare exceptions (Edson, 1988; Jones \& Montenegro, 1983), the literature does little to illuminate the presence or experiences of Black women, or of other women of color, as leaders in education or in other fields. We therefore know little from the feminist 
literature about leadership as experienced by people of color.

However in recent years, Black scholars across a variety of social science disciplines have produced scholarship about the experiences of Black women that begins to bridge this gap (Brewer, 1993; Collins, 1989, 1990, 1991; hooks, 1984, 1989, 1990; Standfield, 1994). In Chapter II, these contributions are discussed in more detail.

\section{Importance of the study}

There has probably been far less a paucity of leaders than inattention to displays of leadership in mundane situations or among the socially invisible classes, which history has poorly chronicled. What I am saying is: Never mind what makes a good leader; leaders come forward as they are needed. Look instead at the sociocultural conditions of leadership. (Freedman, 1980, p. 27)

This study posits a paradigm of leadership that is contextual, non-hierarchical, and dynamic. It investigates the connections between respondents' personal and professional experiences, and develops thick descriptions of whole and complex individuals, as they reflect upon their work, commitments, and visions as leaders. The study will be beneficial to those who want to know more about how a selected group of African American women view their lives and leadership. Policy makers, educators, and community agencies will benefit 
from learning more about the development of self efficacy in these leaders.

The Interview

In framing the interview schedule (see Appendix C), I drew upon the work of Belenky, clinchy, Goldberger, and Tarule (1986), Astin and Leland (1991), and Collins (1989, 1990, 1991) and included probes based upon their work.

Assumptions guiding the study:

1. African American women experience leadership in ways not represented in the literature and that knowledge of these experiences will be helpful to emerging leaders of any background.

2. African American women define leadership in relational terms and develop leadership behaviors consistent with this definition.

\section{Summary}

Chapter I introduces the study and describes my interest in the subject. I discuss the positivist paradigm as promoting a decontextualized and privileged view of leadership, and as an improbable theoretical lens through which to view systemic social change or explore new models of leadership. I discuss the need for an inclusive cadre of diverse leaders who are flexible and connected to others, and who are equipped to address the 
local, national, and global concerns of a rapidly changing world. Finally, I raise the issue of the social and cultural conditions of leadership, and suggest that further study examining the work and lives of leaders of color and others whose experiences are absent from the literature, be undertaken. 
CHAPTER II

\title{
LITERATURE REVIEW
}

\begin{abstract}
Most of us live in what schultz (1972) calls a "taken for granted" reality, by which he means that particular level of experience that presents itself as not in need of further analysis. This taken-for-granted world often seems too confusing, too powerful, or too mysterious to slice beneath appearances, and it is not always easy to see clearly, let alone address, the fundamental problems of social existence that we confront daily. Our culture entraps us in common sense and multiple segmented worlds in which "reality includes a variety of mechanisms for assuring social harmony and conformity to interactional norms, organizational rules, institutional patterns, and ideological concepts." (Berger \& Luckman cited in Thomas, 1993, p. 3)

In developing a social and historical context in
\end{abstract} which to better assess the dimensions of African American women's leadership, I begin this section with a brief review of traditional leadership literature and explore the reality constructed in these models (Bethel, 1994; Kouzes \& Posner 1987; Yukl, 1989). I then describe models of leadership that underscore the complexity of human interaction, including the ethical and moral dimensions of leadership, and the symbiotic nature of the leaderfollower relationship (Gardner, 1990, 1994; Greenfield, 1986; Greenleaf, 1994). Following this, I introduce a reconceptualization of leadership that incorporates the 
values, voices, and concerns of women (Gluck Patai, 1991; Dunlop \& Schmuck, 1995; Gilligan, 1979; Gosetti \& Rusch, 1995; Schmuck, 1980; Shakeshaft, 1982, 1986). Finally, I explore the theme of leadership through the eyes of African American women and introduce other relevant literature that develops a contextual view of the world and work of African American women leaders (Collins, 1990; Wall, 1991).

\section{Leadership Theory}

Traditional leadership literature is closely aligned with studies of organizational theory as characterized in Bolman and Deal's (1988) study. They described four major organizational "frames" that capture the ways in which organizations can be better understood: the structural, Political, Symbolic, and Human Resources. Each lens represents a different set of assumptions meant to shed light on the dynamics of organizational life. The frames, in turn, suggest the kind of leadership that best reflects an organization's goals and culture. For example, the Human Resources theory of management, rooted in Maslow's (1970) theory of human development, assumes the existence of a hierarchy of human needs (from basic needs like shelter, food, and clothing, to "higher" level needs like love and self actualization) many of which can be met in a person-centered organization. A leader for this kind of 
organization is aware and respectful of the personal needs and human aspirations of their workers. A leader who believes that solutions to organizational problems can be found in human capacity, would operate from a different set of assumptions and practices than one who believes that the structure of an organization is looked to in order to identify and solve problems. In real life no one theoretical frame alone explains all of the dynamics and variables of an organization, and a combination of different lenses and theories will provide the broadest understanding of organizational life and leadership. Nonetheless leadership theory, both traditional and emergent, greatly influences the ways in which leadership is thought about, defined, and practiced.

Traditionat Theories of

Leadership

The following section highlights the major ideas in traditional leadership theory, as described by Terry (1985). The Trait Theory posits that leadership is rooted in biology. Leadership capacity is something that one is born with, and under the proper conditions it will flourish--the "Great Man" theory of leadership is supported by this view. Supporters of The situational Theory believe that leadership can be taught, and that as situations change so will the kinds of skills needed by the leader. Leadership is seen as a dynamic process, 
changing with the times and settings. organizational

Theory--Leadership is a role in a hierarchical

organization, and the skills and competencies needed are directly related to organizational goals and structure.

Power Theory--Leadership is viewed as power, either formal or informal. The leader has a greater impact upon others than anyone else in the organization (pp. 1-8).

The models cited above exemplify decontextualized views of leadership that suggest a value-neutral world that functions independently of the social, cultural, and economic realities of the larger society. For example, none of these theories address the relationship between one's place in the economic and social hierarchy relative to race, gender, or class and the implication for leadership theory.

Greenfield (1988), a critical theorist who has written extensively about organizational/educational administration, noted that the quasi-scientific nature of the investigation of organizations has limited the debate in these and other areas. He proposed that further research on organizations and administration should begin operating from a different set of assumptions:

(1) Organizations are not things. They have no ontological reality. . . They are an invented social reality of human creation. It is people who are responsible for organizations and people who change them. (2) organizations are a nexus of freedom and compulsion. As invented social realities, they can not only be created but also manipulated. The creation and maintenance of 
this illusion is the root of what the world understands as leadership. (3) The world of will, intention, experiences, and value is the world of organizations and administration. Conflict is endemic in organizations. It arises when different individuals or groups hold opposing values or when they must choose between accepted but incompatible values. (5) To help us begin to think of leaders in moral terms we should recognize that they are representatives of values: indeed, they are both creators of values and entrepreneurs for them. (6) The ethical dimensions of administration come constantly to the fore once we free ourselves from the metaphors of harmony, optimism, and rationality that administrative science imposes upon organizational reality. (pp. 151-153)

I introduce Greenfield's (1988) work here to set the stage for the discussion that follows. Emergent leadership theories present a more inclusive view of leadership, which consider the complexity of human existence and the ever changing nature of people, times, and institutions.

\section{Emergent Leadership Theories}

Emergent leadership models focus on the moral and ethical dimensions of leadership, as well as a broad and changing social context. For example, in positing definitions of leadership for the new millennium, theoretical models must address as a given the impact of the rapid changes taking place in all areas of civic life. Changes in the definitions of family and community, in international borders, and in telecommunications capabilities have altered the "givens" with which we approach the twenty-first century. The unsettling effects 
of change and the instability that accompanies it, causes one to re-imagine the meaning of leadership. Cleveland (1980, 1982) informed us that change that once happened over a period of centuries, now occurs during one's lifetime and that the development of a resilient spirit is a prerequisite for leaders capable of meeting changing demands with equanimity. Bateson (1989) agreed with cleveland and asserted that an uncomfortable truth of our times is that "fluidity and discontinuity are central to the reality in which we live" (p. 13). The capacity to meet change willingly and creatively is essential for all citizens, and a resilient spirit is a prerequisite for leaders. Later in the study I discuss the characteristic of resilience at greater length, specifically as it relates to the leadership of Black women.

Some see effective leadership as a way of life, a commitment that transcends role and position (Adair, 1994; Gardner, 1990, 1994; Greenleaf, 1994; Terry, 1985). Terry contended that:

leadership is not reducible to traits, skills, organization, power vision or even ethical vision alone. It is a fundamental and profound engagement with the world and human condition. (p. 17)

Terry's view of leadership promotes the idea that leadership is not only what one does, but is what one is. This view is consistent with one Hall (1988) ascribed to African American women leaders at a leadership conference 
for Black women held on December 5,1987 , at the University of Minnesota's Humphrey Institute of Public Affairs: "Black women often define leadership as a 'Iifestyle'; it is the way they conduct their day-to-day business and personal lives" (Hall, 1988, p. 15).

Transformational Leadership describes a process that transforms both the leader and the follower, challenging them to become "better selves" who reach for high ideals such as liberty, justice, equality, and peace (Burns cited in Yukl, 1989, p. 210). Transformational interaction raises both leaders and followers to higher levels of morality and motivation.

In a related context, Nikki Giovanni (cited in Collins, 1990), African American activist poet viewed leadership not as an end in itself, but rather as a process that builds the capacity of both the leader and the follower to provide increasing levels of service: "the purpose of any leadership is to build more leadership. The purpose of being a spokesperson is to speak until the people gain a voice" (p. 157)

Greenleaf's (1994) ideal leader is embodied in the concept of the servant-Leader--one whose leadership originates as a consequence of her wish to serve--with the nature of service established after the decision is made to be of service. The sequence of servant-Leader and the motivation behind this kind of leadership is distinguished 
from that of the leader-servant, one whose primary motivation is to lead, to become a leader, but not specifically for the purpose of providing service. Greenleaf saw this differentiation as being more than mere semantics:

The difference manifests itself in the care taken by the servant-first to make sure that other people's highest priority needs are being served. The best test, and difficult to administer, is: do those served grow as persons; do they, while being served, become healthier, wiser, freer, more autonomous, more likely themselves to become servants? And, what is the effect on the least privileged in society; will he benefit, or at least, will he not be further deprived? (p. 4)

Gardner (1990) argued that especially in times of uncertainty and turmoil, a leader's role is to restate and revitalize the community's shared values and to "conceive and articulate goals in ways that lift people out of their petty preoccupations and unite them toward higher ends" (p. 191).

Leaders must not only have their own commitments, they must move the rest of us toward commitment. - . . Leaders have a variety of ways of accomplishing all of these tasks. What they say, the policy decisions they make, the kinds of people with whom they surround themselves-all are part of the message they send out. And in this dimension the impact of leaders derives only in part from performance and in part from what they are and represent as human beings. (p. 191)

The leadership vision of Gardner (1990), Greenleaf (1994), and Burns (cited in Yukl, 1989) underscores the importance of a moral relationship between followers and 
leaders, and a belief that leaders must promote the highest ethical ideals. However, omitted from the texts of these respected authorities on leadership, is a basic question about "who leads." That is, the bases of their arguments in favor of more enlightened leadership rest upon taken-for-granted assumptions that have historically equated leaders with "white" and "male." Because they fail to discuss the privileged nature of traditional leadership roles, the authors' unwittingly perpetuate the image of leadership as the province of a narrow band of society. Critical and Post Modern Theory tells us that in failing to raise the issue of who is included and who excluded from their dialogues on leadership, the authors continue to promote a privileged view of leadership that suggests that legitimate leaders are white and male, and that leadership by others is incidental and inconsequential. In his popular book on Leadership, Gardner (1990, p. 47) included one reference to the leadership of Black civil rights leader, Dr. Martin Luther King but failed to discuss the value of an expanded, more inclusive leadership pool. Indeed, although Gardner devoted three pages of his book to the topic of women's leadership, a third of this section is devoted to a description of the leadership of Elizabeth $I$, the heir to the throne of England in the sixteenth century. On the surface, Gardner's humanistic leadership paradigm appears 
to be inclusive of women and minorities. However, in failing to seriously tackle the issues of how race, class, and gender relate to leadership, he perpetuates a takenfor-granted reality of leadership from which women and minority men have been effectively excluded.

Gosetti and Rusch (1995) explicated the limitations of leadership paradigms that assume homogeneity and omit the experiences of women or minority men in theoretical design, sample, and analysis. They asserted that "embedded assumptions" about the nature of organizational leadership--that it is white and male--obviates the responsibility of researchers to include or investigate the viewpoints, contributions, or realities, of women or minority men.

We argue that the texts, conversations, writings
and professional activities that construct our
knowing and understanding of leadership come
from an embedded privileged perspective which
largely ignores issues of status, gender, and
race and insidiously perpetuates a view of
leadership that discourages diversity and
equity. (p. 12) They contended that the inclusion of multiple viewpoints not only encourages the development of more complete and useful research models, but more important, opens the way for the cultivation and recognition of a new diverse generation of leaders. Freedman (1980) however, warned that access to "legitimate" leadership roles will not come easily for women and people of color: 
Opening up leadership to women, blacks, and other political minorities must inevitably engage a growing opposition from those who now enjoy a privileged monopoly. Whole classes do not willingly surrender their advantage; institutions are never self-liquidating. It is evident, therefore, that the struggle to broaden the franchise of leadership has to be waged within this system. (p. 33)

\section{Women and Leadership}

That the terms "leader" and "white male" are typically synonymous indicate that the informal rules of our culture are strongly wedded to this combination and create dissonance for those who are neither white nor male. (Mitchell, 1988, p. 9)

Gilligan's (1982) germinal stüly, In a Different Voice, developed the thesis that women both viewed and experienced the world in ways that were different from those previously described in the human development and psychological literature. Her research suggested that women assigned divergent meanings to their experiences, were more likely to make moral judgments based upon the concept of relationships rather than solely upon external conceptions of justice, and at each stage of development put a high value on connectedness and human consequences. Gilligan asserted:

The failure of women to fit existing models of human growth may point to a problem in the representation, a limitation in the conception of human condition, an omission of certain truths about life. (p. 2)

Rather than assigning women's alternative ways of viewing the world as deviance, Gilligan's (1979) elucidation of 
"women's place in man's life cycle" provided an alternative conception of moral development that has served as the theoretical basis for much of the work that has followed on the development and practice of women's leadership.

Just as Gilligan's $(1979,1982)$ studies challenged the theoretical completeness of the established developmental theories (Kohlberg [1984], Piaget [1981], and Erikson [1985]), Tietz and Shakeshaft (1982) questioned how well Maslow's (1970) theory of human development (which provides the theoretical basis for much leadership theory), reflected the values and experiences of women. Maslow's theory defined a hierarchy of five human needs: (a) basic survival, (b) safety, (c) belongingness and love, (d) esteem, and (e) and selfactualization. Tietz and Shakeshaft argued that Maslow's sample of a small group of high achieving, primarily male subjects did not reflect the values of women and did not describe the ways in which women structure meaning into their lives. In reference to Maslow's "self actualizing" person as representing the pinnacle of human achievement, Tietz and Shakeshaft contended that women operate from a different system of values and place "emphasis on attachment, responsibility for and toward others, intimacy, connections, mergers . . . seeking to promote conciliation, cohesiveness, and co-operation" (p. 21). 
A study providing insight into how women's voices, views of self, and construction of reality are interwoven was published as Women's Ways of knowing, by Belenky et al. (1986). In interviews with 90 college students and 45 low-income women, the authors discussed how the women viewed their lives, their relationships, and their history. The data yielded five epistemological categories that served to locate respondents' "voices" and "ways of knowing":

(1) silence--a position in which women experience themselves as mindless and voiceless and subject to the whims of external authority (2) received knowledge--a perspective from which women conceive themselves as capable of receiving, even reproducing, knowledge from the all-knowing external authorities but not capable of creating knowledge on their own, (3) subjective knowledge--a perspective from which truth and knowledge are conceived of as personal, private, and subjectively known or intuited, (4) procedural knowledge--a position in which women are invested in learning and applying objective procedures for obtaining and communicating knowledge, (5) constructed knowledge--a position in which women view all knowledge as contextual, experience themselves as creators of knowledge, and value both subjective and objective strategies for knowing. (p. 15)

In constructing a paradigm in which the experiences of women were used as the unit of analysis, the authors contributed a model that legitimizes the place of women's voices in the literature. In other words, the authors viewed these women's experiences as complete in themselves, and not measured by the degree to which they were "different from" male experience. 
Another study which focused upon the meaning women ascribe to their lives was published in 1991 by Astin and Leland, women of Influence, Women of vision. It is a qualitative study which investigated women's leadership. In interviews with 77 women leaders from across disciplines and representing three generations, the authors documented the leadership experiences of women involved in the "first wave" of the women's movement (1960-1970), and the two generations following. They developed and tested an empirical model of feminist leadership that included three constructs found in feminist discourse: (a) reality is socially constructed and is influenced by social, cultural, and historical context, (b) people's lives are interdependent with the lives of others, making leadership a collective effort, (c) power can be used and seen as energy, not as control. or stated another way, this last point suggests power with, rather than power over (pp. 7-8). The areas of investigation included: social context and issues, leadership, peer and work relations, personal and professional development, and issues and legacies of the women's movement. The Astin and Leland study diverged from previous leadership studies in that it does not differentiate between "personal" and "professional" experiences. Rather, it probed for an understanding of the interrelated nature of the personal and professional 
tensions in women's lives and develops a multidimensional, contextualized picture of women leading in contemporary times. The authors further contextualized the experiences of these leaders by locating them in the different historical moments of the modern women's movement. A major finding of the study was the importance of mature leaders actively serving as mentors for the next generation of leaders. A second finding was that established leaders require ongoing support and nurture from other women if they are to continue their effectiveness (pp. 160-170).

Feminist scholarship has altered traditional social sciences research by including the absent voices of women and by championing the legitimacy of women's experiences as a theoretical basis of knowledge or truth (olesen, 1994). No single "feminist" ideology has emerged, rather, three epistemological strands now frame feminist scholarship: first, standpoint Theory--builds upon research that values the experience of women in everyday Iife; second, Feminist Empiricism focuses upon the intersubjectivity of truth, including the commonly created meanings developed between the researcher and the respondent; third, Postmodern Theorists regard learning the "truth" about women's lives in an oppressive culture as an illusion, and believe that because reality is always shifting, it is best investigated through endless stories 
and texts (Pp. 162-164). These theories represent a significant shift from positivist thought and each competes for a role in the social sciences discourse on truth, meaning, and legitimacy.

Although the advent of Feminist Research has broadened the parameters of leadership discourse, and challenged the utility of narrowly conceived, decontextualized research designs, it has some serious limitations. Like earlier leadership studies that posited the "norm" as white and male, the "norm" in these works is white female experience. While African American women were included in Astin and Leland's study (1991), as well as in Belenky et al. (1986), the aggregated reporting of the data in both studies suggests a uniformity of experience defined by gender alone. Data on the effects of the interlocking status of race, gender, and class for African American women were not collected. Perhaps the omission of a more in-depth study of African American women's experience in the work of white feminist scholars is inevitable. Perhaps, as African American sociologist Etter-Lewis (1991) claimed, "all women must tell their own stories in their own words" (p. 44). The political implications of self constructed discourse are clear. As Audre Lorde (cited in Collins, 1990) believed, "It is axiomatic that if we do not define ourselves for 
ourselves, we will be defined by others--for their use and to our detriment" (p. 26).

The following section focuses upon the theoretical, historical, and contemporary dimensions of the lives and leadership of African American women, as investigated through the scholarship of primarily African American women.

Black Women's Leadership: What is Known?

Much that has been written about Black women's leadership comes from the field of educational administration (Doughty, 1980; Jones \& Montenegro, 1983, 1988; Ortiz, 1980a, 1980b; Yeakey et al., 1986) and provides primarily statistical, impressionist, and noncontextual studies of African American women in positional leadership roles. Other studies present biographical data on famous Black Women (Bryan, 1988; Giddings, 1988; Perkins, 1988).

A conference sponsored in 1987 by the Center for Leadership for Black Women at the University of Minnesota brought together 100 Black women to discuss their experiences as leaders. The goals of the conference were to explore the leadership of African American women, to provide role modeling for young women, to help all women develop strategies for individual and collective empowerment, and to build coalitions and teamwork in Black 
communities and nacross cultural, gender, and class lines, and globally" (Hall, 1988). The dual challenges of racism and sexism were described by participants as ever present reminders of their status as Black American women. Other challenges cited were the myth of the "double advantage" of Black women managers (Fulbright campbell cited in Hall, 1988), the experience of Black academics working in primarily White institutions (Moses \& Frierson cited in Hall, 1988; Farmer cited in Hall, 1988), and the effects of discrimination, isolation and negative stereotypes on Black women as leaders. Some mentioned the challenge of being in a leadership position where they are positioned to "control/and or destroy other Blacks" (p. 12). Observations and recommendations that came from the five African American women leaders who served on a panel at the conference included:

- Leadership is not always positional

- Leadership is collective as well as individual

- Leadership development is life-long

-The family and African-American communities are important forums for the development and practice of leadership -Both popular culture and the Black community share the responsibility for "righting the wrongs" of racism/sexism -Black women must expect to experience racism/sexism as part of their lives, but take the responsibility for creatively overcoming the barriers

-Black women want to be considered on their own

terms, not just in comparison to others

-Black women often define leadership as a

"lifestyle" it is the way they conduct their day to day business and personal lives 
-African-American women must assist in eliminating long-term feelings of powerlessness within the society

-African-American women, as well as other

Americans, share a set of human rights that

transcend biological/racial/gender differences.

(p. 15)

The thoughts of the five panelists convening the conference are echoed throughout the literature on African American women, as will be seen later in this chapter.

\section{Non-Positional Leadership}

African American sociologist Jacquelyn Mitchell

(1988) believed that the focus of traditional leadership literature on positional leadership roles, results in lost opportunities to learn more about the dimensions of nonpositional leadership, which has historically flourished in minority communities. In Mitchell's 1988 study, she followed three Black women filling "cultural leadership roles" in their communities. The women exercised power and authority in their communities, and earned respect as they performed their work in three separate Black neighborhoods. One study participant was the proprietor of a beauty parlor, the second a non-credentialed teacher in a community based school, and the third, a woman who served as "queen grandmother" to the neighborhood, freely dispensing advice and admonitions as she saw the need. Mitchell's work points to the informal cultural rules that defined the leadership roles of these three women. Although unwritten, the rights and responsibilities of the 
leaders and their followers were clearly drawn. Mitchell asserted that while it is necessary to study formal leadership structures in a complex society, important lessons can also be learned from informal leadership and the authority and practices of non-positional leaders. Mitchell contended that authority and power are conferred upon non-positional leaders who are able to master "the informal rules of a culture and develop skills based upon that knowledge to hold things together and enable people to see the same thing" (p. 10).

It also seems reasonable to assume that authority entails making rules that others accept and abide by. This ability to enable others to see the same thing means giving interpretations of the historical and immediate contexts and their relationships to the self and the situation. This mode of culture-building can provide the standards of behavior and the criteria of evaluation with which established group identities resist hostile environments. (p. 10)

The ability of leaders to enlist others in their vision, enabling them to "see the same thing," is reminiscent of Gardner's (1990) view of one of the tasks of leadership.

Mitchell (1988) posed the question of whether the leadership roles vested with traditional sources of power, are the ones in which women and minorities want to invest:

The issue for women and minorities is whether we adapt ourselves to the established leadership roles or whether we adapt them to us, infusing in them new options and greater perceptions based on our experiences in achieving professional status. (p. 9) 
Etter-Lewis (1993) conducted research in which she interviewed 80 African American women across a range of professions, all of whom had received their first college degree in the 1930s. The discipline, tenacity, and strong will exercised by these women in often psychologically brutal and physically threatening settings, is captured in their own voices. Etter-Lewis endorsed oral narrative as a particularly useful tool in conducting this research because it "offers an intimate perspective of a narrator's interpretation and understanding of his/her own life unabridged" (p. xii). The author included nine of the narrative texts in her book, My soul Is My own. As a linguist, Etter-Lewis focused not only upon the content of these life stories as they unfolded, but also upon the style and mode of expression of respondents and in the process gathered richly layered data.

The author concludes that oral narrative is a way of rendering visible the lives of African American women whose experiences have often been presented as "token women in Black texts and as token Blacks in feminist ones" (Giddings cited in Etter-Lewis, 1993, p. xvi).

The notion that African American women are an invisible group on the sidelines that easily can be combined with other groups is a convenient fiction that conceals their power and importance. They have played major roles in all of American culture and continue to do so in spite of resistance and a variety of formidable barriers. These women have demonstrated repeatedly that change requires nothing less 
than the complete alteration of what we do and believe. (p. xvii)

The women participating in my study, like those mentioned above, create change in their lives by refusing to accept as inevitable the circumstances of sexism, racism, or classism. In chapters $I V$ and $V$, more is seen about how they achieve this.

Three doctoral dissertations published in 1991 focused on the leadership of African American women. The first study, The African-American Woman Practicing in Nontraditional Professions: A Life History Approach (Talley-Ross, 1991), interviewed 17 women practicing in non-traditional, male-dominated professions including law, medicine, corporate management, and journalism. The focus of the study was on the adaptive strategies adopted by the respondents in successfully attaining high status positions. Although participants had very different life experiences, all had developed feelings of self reliance, and successful accommodation to the racism that was part of the lives. The second study, The construction of Identity Through The Presentation of Self: Black Women Candidates Interviewing for Administrative Positions At A Research University (Woodbrooks, 1991), involved interviews with six women. The purpose of the study was to examine the factors contributing to the way Black women candidates presented themselves during an actual interview process at a university where they applied for open 
positions. Themes which emerged were: feelings of marginalization; the importance of mentors; assertiveness as a matter of survival; cultural diversity and organizational fit; people who have influenced identity construction; and the double jeopardy of being Black and female. The third study, Personal Perspectives of Major Factors That Influenced the Educational, Personal and Professional Development of Senior-Level Black Women (Chatman, 1991), interviewed 14 women in higher education in order to discover the major factors that contributed to their professional success. The conclusions of the study were that early experiences and influential role models were important factors in the success of these women. Barriers to Black women becoming administrators were outlined as were recommendations for their support once leadership positions had been achieved.

What my study adds to the literature is a more contextual view of the interwoven nature of the personal and professional experiences of African American women leaders, and how the dynamics of race, gender, and social class have affected their lives and work.

\section{Dimensions of African American Women's Experience}

In order to understand the meaning of Black women's leadership one must listen not only to their personal stories, but must also become aware of the historical, 
political, and social context that undergirds their individual experience. African American women are defined by a life lived in a society that denigrates women of African descent (Collins, 1990; Giddings, 1984; hooks 1989; Hull et al., 1982). This potent reality is the starting point for any relevant analysis of Black women's lives or leadership.

In their book, All the women Are White, All the Blacks Are Men, But Some of us Are Brave, Hull, scott, and Smith (1982) related the ways in which the history and even the presence of Black Women in the United States has been obscured. In feminist literature, white women are the focus, in the history of Blacks, men are the reference point. The lives, accomplishments and existence of Black women have been subsumed under these two categories. However, during the past decade, African-American women scholars have documented the lives, and told the stories of Black women living at the intersection of race, class, and gender (Etter-Lewis, 1993; Giddings, 1984; Hull et al., 1982). The meaning of Black women's labor (EtterLewis, 1993; Jewell, 1993; Jones, 1985), political activity (Bryan, 1988; James, 1993), and intellectual traditions (Jones, 1985; Lorde, 1984; Wall, 1991) resurrected through the scholarship of African American women reveals a rich tapestry of the lives of Black women lived in struggle, resistance, and very often in triumph. 
Hull, Scott, and Smith (1982) and other Black women scholars (Collins, 1990, 1991; Etter-Lewis, 1991, 1993; hooks, 1989, 1990, 1993; Jewell, 1993; Jones, 1985) contend that it is the task of African-American women to write themselves into history, to describe their own experiences, to name their own lives. Further, they argued that while there is much to celebrate in the lives of "famous" Black women, it is in studying the multi-textured "unexceptional" everyday lives of Black women as sisters, mothers, laborers, and non-positional community leaders, that we begin to understand the true dimensions of Black women's lives, including their leadership. In including the lives of non-positional Black women leaders in this study, we develop an expanded view of leadership that transcends title and position, that has served African American communities well since the time of slavery.

\section{Black Women: Family and Work}

In order to fully grasp the meaning and tasks of African American women's leadership, one must understand the inherent contradiction of becoming a leader, as commonly defined, against the backdrop of the traditional status of Black women's work in America--work that has typically been menial, backbreaking and poorly paid. In Labor of Love, Labor of Sorrow, Jones (1985) described the central role that work has played in defining African 
American women beginning in 1830, with the slave economy. She described Black women's work in the cotton economy after reconstruction, and their subsequent journey North between 1900 and 1930 where most became domestic workers for white families. Although recruited for factory work during World War II, at higher wages than had previously been available to them, the end of the war found Black people still battling discriminatory practices in the workplace.

However, Jones (1985) pointed out that the drudgery and menial nature of this work contrasted sharply with the status that Black women have traditionally had in their own homes and communities:

Black women's work took place within two distinct spheres that were at the same time mutually reinforcing and antagonistic. One workplace was centered in their own homes and communities, the locus of family feeling. Beginning in the slave era, the family obligations of wives and mothers overlapped in the area of community welfare, as their desire to nurture their own $k$ in expanded out of the private realm and into public activities that advanced the interests of black people as a group. In contrast to this type of work, which earned for black women the respect of their own people, participation in the paid labor force (or slave economy) reinforced their subordinate status as women and as blacks within American society. (p. 3)

After a period of relative prosperity and greater educational opportunities during the 1960 s and 1970 s for some Black women (Jones, 1985), the ranks of the Black middle class professional, and white collar workers 
increased. However, today a growing number of women cannot earn living wage jobs under present conditions:

In matters of employment, for example, the effects of being both black and female are particularly potent at the job preparation stage, where being black means fewer years of schooling, accelerated entry into the labor force, greater need to finance own education and higher unemployment rates. (Lykes, 1983, p. 81)

Today, the largest category of Black women workers is clerical and service workers including "household workers, janitors, cleaners and public service work, jobs which are extensions of the private household services role" (Brewer, 1993, p. 26). As the internationalization of the economy becomes a greater part of labor's landscape, low paying manufacturing jobs formerly performed by Black women, are increasingly being farmed out to poor women in third world countries, who work for lower wages. Therefore while it is true that there are more middle class professional Black women today then in earlier decades, it is also true that an increasing number of Black women with little education are completely locked out from living wage employment.

Because of the historical status of Black women's work, the image of Black women performing low paying, dead end jobs is one that is firmly implanted in the minds of many Americans. For many, the anomalous presence of African American women in positions of leadership challenges the "natural order," and the "taken for granted reality" of who leads. Regardless of the Black woman's 
arena of leadership, her very presence deconstructs historical and contemporary perceptions of her "place" in the labor hierarchy. That African American women in leadership positions are an anomaly is illustrated by the reports of respondents in this study of the frequency with which the legitimacy of their presence in a board room, a principal's office, or in a legislative seat is routinely challenged.

\section{Black Women and controlling} Images

African American women who are leaders have, by definition, managed in part to deflect negative images and to construct for themselves an identity of agency and connection. However, the pervasiveness of negative images of Black women projected in the media and elsewhere reinforces the objectification of $B l a c k$ women as "the other," and engenders stereotypes of Black womanhood that are difficult to counteract. Negative images do special harm to Black girls and young women as they develop a perception of self and assess the possibilities open to them in the world:

In contemporary culture the media have become central to the constitution of social identity. It is not just that media messages have become important forms of influence on individuals. We also identify and construct ourselves as social beings through the mediation of images. (Angus * Jhally cited in hooks, 1990, p. 5) 
In From Mammy to Miss America and Beyond, sociologist Jewell (1993) related how the historical and contemporary media portray Black women as "possessing certain values, belief systems and lifestyles that do not entitle them to receive societal resources, but account for their marginal status in salient societal institutions" (p. $x)$. The "societal resources" of which the author speaks include equal access to education and jobs, not to so called "entitlements." Jewell contended that the negative images that symbolize African American womanhood are not new, but rather have persisted since the time of slavery, especially those images of the Black woman being "a mule of the world" (Hurston cited in Collins, 1990, p. 43) whose backbreaking labor is assumed as a part of the natural order of things, and of the immoral, "bad Black girl," seen as willing sexual object. Jewell described three particularly persistent images of African American womanhood: Mammy--who stereotypically is "distinguished by her occupation, emotional qualities, physical make-up and behavior" (p. 38). Portrayed as submissive to her slave owner, and in a later era to her white domestic employer, ever smiling, devoted, and content with her lot in life-she is assumed to have no identity of self, beyond the laboring self.

Created to justify the economic exploitation of house slaves and sustained to explain Black women's long-standing restriction to domestic service, the mammy image represents the 
normative yardstick used to evaluate all Black women's behavior. (Collins, 1990, p. 71)

A second image, Aunt Jemima, is much like that of Mammy in terms of appearance, she is usually shown as a cook, and again is portrayed as "extremely jolly." A third persistent image of African American womanhood is of Sapphire, the sharp tongued, verbally emasculating "bitch" whose sharp words especially target African American men. These and other negative images are perpetuated in the print media, on television situation comedies, and in the treatment of African American women in the public arena. The recent media vilification of Dr. Anita Hill--during the Supreme Court hearings of Clarence Thomas, of Dr. Lani Guinere--clinton's nominee to the U.S. Civil Rights Division whose name was withdrawn after she was labeled as a "quota queen," and of Dr. Joyclyn Elders--recently deposed Surgeon General, who was fired after allegations that she encouraged promiscuity and other immorality (by speaking out on sexually charged issues), exemplify the perniciously negative ways in which Black women are imagined, and the ways in which the audacity of their leadership is challenged.

Called Matriarch, Emasculator and Hot Momma. Sometimes sister, Pretty Baby, Auntie, Mammy and Girl. Called Unwed Mother, Welfare Recipient and Inner city Consumer. The Black American Woman has had to admit that while nobody knew the troubles she saw, everybody, his brother and his dog, felt qualified to explain her, even to herself. (Harris cited in collins, 1990, p. 67) 
Collins (1990) contended that contemporary images of the Black welfare mother and the Black matriarch are variations upon a theme of devaluation of Black womanhood.

While the mammy typifies the Black mother figure in white homes, the matriarch symbolizes the mother figure in Black homes. Just as the mammy represents the "good" Black mother, the matriarch symbolizes the "bad" Black mother. The modern Black matriarchy thesis contends that African-American women fail to fulfill their traditional "womanly" (Moynihan, 1965) duties. (p. 74)

Collins (1990) suggested that the "controlling images" that define and often paralyze Black women into inaction, are designed "to make racism, sexism, and poverty appear to be natural, normal, and an inevitable part of everyday life" (p. 68). She further asserted that schools, media, government agencies, and corporations, as well as the Black community itself, often reinforce the subordination of Black women in the policies promoted and the expectations communicated.

A flip side of objectification as "other" is for Black women in predominantly white settings to become "exoticized, special" (hooks, 1990, p. 91), in ways unrelated to actual achievements. This has its pitfalls, as described by Dumas (1979):

The black woman executive, perceived to be either good or bad, becomes a kind of superstar among some individuals or groups in the organization. People love her when she gives what is desired and hate her when she fails to perform as expected. In either case people are moved by an image they have constructed of the Black person in the leadership role--how they 
imagine her to be by her life style, attitudes, values and what they symbolize for the beholder. When she is good, she becomes their heroine. When she is not good, she becomes their villain --but always an object for them to identify with positively or negatively. (p. 212)

The depth to which negative images of Black women is implanted in the American psyche is revealed in the number of times Black women working in the majority culture report being told that they are "different from" other Black women (read: smarter, kinder, better read, more self confident, softer, more decent). Such is the power of stereotypes. It is not entertained in the biased mind that what she is "different from" are the deeply embedded negative images of Black women imprinted in the mind of the beholder. The following conversation relates the experiences of a young Black woman whose white friends relate to her on the basis of their stereotypes about Black women. They doubt the evidence of their own experience of Karen, and in so doing negate an essential part of who she is as a Black woman:

How am I supposed to react to well-meaning, good, liberal white people who say things like: "You know, Karen, I don't understand what all the fuss is about. You're one of my good friends, and I never think of you as black." Implicit in such a remark is, "I think of you as white," or perhaps just, "I don't think of your race at all." (Russell cited in collins, 1990, p. 79) 


\section{Black Women and the Construction \\ of self}

Why this theme of self definition should preoccupy African American women is not surprising. Black women's lives are a series of negotiations that aim to reconcile the contradictions separating our own internally defined images of self as African American women with our objectification as the other. (Collins, 1990, p. 94)

What then are the dynamics of Black women's construction of a positive self? And how is "self" defined in this construction? collins (1990) contended that Black women do not define self as increased autonomy from others,

instead, self is found in the context of family and community. By being accountable to others, African-American women develop more fully human, less objectified selves. (p. 105)

Identity is not the goal but rather the point of departure in the process of self definition. In this process Black women journey toward an understanding of how our personal lives have been fundamentally shaped by interlocking systems of race, gender, and class oppression. (p. 106)

Agreeing with Collins (1990), Etter-Lewis (1991) spoke further about the importance of the group or community in developing a positive sense of self:

Mckay acknowledges that several scholars have noted that the black self is "conceived as part of a group." She explains that "community identity" is essential for at least two reasons: (1) it allows for the rejection of bankrupt self-images "imposed by the dominant culture," and (2) it permits marginalized individuals to embrace alternative selves constructed from more positive (and more authentic) images of their own creation." (Etter-Lewis, 1991, p. 53) 
From the work of major African American women theorists (Collins, 1989, 1990, 1991; hooks, 1984, 1989, 1993; Lorde, 1984) a framework begins to develop that is useful in understanding how Black women leaders develop a conceptualization of self, it includes: moving from silence to speech; defining the politics of location; building community and connection; and developing resiliency. The following sections discuss these concepts in more detail.

\section{Black Women Moving From}

\section{silence to speech}

"Language is also a place of struggle" (hooks, 1990, p. 146).

The movement from silence to speech is a theme that runs through the scholarly and literary work of many African American women. "To be able to use the range of one's voice, to attempt to express the totality of self is a recurring struggle in the tradition of Black Women writers (Christian cited in Collins, 1990, pp. 93-94). At the heart of the struggle of claiming speech is the risk of self exposure and the possibility of denunciation or punishment.

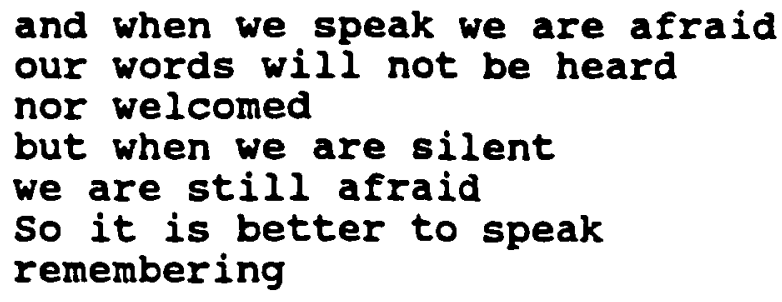


we were never meant to survive. (Lorde cited in hooks, 1989, p. 129)

Collins (1990, p. 95) argued that for Black women "finding a voice" is central to the development of a positive identification of self. She listed churches, extended families and community organizations as places where "safe speech" is allowed to flourish, and where resistance to objectification as the "other" can be developed. The exchanges between Black women nourish the sense of self:

In the comfort of daily conversations, through serious conversation and humor, African-American women as sisters and friends affirm one another's humanity, specialness, and right to exist. (p. 97)

This kind of speech, dialogue, takes place between equals, and is humanizing speech; it is speech that "challenges and resists domination."

Moving from silence into speech is for the oppressed, the colonized, the exploited, and those who stand and struggle side by side, a gesture of defiance that heals, that makes new Iife and new growth possible. It is that act of speech, of "talking back", that is no mere gesture of empty words, that is the expression of our movement from object to subject--the liberated voice. (hooks, 1989, p. 9)

As a college professor on a primarily white campus, Collins (1990, p. 98) described a language related barrier she has faced as an African American woman. In struggling to present her ideas in language that is both rigorous (to meet the standards of the academy) and accessible (to Black women of all classes), she often experienced a sense 
of discordance: in framing her ideas in language that is familiar to, and comfortable for, the dominant group, the meaning of her ideas and work is changed. hooks (1989) faced a similar dilemma in the academy, as she strove to use simple language and to relate her personal experiences as valid intellectual discourse. She remarked that her deliberate commitment to simple language is "often considered by academics and/or intellectuals to be a sign of intellectual weakness or even anti-intellectualism" (p. 77). The struggle associated with moving from silence to speech is a theme of other African American scholars who wish to bring their authentic speech and voice to their work without alienating colleagues or challenging the system beyond its endurance:

Silence is the absence of our words and the presence of our complicity. If silent, we lose our ability to challenge. African American women have an important stake in reworking academe so that silence is not a prerequisite for professional progress (or survival). This requires courageous speech. (James \& Farmer 1993, p. 223)

Feeling silenced, gaining a voice, and fear of speaking are dominant themes addressed by most of the women interviewed for study and are discussed again in Chapter V.

\section{Black women and community}

Motherhood and other Motherhood (fictive kin) have traditionally been important leadership roles for Black 
women (Collins, 1990; James, 1993). "'other mothers' can be defined as those who assist blood mothers in the responsibility of child care for short to long term periods in formal or informal arrangements" (James, 1993, p. 45). The practice of "other mothering" was seen in many African tribes and has provided the only means of survival for generations of children in the Black community whose parents could not care for them. In addition to caring for young children, "other mothers" often care for the biological mothers of the young children providing support, affection, and role modeling. "Other mothering," while not as common in Black communities as in earlier periods, is still practiced: several weeks ago, my neighbor and her 22-year-old daughter became "other mothers" to a 16-year-old non-relative in need of a home. My neighbors have made a joint commitment to the young woman for the foreseeable future. She has already started to blossom. In passing down traditions and providing support in an often hostile world, mothers and "other mothers" imbue younger generations with the tools needed for survival.

Motherhood can serve as a site where Black women express and learn the power of self-definition, the importance of valuing and respecting ourselves, the necessity of self reliance and independence, and a belief in Black woman's empowerment. (Collins, 1990, p. 118) 
Black Women and Resiliency

Resiliency, the ability to bounce back after negative experiences, is a combination of coping strategies that enables children and adults to survive even when external conditions are extremely difficult and persistent. EtterLewis (1991) found that many of the women she interviewed during her research on pioneering Black women in the professions, developed resiliency early in their lives and were able to regenerate their self-esteem through the lessons learned early in their families. Others said they became resilient through their constant encounters with racism:

Thus, many of the black women in my study
developed a self-concept endowed with the power
to regenerate the self-esteem naturally lost
through repeated assaults by a racist society.
Sometimes this ability to restore a damaged
self-image was learned from the family. At
other times it was acquired from the sheer
repetition of daily living. Whatever the source
a regenerated self-image served as an antidote
for the self-hatred that could develop as a
byproduct of racism. (p. 54)

Resilience research was introduced by child development researchers and other social scientists who sought to change the focus of their research agenda from a deficit model (looking at what is wrong with children and their lives), to a model that focused upon the social and environmental factors that foster strength, resistance, and resilience in socially vulnerable children. Specifically, researchers wanted to isolate and to 
understand the factors that enabled some children living in negative situations including poverty, abandonment, racism, life with drug affected parents, etc., to survive childhood intact, and to become healthy, well-functioning adults. Resiliency studies compared emotionally healthy children with children from similar circumstance and comparable experiences, who exhibited major developmental and/or adjustment problems including criminal activities, drug abuse, violence in childhood, and later as adults:

As the children studied in these various longitudinal projects grew into adolescence and adulthood, a consistent--and amazing--finding emerged: While a certain percentage of these high-risk children developed various problems, (a percentage higher than in the normal population), a greater percentage of the children became healthy, competent young adults. For example, Manfred Bleuler found that only 9 percent of children of schizophrenic parents became schizophrenic, while 75 percent developed into healthy adults. .. Similarly, Michael Rutter's research on children growing up in poverty found "that half of the children living under conditions of disadvantage do not repeat that pattern in their own adult lives." (Garmezy 1991 cited in Benard, 1991, p. 2)

The resilience research contributes to my greater understanding of factors that may have helped Black women survive racism and other negative experiences intact.

Black Women and the Politics of Location

A critical survival strategy (Collins, 1989; hooks, 1990) for African American women, and for all people of marginalized groups working in predominantly white 
settings, is the ability to "size up" the setting, and to locate oneself within it. hooks referred to this as "the politics of location," a "view from the margins," that identifies one's relationship to the power center:

To be in the margin is to be part of the whole but outside the main body. . . Living as we did--on the edge--we developed a particular way of seeing reality. We looked both from the center as well as on the margin. We understood both. This mode of seeing reminded us of the existence of a whole universe, a main body made up of both margin and center. (p. 149)

A conscious view of one's marginality, asserted hooks (1990), is a site of potential power that ultimately affords a location from which to see, act and speak with clarity and with compassion, "It offers one the possibility of a radical perspective from which to see and create, to imagine alternatives, new worlds" (p. 150).

Developing a similar concept, Collins (1989, 1990, 1991) defined her status as an African American woman sociologist as being an "outsider within," a position that she shares with others from marginalized groups. She described the repeated and contradictory ways in which the invisibility of Black women is brought home to her in the discipline of sociology: Often she was aware of the omission of sociological facts and observations of Black women's lives. At other times, when Black women are included in the data, she noticed the differences between her own experiences as a Black woman and the descriptions of those experiences reported by sociologists (Collins, 
1991, p. 51). Like Smith (1987), collins felt

professionally invisible at these times. Also like Smith, who developed an analytic framework in which she investigated the everyday experiences of women as a legitimate area of research, collins created a theoretical model-Black Feminist Epistemology-that articulated the standpoint and explicated the experiences of Black women. collins saw value in conserving the "creative tension" of the outsider within status, by using it as an enhanced way of seeing the world. She promoted this location as a place from which Black women can produce scholarship with distinctive analyses of race, class, and gender (collins, 1991, p. 35), that uncovers a wider range of reality than most social sciences researchers have access to.

Influenced by the work of simmel on the sociological significance of the stranger, Collins (1991) noted the potential benefits of the "outsider within" status:

simmel's definition of (1) objectivity as "a peculiar composition of nearness and remoteness, concern and indifference," (2) the tendency for people to confide in a "stranger" in ways they never would with each other, (3) and the ability of the stranger to see patterns that may be more difficult for those immersed in the situation to see. (p. 36)

"Outsider within" status enables African American women and others from marginalized groups to develop a more comprehensive and hopefully more compassionate view of reality. To the degree that one can maintain an objective but concerned distance, it may be possible to 
engage in creative problem solving not available to those fully immersed in the setting.

\section{Summary of Chapter II}

In this chapter I briefly discussed traditional and emergent leadership literature and pointed to the failure of either to develop theoretical models that specifically investigate the realm of leadership from the perspectives of women and men of color. I discussed women's leadership research that honors the ways in which women know the world. Next, I presented what is now known about the leadership of Black women. After this, I examined the historical influences and present day legacies of Black women as they relate to work; controlling (negative) images; construction of self, community, and resilience. 


\section{CHAPTER III}

\section{RESEARCH DESIGN AND METHODOLOGY}

I begin the chapter by reviewing the purpose of the study and describing its basic assumptions. I next discuss three post positivist paradigms that together provided the focus for the study's design and its theoretical underpinnings. Following this, I locate myself as researcher, describe the research design, and discuss recruitment procedures. Next, I describe the development of the interview instrument and relate my thoughts on the dynamics of the interview relationship. Finally, I describe steps I used in analyzing the data, and discuss the limitations of the study.

\section{Purpose of the study and}

Basic Assumptions

The purpose of this study was to learn more about leadership from the perspectives, norms, and values of a selected group of African American women leaders. In so doing, I hoped to develop a more inclusive view of the realities of leadership, and a better understanding of the impact of the interlocking status of race, gender and class on the practice, pursuit and perceptions of leadership by Black women and reflect on the implications 
of this understanding for educational leadership and practice. In addition, I wanted to develop a more wholistic picture of leaders than is routinely reported in the literature by exploring the intricacies, tensions and connections between respondents' personal lives, their professional activities, and their political and sociocultural milieu.

As noted earlier, there is little in the leadership literature that portrays leaders as multidimensional individuals who, in any sphere of leadership, simultaneously juggle personal, social, cultural, and political realities that have an impact on the ways in which they identify, approach, and implement their leadership tasks. The decontextualized nature of most traditional models of leadership fosters a perspective of separateness, and the illusion that leadership takes place in a political and social vacuum.

In probing the confluence of the historical, personal, and professional events of their lives, I hoped to better understand the antecedents and the present day dimensions of the respondents' leadership. The interview instrument was designed to accomplish this purpose.

\section{Basic Assumptions of the study}

1. African American women experience leadership in ways that are not explicated in the leadership literature. 
2. African American women define leadership in ways that are rooted in their cultural and historical experiences and perspectives.

\title{
Definition of Terms
}

African American--Is used interchangeably with Black and refers to Americans of African descent, a category culturally constructed and synonymous with racial identity.

Leader--Refers to those identified in their community as making a positive difference in working toward and meeting a defined set of goals. Leaders may be positional --having visible positions in formal structures, or nonpositional--exerting leadership beyond position (Astin \& Leland, 1991).

\section{Constructed Knowledge and \\ Theoretical Paradigms}

\begin{abstract}
First, there is the ontological question. What is the form and nature of reality and, therefore, what is there that can be known about it? Second, there is the epistemological question. What is the relationship between the knower and the would-be-knower and what can be known? Third, there is the methodological question. How can the inquirer (would-beknower) go about finding out whatever he or she believes can be known? (Guba Lincoln, 1994, p. 108)
\end{abstract}

In opening this section, I return to the importance of the paradigm as a human construction that signals the world view of the researcher, the subjects or areas that 
are deemed to be researchable, the methods appropriate to conduct the investigation, and the kind of relationship permissible between the inquirer and the respondent.

As previously discussed, the positivist paradigm promotes a scientific view of the world that decontextualizes relationships and investigates and interprets that which is quantifiable or "objective." The strength of this model is seen when variables can be significantly controlled, such as in the fields of chemistry, geology, and other physical sciences, and the outcome is predictable within certain limits, and is (ideally) replicable. This model has been applied to education and the social sciences since the nineteenth century. However, some scientists in the twentieth century have challenged the separability of the observer from observed reality. When human beings in all of their variability are the "subjects" being investigated, the logic of the positivist lens is most clearly called into question. What is also lacking in the presumed objectivity of the positivist paradigm is an acknowledgment that there are many ways of viewing and experiencing the world, and that there are perhaps as many ways of investigating and reporting these experiences. Searching for simple answers in the midst of a chaotic and complex time, adds little to the leadership dialogue. For the purpose of this study, I focus upon the meaning of 
human experience, particularly, on the meaning that the respondents ascribe to their own lives.

In probing for the meaning African American women ascribed to their lives and leadership, I drew upon several theoretical constructs that assume the variety and validity of subjective human experience. Each of the following paradigms contributes to the theoretical underpinnings of the study: critical theory challenges the "truth" of taken-for-granted reality and reexamines what is real. Critical theorists expose inequities embedded in social and political structures and introduce the inversion of these hierarchies as new possibilities for organizing society. Feminist theory opens up the literature to the absent viewpoints and silenced voices of women, and questions the universality of traditional social sciences scholarship that has primarily reflected the viewpoints and experiences of white middle-class males. African American women's standpoint and epistemology are grounded in the assertion that neither Afro-Centric theory nor feminist theory accurately portrays the experiences of African American women who simultaneously embrace the status of African American, and of women. African-American women theorists and others contend that the interlocking nature of race, gender, and class oppression combine to create unique experiences for African American women. These experiences are not 
typically represented in either the Afro-Centric or the feminist literature. The challenge of these theories is discussed in greater detail in the following pages.

\section{critical Theory}

Critical theory challenges the status quo and the taken for granted reality of the way things are. Unlike positivist theory, critical theory assumes a values orientation and asserts that "ideas possess a dual-edge capacity to both control and liberate" (Thomas, 1993, p. 20).

$$
\begin{aligned}
& \text { - we can say that the positivist's goal is } \\
& \text { to predict and control, the hermeneutics' is to } \\
& \text { understand, and the critical theorists'approach } \\
& \text { is to emancipate-that is to uncover aspects of } \\
& \text { society, especially ideologies, that maintain } \\
& \text { the status quo by restricting or limiting } \\
& \text { different groups access to the means of gaining } \\
& \text { knowledge. (Nielsen, } 1990, p \text {, 9) } \\
& \text { The critical theorist, as historical revisionist, }
\end{aligned}
$$
critiques social institutions and accepted meanings and adopts the stance of activist and advocate (Guba \& Lincoln, 1994, p. 112). But this very act "implies that by thinking about and acting upon the world, we are able to change both our subjective interpretations and objective conditions" (Thomas, 1993, p. 18). The knowledge claims of critical theorists carry with them an emancipatory obligation to use their understandings to bring about social change (Woodbrooks, 1991). Critical Theory is a useful frame in researching the experiences of 
women and people of color, particularly because the theory assumes that hidden inequities are built into past research and that these models must be reexamined in light of more current knowledge about multiple views of reality.

\section{Feminist Theory/Constructed Knowledge}

Constructed knowledge describes the way in which some women, through a combination of objective and subjective strategies come to know and negotiate their worlds (Belenky et al., 1986). These women "view all knowledge as contextual, and experience themselves as creators of knowledge" (p. 15). To some degree, all modern feminist scholarship is based upon a belief in the validity of constructed knowledge as is indicated in the following discussion of these theories.

Feminist scholarship has altered traditional social sciences research by including the silenced voices of women and by championing the legitimacy of women's experiences as a theoretical basis of knowledge or truth (Olesen, 1994). No single "feminist" ideology has emerged, rather, three epistemological strands now frame feminist scholarship: First, Feminist Empiricists are committed to traditional qualitative and ethnographic research methods and focus upon the intersubjectivity of truth, including the commonly created meanings developed between the researcher and the respondent; second, 
Postmodern Theorists regard learning the "truth" about women's lives in an oppressive culture as an illusion, and they assert that because reality is always shifting, the "truth" is best investigated through endless stories and texts. The third theory, standpoint Theory, builds upon research that values the experience of women in everyday life (Olesen, 1994, pp. 162-164). In addition, standpoint Theory suggests that those who stand outside of social and political mainstreams, i.e., women, and men of color, can use their positions to develop meaningful critiques of the world:

- . Standpoint epistemology begins with the idea that less powerful members of society have the potential for a more complete view of social reality than others, precisely because of their disadvantaged positions. That is, in order to survive (socially and sometimes even physically), subordinate persons are attuned to or attentive to the perspective of the dominant class (for example, white, male, wealthy) as well as their own. This awareness gives them the potential for what Annas (1978) called "double vision" or double consciousness-a knowledge, awareness of, and sensitivity to both the dominant world view of the society and their own minority (for example female, black poor) perspective. (Nielsen, 1990, p. 10)

These theories represent a significant shift from positivist thought and each competes for a role in the social sciences discourse on truth, meaning, and legitimacy. Further, they have served to pave the way for the development of a Black women's standpoint and epistemology. 
While a Black women's standpoint and its accompanying epistemology stem from Black women's consciousness of race and gender oppression, they are not simply the result of combining Afrocentric and female values-standpoints are rooted in real material conditions structured by social class. (Collins, 1989, p. 758)

\section{Black Women's Standpoint}

I suggest that Black feminist thought consists of specialized knowledge created by African American women which clarifies a standpoint of and for Black women. In other words, Black feminist thought encompasses theoretical interpretations of Black women's reality by those who live it. (Collins, 1990, p. 29)

Black women's standpoint represents the development of a world view rooted in the common experience of women living in a society that denigrates women of African descent. Core themes of struggle and resistance, of performing work that is devalued by society, and of the role of motherhood and community in forming identity emerge as common historical themes (Collins, 1990, p. 22). In addition, combating controlling images, developing a "common sense" approach to problem solving, and using one's marginality as a tool to critique and navigate one's world, are frequently mentioned themes of Black women's experience.

It is only in recent decades that African American women scholars have had access to the academy in sufficient numbers to critique the experiences of African American women, and to begin to develop a theoretical 
context for understanding and describing their lives. Notable among the women who have paved the way for the study of African American women are: Giddings (1984); Jones (1985); Collins (1989, 1990); Jewell (1993); EtterLewis (1993); and Lorde (1984), hooks (1984, 1989), and Vaz (1995). During the past decade their work has begun to bridge the "fault-lines" that have obscured the presence and contributions of Black women in America (Smith, 1987). These authors and a growing number of other Black women scholars have contributed to the emergence of an interdisciplinary scholarship that claims value for their lives, and legitimacy for their scholarship.

Like other subordinate groups, African-American women not only have developed distinctive interpretations of Black Women's oppression but have done so by using alternative ways of producing and validating knowledge itself. (Collins, 1989, p. 746)

This study is grounded in a Black women's standpoint that places Black women's experiences at the center of analysis. In answer to the question "How do we know the world?," the standpoint suggests that Black women know the world as survivors, and not as victims, as mothers and as "other mothers." In answer to the question "What is the nature of reality?," the Black women's standpoint embraces a reality that is defined by complexity and contradiction, by an acknowledgment that racism is a constant that must not become an excuse for giving in or giving up: that 
reality is self, internally defined. In answer to the question "How do Black women gain knowledge about the world?" The standpoint suggests that knowledge is gained through real life experiences, by paying attention to the past and to the present, to the margins and to the center, to the pieces and to the whole. And by listening and responding to our own and each other's authentic voices (Collins, 1990).

The existence of a Black Women's standpoint suggests that there is always choice and the power to act, regardless of the bleakness of circumstances. The standpoint views the world as one in the making, and raises the issue of individual responsibility for bringing about change. It also asserts that while individual empowerment is key, only collective action can effectively generate lasting social transformation of political and economic institutions (Collins, 1990, p. 237).

Collins (1990) made the distinction between Black feminist thought and Black Feminist standpoint. Black Feminist standpoint is the everyday, taken for granted knowledge shared by members of the same group, i.e., Black women. This definition does not erase the differences in individual life experiences, socioeconomic class, and viewpoints among Black women nor does it imply that all Black women consider themselves feminists. Rather, Black feminist consciousness as used in this study adheres to a 
definition by Black feminist sociologist Deborah $\mathrm{K}$. King (cited in collins, 1989):

Any purposes, goals and activities which seek to enhance the potential of women, to ensure their liberty, afford them equal opportunity, and to permit and encourage their self-determination represent a feminist consciousness, even if they occur within a racial community. (p. 751)

Valerie Smith (cited in Wall, 1991), Black professor of English and Black feminist criticism, further clarified the definition of Black feminist theory as used in this study:

I understand the phrase black feminist theory to refer not only to theory written (or practiced) by black feminists, but also to a way of reading inscriptions of race (particularly but not exclusively blackness), gender (particularly but not exclusively womanhood), and class in modes of cultural expression. Rather, I examine black feminism in the context of these related theoretical positions in order to raise questions about the way the "other" is represented in oppositional discourse. (p. 39)

Black Feminist Thought is the systematic and coherent articulation of everyday realities by those who are part of the group (Black women) and who have acquired the tools, (i.e., scholars, poets, "cultural workers") to express the group's standpoint. Black feminist thought:

can encourage collective identity by offering Black women a different view of themselves and their world than that offered by the established social order. This different view encourages African-American women to value their own subjective knowledge base. By taking elements and themes of Black women's culture and traditions and infusing them with new meaning, Black feminist thought rearticulates a consciousness that already exists. More important, this rearticulated consciousness 
gives African-American women another tool of resistance to all forms of their subordination. (Collins, 1989, p. 750)

\section{Afro-Centric Feminist}

\section{Epistemology: A Paradiom}

Afro-Centric Feminist Epistemology claims legitimacy for a world view lived in and articulated by African American women. The evolution of this epistemology represents the fusion of scholarly investigation across academic disciplines where Black Women's experience is at the center of analysis (Collins, 1989, 1990). In this construct Black women's experiences are evaluated not in relationship to their degree of deviance from the experiences of White or Black men, or of White women, but as having meaning, coherence, and legitimacy in and of themselves. Afro-Centric Feminist Epistemology is posited as the qualitatively unique experience of life lived at the juncture of race, gender, and class--a life that is superimposed by the persistence of culturally embedded negative images of Black womanhood.

collins (1990), the major architect of Afro-centric Feminist Epistemology, referred to it as an "epistemology in progress." The bases of the Afro-Centric Feminist Epistemology knowledge claims are as follow:

(1) There are two types of knowing, knowledge and wisdom - Living life as Black women requires wisdom since knowledge about the dynamics of race, gender, and class subordination has been essential to Black women's survival. AfricanAmerican women give such wisdom high credence in 
assessing knowledge . . . Knowledge without wisdom is adequate for the powerful, but wisdom is essential to the survival of the subordinate. (Collins, 1989, pp. 758-759)

Thus, concrete experience as a criterion for credibility frequently is invoked by Black women when making knowledge claims.

(2) The use of dialogue with other members of a community is important for new knowledge claims - "Dialogue implies talk between two subjects, not the speech of subject and object. It is a humanizing speech, one that challenges and resists domination" (hooks cited in collins, 1990, p. 212).

Dialogue promotes connectedness rather than separation and is an essential component of the knowledge-validation process for Black women. (Collins, 1989, p. 763)

Dialogue promotes the discovering of common truths, and the validation of self.

(3) The ethic of caring - The ethic of caring suggests that personal expressiveness, emotions, and empathy are central to the knowledge validation process. Ideas cannot be divorced from the individuals who create and share them. Talking with the heart (Collins, 1989, p. 765) promotes connection, builds trust and a common level of presence. The ethic of caring suggests that personal expressiveness, emotions, and empathy are central to the knowledge-validation process (Collins, 1990, p. 215).

(4) The ethic of personal accountability - Not only must individuals develop their knowledge claims through dialogue and present those knowledge claims in a style proving their concern for their ideas, people are expected to be accountable for their knowledge claims. (Collins, 1989, p. 768)

Black feminist epistemology grounds Black women's standpoint in a coherent theoretical model placing Black 
women's experience at the center of analysis. It provides a useful framework in the investigation of the lives of African American women leaders.

\section{Locating Myself as Researcher}

My interest in this study grew out of my own experiences as an African American woman who has worked in a variety of leadership positions during the past 18 years, most recently as an elementary school principal and for a philanthropic foundation in the Pacific Northwest. While still an elementary school principal, I began doctoral work in Educational Policy, Foundations, and Administrative Studies at Portland State University, and became aware of the lack of congruence between my own dayto-day leadership experiences and the descriptions in the literature of the world of educational leaders. Notably absent from this literature were critical analyses of the impact of race, gender, class on the practice and conceptualization of leadership. In addition, there was little in the traditional literature that described leadership within the context of the larger social world, a world that daily made a major impact in every area of school life. I hope that this contextual study on African American women leaders will contribute to the literature a new point of reference for the definitions of leadership and of leaders. 
Research Questions

In probing for the meaning that African American women leaders ascribe to their lives and leadership, I posed the following questions:

1. At the intersection of race, gender, and class, how do African American women leaders describe their lives and leadership?

a. What are the similarities and differences in the personal and professional life experiences of African American women leaders?

b. Which educational, social, and experiential opportunities appear to foster leadership development for African American women?

Development of Interview Instrument

I used a modified open interview schedule and included probes from three sources (see Appendix c). The first set of probes came from Belenky et al. and were used to focus upon relationships, and how respondents viewed life in the present. The second set of probes related to Black women's standpoint, the outsider within, controlling images, silencing and gaining a voice, and the construction of self. The third set of probes related to issues of leadership, including antecedents and early experiences, and the costs and demands of leadership. I began each interview with the statement, "I am interested 
in exploring with you the personal and professional experiences that have shaped the person that you are today. I would like to start off by asking you to describe your childhood and the memories that stand out most for you." In some interviews, this opening question was one of the few direct questions asked; in other interviews, I used appropriate probes to elicit information in particular areas that seemed appropriate within the context of the individual interview.

\section{Respondents}

Seven women were selected for the study, four of whom were identified through professional and social networks. I learned of one of the others when she was interviewed on a national radio broadcast, and of the other two through newspaper articles profiling their work. of the seven participants, four are positional leaders: a high school principal, a senior level community college administrator, a state legislator, and the executive director of a large philanthropic foundation. Also participating were three non-positional leaders who work prominently within their communities in a variety of ways, that are described later in the study. In selecting respondents for the study, I looked for established leaders who appeared to work collaboratively with colleagues and to strive for congruence between their personal lives and public activities. In addition, I chose those whose leadership 
practices seemed to me unusual in some way, i.e., without having consciously defined what I sought, I selected women who equated their leadership with a purpose beyond themselves (elsewhere in the study, I refer to this quality as a commitment to service).

\section{Data coltection}

A letter was sent to each respondent outlining the nature of the study, and requesting an interview (see Appendix A). The letter stated that as an African American woman myself, I was interested in broadening the leadership literature by including the voices and experiences of African American women. Enclosed with the letter was a description of the study, and a Participant's Profile Form requesting demographic data (see Appendix B). I made follow-up telephone calls to determine interest and to arrange a time for the interview. Every person contacted agreed to take part in the study.

I used a tape recorder in six of the interviews, which were then professionally transcribed. The seventh interview was not tape recorded because of the respondent's choice, and I took hand written notes during this interview. This interview did not result in as rich a source of data of the other six. Interviews lasted between one and $a$ half and three and a half hours. Three of the interviews were conducted in the respondent's homes. One was conducted in my hotel room in an East 
Coast city where I attended a professional conference, one in my Portland home, and two in respondents' offices. Respondents had an opportunity to read and review their transcripts before the final copy of dissertation was submitted.

\section{Conducting the interview: Developing a dialogic}

relationship. I selected the long interview as a tool which would allow me time to build rapport with respondents, and to obtain the depth of response I was interested in soliciting:

The long interview is one of the most powerful methods in the qualitative armory. For certain descriptive and analytic purposes, no instrument of inquiry is more revealing. The method can take us into the mental world of the individual, to glimpse the categories and logic by which he or she sees the world. It can also take us into the lifeworld of the individual, to see the content and pattern of daily experience. The long interview gives us the opportunity to step into the mind of another person, to see and experience the world as they do themselves. (McCracken, 1988, p. 9)

My letter to the respondents had set the stage for an interview between equals, and my introductory remarks at the time of the interview followed-up on this. I restated that while my role was as interviewer, I was also someone who shared as a Black woman in a leadership role, historical, social, and possibly professional similarities with the respondent.

Oakley (1981) asserted that for a feminist, "interviewing women is a contradiction in terms," 
connoting as it does both a differential of power between the interviewer and the interviewee, and an endorsement of an interview paradigm that values "objectivity, detachment, hierarchy and 'science' as an important cultural activity which takes priority over people's more individualized concerns" (p. 38). In Black Feminist Epistemology, primacy is given to dialogue, and to Black women meeting others as subjects, rather than as objects. Because I subscribe to these points of view, I sought to create during the interviews an informal, open, and dialogic relationship. The establishment of an interview relationship between equals added immensely to the depth and degree of openness that emerged in each interview. My professional and personal experiences enabled me, as an African American woman, to bring "Theoretical Sensitivity" to the interview process (Strauss \& Corbin, 1990). This framed the interaction between the respondents and me, and provided an early and comfortable interviewer-interviewee level of communication. Theoretical sensitivity is described as the use of personal and professional qualities and experiences one brings to the interview process which increases one's understanding of what is occurring during the interview (p. 42).

Theoretical Sensitivity . . refers to a personal quality of the researcher. It indicates an awareness of the subtieties of meaning of data. One can come to the research situation with varying degrees of sensitivity depending upon previous reading and experiences 
with, or relevance to an area. It can also be developed further during the research process. Theoretical sensitivity refers to the attribute of having insight, the ability to give meaning to data, the capacity to understand, and capability to separate the pertinent from that which isn't. All this is done in conceptual rather than concrete terms. (Strauss \& Corbin, 1990, pp. 41-42)

While the concept of Theoretical Sensitivity is introduced as a researcher's tool when using Grounded Theory, it was useful to me even though the size of this study was too small to apply the theory. My own heightened awareness of the nuances of this research is the result of my extensive acquaintance with the biographical and autobiographical literature of Black women, as well as the literature cited in the Iiterature Section in Chapter II. In addition, my professional experiences as a Black woman in leadership positions in several settings over the past 18 years, and my personal experiences of having been raised in a Black working class family in the United States, enabled me to bring a certain breadth of vision that is relevant to the research topic. Other Black women researchers report on the value that their personal experiences added to the insight they were able to bring to their research. Sociologist Lightfoot (1994) spoke of how the contours of her life as a Black woman are reflected in the relationships she was able to develop with six highly accomplished African 
American men and women she interviewed for her study, I've Known Rivers: Lives of Ioss and Liberation:

The subtext here is the narrative of a relationship that is the vehicle through which the life story is remembered and expressed. Rather than being "interviewed" these six people are "collaborators" or "cocreators" of their life stories. The message and the meaning of the stories come from the interaction, our duet, the convergence of our experience. I am both audience and mirror, witness and provocateur, inquirer and scribe. Sometimes I am also the storyteller. To achieve the intimacy and trust that will inspire the confidence of my collaborators, I must be willing to share my own experience. (p. 620)

In a related context, sociologist Joyce Ladner (1987) described the value of her personal experiences as a Black woman, and the role her early life experiences played in her later research. The "theoretical sensitivity" she brought to her research enabled her to develop alternative interpretations of the life experiences of the poor Black girls she studied in a large urban area. On the one hand, her training as a "scientific" observer had taught her to maintain an emotional distance from the girls she studied, as well as to apply a sociological lens that viewed their lives from a perspective of deviance. On, the other hand, Ladner's own experiences as a Black girl and woman living in America had equipped her with another angle of vision that made it impossible for her to divorce herself from the lives of her subjects, or to judge their behavior as purely negative or maladaptive: 
I am sure that the 20 years I spent being socialized by my family and the broader Black community prior to entering graduate school shaped my perception of life, defined my emotive responses to the world and enhanced my ability to survive in a society that has not made survival for Blacks easy . . . Because of this cultural sensitivity I had to the life-styles of the over 100 adolescent, preadolescent and adult females I 'studied,' I had to mediate tensions that existed from day to day between the reality and the validity of their lives and the tendency to view it from the deviant perspective in accordance with my academic training. (p. 75)

Ladner (1987) accepted that her life experiences as a Black woman made a positive contribution to her role as researcher. In doing so, she was able to develop a more contextual study, and a vastly more insightful analysis of the lives of her subjects than would have otherwise been possible.

\section{Interview Schedule Analysis of} the Data

Upon the completion of each interview, the tapes were professionally transcribed. I color coded each set of transcripts and read them to develop a general feel for the data. I reread the transcripts while listening to the tapes for the emergence of themes, i.e., ideas, feelings, or words that appeared with some consistency in the documents. This process was repeated a minimum of four times for each transcript. I also noted in the margins of the transcripts those places where sensitive and/or emotional topics were related. After analyzing each transcript in the manner described, I sought out the 
similarities and the differences between the transcripts and developed approximately 30 rough coding categories. I then cut and pasted each color-coded transcript assigning each item to one of the 30 overarching categories. Finally, I whittled down the categories and developed the major themes which are described in chapter $V$.

\section{Limitations}

I am aware of the following possible limitations of the study:

1. In deciding to interview only seven women, I have offered only a small slice of the reality of African American women leaders.

2. Respondents were not randomiy selected, therefore data are not intended to generalize to all Black women leaders, but rather to open up the literature to the experiences and the voices of this specific group of women.

3. Because respondents fall within a narrow age range--all were in their forties and fifties--their lives and leadership may not be representative of younger or older cohorts of African American women leaders.

4. Finally, because of my shared status with respondents--being a middle-aged, African American woman, who has been in leadership roles for the past 18 years-this was clearly a study of personal significance to me. The "theoretical sensitivity" which enabled me to discern 
subtleties of language, to respond to the emotional tenor of the interviews, and to bring a personal and historical perspective to my analysis and interpretation of the data, may also have prevented me from exploring areas which I might have been "too close" to observe clearly. It is interesting to note that a limitation mentioned in the previously cited dissertations (Chatman, 1991; TalleyRoss, 1991; Woodbrooks, 1991) on African American women leaders, is that the researchers did not share the same racial or social class background as the respondents, and saw this as being in some ways problematic for their studies.

\section{Summary, Chapter III}

I began this chapter by reviewing the basic purpose and the assumptions of the study. I speak about the limitations inherent when applying a positivist lens to investigations in education and the social sciences. I introduce critical theory, feminist theory, and Black women's standpoint and epistemology, which together provide the expanded lens I used in designing and carrying out my study. I locate myself as the researcher and present the research question. I discuss data collection and the interview relationship. Finally, I discuss possible limitations of the study. 
In our eagerness to counteract the negative stereotypes, we must not create a different one, which also fails to reflect accurately the varied lives of Black women. Even though many Black women are able to overcome difficult situations, Black women are not "superwomen" devoid of needs and emotions. (Hull, Scott, \& Smith, 1982, p. 96)

This study explored the personal and professional experiences, perspectives, and commitments of seven African American women leaders. Although the respondents were born within a decade of one another, and share other similarities including race, gender, and the status of leader, the following profiles reveal them to be multidimensional individuals each with her own unique strengths, weaknesses, and personality. For instance, although as Black women all respondents faced discrimination based on their race and/or gender, each has developed distinctive coping mechanisms that reflect their past histories, personal style, specific milieus, and long and short term goals.

The primary purpose of this chapter is to introduce the respondents and to hear related in their own words the areas that emerged in the interviews as critical events and processes in their lives. 
I begin this chapter with a brief discussion of the study demographics and follow with an introductory profile of each respondent.

That some profiles provide more detail than others is due to the length of each interview which was in all cases determined by the respondent.

\section{Demographics}

\section{Family}

Four respondents grew up in extended families who played a major role in their lives, and five of the seven named their grandmothers as being very influential in their childhood. Two of the women were raised in nuclear families with their mother, father and siblings. One respondent lived with her father and siblings after her parents divorce, and had no contact with extended family.

\section{Siblings}

Two respondents were only children, one was the youngest child, three were middle children, and one was the second oldest. Three respondents had two siblings, and two had three siblings.

\section{Marital Status/Significant} Relationships

Two respondents were married at the time of the interviews, two were single and had never married, three 
were single and divorced. Two respondents were lesbians and five were heterosexual.

\section{Children}

Four respondents have adult children; three have never had children.

\section{Community}

Five of the seven respondents grew up in supportive Black communities where they and their families were established members of the community. Four lived in northern states, and two in the southern states, and one lived approximately half of her childhood in the north and the other half in the south.

\section{Education}

One respondent attended college but did not graduate, two received bachelor's degrees, and four received graduate degrees. Four of the respondents were from families where at least one parent had graduated from college, and the pursuit of higher education for them was a family expectation. Three of the respondents were not from college educated families, but in all families, education was highly valued, and children in the family were expected to excel in school and to attend college. 
Social class

The issue of social class within the Black community has not been adequately defined in the social sciences literature. Collins (1990) pointed out that the status attainment and class conflict models describing social class in the general population do not describe the dualstatus of Black women in the class hierarchy; this applies equally to the status of Black men. In the segregated Black communities where most respondents grew up in the 1940 s and 1950s, professionals, laborers, and unemployed lived side by side and went to the same schools and churches. This is not to say that a subtle caste (color) and class system was not at work. Some jobs, such as teaching, working on the railroad or in the post office, conferred a higher status, and lighter skinned Blacks have traditionally been accorded higher status in the Black and broader community than darker skinned Blacks. The issue of social class is raised later in this chapter and is also discussed in Chapter VI.

\section{Profiles}

The following profiles present the candidates and the major themes that emerged during their individual interviews. In the interest of confidentially, names have been changed as have other identifying characteristics. Each profile begins with a statement about leadership by 
the respondent and is followed by accounts of personal and leadership experiences that were viewed as important in their lives.

\section{Paula's story}

[Paula]. I take my position very seriously and I don't want to be seen as the supervisor or the boss. I want to see that I'm there to get everything coordinated and moving. But I think my strength and power comes from the empowerment of the people who work under me. But in order for them to be able to function as a team, I have to provide the leadership.

In her early 50s, Paula works as a senior level community college administrator in a midwestern city with a small minority population. She is among the nation's leading reformers of science education, and travels several times a month to serve on national boards, task forces and as a consultant. Paula feels a special commitment as an African American woman to make science accessible to all students because, "I know what it is like to feel disenfranchised." In her present position for seven years, she has been instrumental in changing how science is taught to undergraduates on her campus and throughout the country. As one of few African Americans in her college, and one of few women to achieve recognition in the field of science education, she is often the only African American present in her professional meetings. Although she is now accustomed to this, the subtle pressure of being always visible and 
different takes a toll. Kanter (1981) pointed to the peculiar "token" status of being the minority or the woman in an otherwise homogenous group, and the need to be constantly alert, constantly high performing, constantly aware that their "token" status means being under a microscope much of the time.

Even after many years of recognition for her professional contributions, Paula relates that she has only recently begun to feel "legitimate" in her leadership role:

I think I'm more in control professionally. I have a little bit more say because I'm not worried about achieving or feeling legitimate. [Nor do I ask myself] Did I get this appointment because I was a female or a minority? I feel like what I'm doing now is legitimate because of some of the things that have happened. Some of the kinds of appointments and invitations that I'm getting you don't get because they're trying to fill a quota. We're talking less than two years here, probably in the last year. And that's significant.

The quest for legitimation for some, as strauss (1982, p. 173) pointed out, and as Paula's words confirm, is a continuing process of establishing the authenticity of one's work and moreover the realness, propriety, morality and legality of one's existence.

The youngest of three children, Paula grew up in a close knit family in a small town on the east coast. Along with an older brother and sister, she was raised by her mother and an extended family of her mother's five brothers and sisters and her maternal grandparents. They 
all, particularly Paula's mother, served as role models

for Paula's later accomplishments:

Probably the best way to describe my childhood-I was raised by my mother who was a very strong, focused, dynamic, well-educated woman. She would have five-year plans and hit it on the button every single time! so there were two things [she taught me were important] one, discipline and organization and second, long and short-term planning. Normally you hear about someone having a goal, but it's a short-term one. My mother would have five-year plans, and always hit the mark. To some extent when I reflect back, particularly in my 20s, I perceived her as rigid.

Another very significant thing. . . I really was raised by an extended family. She (mother) had five sisters and brothers, and they are extremely close. Three females who were the youngest and three males. All of the males stayed married to their wives, including my grandfather, and my grandmother never worked a day in her life. Whereas all the females, excluding my grandmother--but in my mother's generation and my generation, at one time or another got divorced.

As one of only five Black families in the town, Paula's mother, a college professor, and her aunts and uncles, also college educated, gave a clear message that "we were better (than other Black families in town) in that we were more educated . . . it was a confusing message." What Paula describes as an early "identity crisis," was related to her family's social separation from less educated Blacks on the one hand, with their coinciding strong message about Black pride, on the other. Identity is a recurring theme as Paula reflects on her childhood. 
And then the other thing significant in my childhood, probably to the point of crisis many times was my identity. I knew I was Black, I came from a very strong Black family and never had any doubts about it, but my early-childhood education was in a predominantly white elementary school in a very small town, which was very, extremely, hard one me. And by the time I went to high school, which was a fully integrated school in a large city, the Blacks considered me country, and the whites consider me Black. So it was like. . . I fit nowhere. But being in a big city I was able to continue on and function, but I think the identity crisis was always there in terms of fitting in the outside world. . . it was never within the family, it was always outside the family.

social class and/or caste (color) issues, rarely discussed openly in Black America, is mentioned by the majority of respondents as an issue they have dealt with intra racially. Generally the reference is related to times of intra-group discrimination. Talley-Ross (1991) reported, in her study of high achieving African American women in the professions, the experience of some African American women leaders with intra-group discrimination:

The African American woman who begins to achieve not only faces significant discrimination from white members of the dominant culture, but also is viewed suspiciously by members of her own culture who view her as "unblack" or "acting white." (Fordham cited in Tally-Ross, 1991, p. 33)

Like her mother and aunts before her, Paula has combined motherhood with a demanding professional life. She is the divorced mother of three daughters, two of whom have graduated from college, and the youngest of whom is about to graduate from high school. Although the girls' 
father has played an active role in their lives, geographic distance has meant that Paula has done most of her parenting alone. When Paula mentions her daughters, she radiates love and pride and refers to her valued relationship with them:

I have three girls. And they're my life. Yes, I wanted them. I remember the day they were born. We have a very, very close relationship. They're good kids. I got two through college already, and one is graduating from high school. And I gave them the same message I got--(from her mother) go to college. I'll get you through college debt-free. I might be heavily in debt, but you'll be debt-free so you can start your life (after graduation).

Despite her high professional status, and solidly middle-class background, Paula has felt the stigma of being a Black single mother, and identifies with other Black single mothers who are painted with a wide brush as uncaring and irresponsible. The controlling and negative images projected upon Black women (Collins, 1990; hooks, 1990; Jewell, 1993) transcend social class and affect women across the socioeconomic spectrum:

It infuriates me when you get labeled a single parent and (are pictured) as not taking care of your kids. They have what they need, and they've been my life. They're good, they're solid. And I also, I think one thing that I gave them that wasn't given to me, it was the freedom of choice to literally do whatever it is they really want to do . . . Well, with times being changed, where the female in general is liberated, and with my girls choosing a profession, I also said, "Whatever it is you want to do in life. You can have whatever you want." They were raised in a more liberated environment (than I was). 
In raising her own daughters, Paula has expanded upon the messages about success transmitted to her as a young woman. Her wish to study art in college was discouraged by her mother who steered her toward a more steady, mainstream career. Paula has encouraged her daughters to think independently, and to rely upon their own inner compasses in discovering how they want to live their lives, and in deciding what work they want to do:

They have traveled overseas. I insisted on it, just so they could have experience outside of this country. I mean, they go away to college. They have interracially dated. The oldest one now . . - she definitely wants to marry Black. The youngest one has never dated Black. It's mind-boggling to me that I let them make those choices. And I feel very good about it because I think that they do have a sense of self, even through we are still in a divided world. And I think, quite frankly, that's the greatest contribution I made, is having these kids and raising them--far, far more so than the job. Those girls just . . . they're everything to me. I wanted that. Yeah, I feel about my life, that's what's going to be lasting... . is (mothering) my kids.

Although Paula sees motherhood as being her greatest accomplishment, she is ready to move onto the next stage in her own life when her active mothering days will be over.

Some want to hold onto their kids . . . but now I can let go and my joy will come if they can put their lives together, however they want to put them together. Now, I must admit, probably deep down inside, I want them to get married and give me some grandchildren, I want that kind of Iife. But I know that if they don't, I suppose I could live with it. But I am ready to let go of them. Because now I want to see my children as individuals who blossom outside of my 
influence. And then I can look back and say what they are today I had a little something to do with it. But I can't invade, it's their life now. So I can get joy out of that part, too.

Although her professional achievements along with motherhood have defined Paula's adult life, it is with some ambivalence that she views her accomplishments and the personal costs of her achievements. She is especially aware of the ways in which the demands of her professional life and her public image may have compromised her relationships with Black men. Paula speaks of her professional relationships with Black men:

And when I try to network with the brothers (Black men), it's a problem. Either they're not interested because. . . similar to me, they have been pushed into the limelight. It's like they want center stage. And they don't want to share it. And I don't fault them . . . because to get to that place, my God, they probably had to work twice as hard as I did in a different sort of way . . . and to share the stage is threatening, at least in my mind. So to network has been frustrating, at best.

Paula appears to believe that in many instances Black men are more targeted than Black women in the workplace.

\section{Kim's story}

[Kim] . . You are the conduit for a lot of other voices. You have the fortune, the gift, that was given to you. It's not yours even, it was given to you. School, language, the ability to hone ideas down to a graspable size. I have those--I didn't do those... . I mean there are some parts of me I think I created, but those things are as much a consequence of circumstance and perhaps luck, and so my responsibility is to use them. 
Kim, in her mid-fifties, has lived in a mid-size Colorado city for more than 20 years. She has worked for many years in elective and appointed statewide and municipal positions, but is best known for her leadership as a human rights activist who for many, represents the conscience of the gay/lesbian movement in her state. Kim is known as a gifted orator, a principled strategist, and a coalition builder, and is regarded as a major force in helping to defeat a ballot measures aimed at limiting the civil rights of lesbians and gays.

Kim's earliest memories are of her nurturing grandmother with whom she and her brother went south to live after her mother left the family, and her father went away to serve in World War II. They lived in a "very nice house" in a racially segregated area in a southern state where her college educated family was well known and respected:

And, you know, it's an interesting piece, because I don't remember a lot of the first two years that we were there in terms of my reactions to my mother being gone. But I do remember just the warm atmosphere and somebody who was clearly in charge--my grandmother, cooking every day. And there was really, really a lot of comfort that came from my grandmother. I can remember that she would put me over her knees, and I got a lot of comfort from kind of humming . . You know how kids are? You have that little mmmm . . And she would just jostle me on her knees, and I'd kinda go to sleep, or feel very comfortable, and get up and go play. She always made the time.. . She was 60 years old when we came. 
In taking on the care of her young grandchildren, Kim's grandmother served a role undertaken by many Black women, that of becoming the mother surrogate or "other mother" (Collins, 1990) to her own kin. Kim's grandmother exemplified hard work, generosity, and compassion for those less fortunate. During hard economic times, Kim remembers men knocking at the back door to ask for work and "Mamma always found work for whoever came to the back door and asked for work, and she always found food. So these are big impressions on a little kid." Like other respondents influenced by their grandmothers, Kim recalled her grandmother as a person who embodied an ethic of caring and personal responsibility that was exercised in her daily life. Collins $(1989,1990)$ asserted that "an ethic of caring," and an "ethic of personal accountability" lies at the heart of a Black feminist epistemology.

Kim was an early and eager learner who was recognized as precocious by her family and teachers. Her early education was in a community that valued and supported her as a learner.

I learned to read before I went to school, and my early schooling was in segregated schools. And a lot of that experience was very good for me because my aunts and uncle were teachers. My grandparents had been teachers--my dad's mother and father had been teachers. So when I got to school, people knew I was coming, number one. They knew I could read, number two. And they knew all of my family. So one of the advantages I had was when I got bored I'd get up and walk 
out of the classroom to the principal's office. [A close friend of the family, the principal welcomed Kim and worked with her individually.]

After Kim's father returned from the war, he remarried and the family moved to Tennessee where her father returned to college and another brother was born. The family lived in a trailer on the college campus and became part of a community where "people kinda took care of you." One strong memory stands out for Kim that happened when she was seven years old:

- But there was another time in my life when
my father played an important role. I wouldn't
ride in the back of the bus, and one of his
friends told him. And so he called me--we were
in the trailer--and he called me into the front
part. "I understand you won't ride the back of
the bus" - . I said, No, sir. He said, "why
not?" I said, "Because it's not right for them
to make us sit back there because we're
colored." And I was seven years, old, and my
father looked at me and said, "you do what you
think is right." And to this day, I still think
that's wonderful.
More than 40 years later, kim identifies this
conversation with her father as one of the most important she ever had with him. She experienced his support of her right to make this decision as an affirmation of her judgment, and as an indication of her personal power. However, she had equally powerful unhappy experiences involving her father, including one that occurred during her second year of college:

After about a year-and-a-half there (a historically Black southern college) I went over - - my dad hadn't paid all the bills in the first year and they refused to give me a meal 
ticket. I said, "please give me one more meal ticket." I took it and I sold it. I bought a train ticket home, turned in my linen, got my linen deposit. As much as I love my dad and a lot of good stuff he does, when it comes to money and sharing or taking care of his children in a certain kind of way, he's never done it. We always had food, and we always had a house, and we were always warm . . . . College was not something he was spending (money on) for his daughter.

After her father's college graduation, the family moved for a short time to live with Kim's stepmother's family in another rural southern area, a period in her life which she remembers as the last happy time of her childhood. They moved from that house to one in which she lived only with her nuclear family:

And we were living kind of in a nuclear family situation, which was not a happy household. And the children in that household--including myself-were emotionally, verbally abused, primarily by my stepmother who was a very unhappy woman. And I think about that marriage and my father, and I would have been a very unhappy woman too. Her only mistake was that she took it out on my brother, my oldest brother, and myself. Her two children she took care of and protected. But the four of us loved one another and were very, very, close. And there was just nothing that could drive a wedge between us. That ended when I was about 13 or 14 years old--my uncle walked through the house - . he was visiting from Detroit, and he saw how I was being treated, and he walked to my grandmother and said, "I'm taking $\mathrm{Kim}$ to Detroit." And I went! But I think for that year I was probably one of the most depressed children in the world.

Reunited with her mother who was then living in Detroit, Kim lived with her and a stepfather for two years, during which time she was sexually abused by the 
third man since she was 11 years old. Although a time of tumult in her life, Kim excelled academically in high school, developed strong friendships, and began to emerge as a school leader. She describes a pivotal leadership experience that occurred during her adolescence, in Detroit, in 1956 when she led a classroom discussion of race:

And it went wonderfully. It was a discussion. The teacher allowed it. One student, one Black male student, left--he didn't want to be there. And I think it was scary for him. But we talked about things like values and attitudes and how to get along. In my senior year, one of my classmates, he had just started to grow, and he had been such a short guy all of our school year. And he wore a big pocket watch. He went to another side of town to visit a white friend and was killed by a group of white boys riding around in a car looking for a nigger... they beat him to death on the street. Everybody in the school was outraged . . . and the principal had to call an assembly to ask people, please, not to go hunting for the young men who had done this. And so I think I played a role in talking to lots of different people about it. I think that the role I played was very similar to what I play now, which is, "Let's get this stuff on the table, and let's be clear what it's about."

When asked to comment about the meaning of leadership

to her today, $\mathrm{Kim}$ responded:

I think of myself more as a facilitator and conduit.. . I'm not trying to downplay any of the things that I do, because I think that I do have a knack for taking that thing that is kind of abstract and making it concrete. I think I also have a knack for juxtaposing the stuff out of your head with the stuff out of your heart and bringing those together for people. But I'm not sure that's what leadership is. 
Kim expands upon her role as a leader and recognizes

the potential of problems for leaders who isolate

themselves:

What I know is the biggest danger for me is getting to be the charismatic leader who is isolated from everybody else; and with that in mind, I just try to make a really good effort not to become that person.

Isolation--nobody to call you on anything, nobody to help you with anything, nobody to give you input. You're making it all up (on your own), and all you get is kudos and kudos and kudos.

Kim is committed to cultivating new leaders, as are other respondents:

Number one is that I can't do it all. Number two is other people need the experience. I'm not here to be the permanent fixture. I mean I'm gonna die one day. There are people with more energy. There are people with new thoughts. There are people with different approaches. And it's fine with me. It's like it's their turn. So if I don't relinquish some of that--and that's the other piece, is recognizing that, whether I think I have power or not, I do.

\section{Jean's Story}

[Jean] - . Then you have to be yourself, believe in yourself, and you have to be strong because there are going to be all kinds of things that are going to be thrown your way. They can give you high levels of stress and make you want to stop and turn back, or frustrate you. I would say develop some outside interests, along with humor.

I met Jean for the interview at her home in early summer. She had just returned from playing tennis, and looked radiantly alive and healthy. In her late 50s, Jean 
had recently decided to take early retirement from her work as a high school principal. As Jean prepared a simple lunch I could see family photographs, healthy well cared for plants, and in the backyard a swimming pool that she and her husband, a physician, installed when her now adult children were young.

Jean was born and raised in a mid-size colorado city to a mother who was a teacher, and a father who worked on the railroad. As the interview unfolded, it became clear that Jean had encountered more blatant racial

discrimination at every turn of her personal and professional life than others interviewed for the study. I speculate that because Jean is slightly older than the other respondents, and entered college and the job market before the civil rights movement, discrimination was more overt during her coming of age years.

Jean was coached by her family at an early age on how to deal with the racism and discrimination they knew that she and her siblings would encounter. She was expected by her parents to attend college, and to become either a social worker or a teacher, the only two professions open to Black women at that time.

Upon high school graduation, Jean attended a college in a small town 60 miles away from her home.

I chose to go to wills college which is in a small town in Colorado, mainly because there was so much segregation, and discrimination, in the south. My parents thought that we had to have 
the exposure of the real world and if we were going to work in colorado, we needed to get our education in colorado. At the time I was the only Black, not only in the school, but in the whole town, and they had a motto there at the time, and that was, "The sun will never shine on a darky here."

Jean refers to encounters with discrimination and racism at wills as being mainly "subtle." However, she describes many blatant acts of discrimination that began in her first year at the college:

In fact, they had assumed that no one wanted to room with me, being the only Black. And so they gave me a room by myself . . Everyone else had a roommate. But the irony of it was, they (dormmates) were jealous that I had a room by myself! It's funny how segregation and discrimination works!

After the first year, Jean had a roommate every year, and more than 30 years later, she meets monthly with friends from her college years.

As the only Black student in the college and the town, Jean relates:

But one thing I was determined to do was to be involved in everything I possibly could. And I tried out for the cheerleaders, and I was a cheerleader, and Mills at the time was a very small town, and so most of their social activities centered around the college. So when we would have our band and our parades and march down the street and I'd be leading the way with my white skirt and purple and black sweater. I can still see it! And then a child would say, "Hey mom, look at the nigger." And that voice went all through me. Pretty soon, they finally got used to me.

A particularly low point for Jean occurred during her first Mother's Day Weekend: 
I did experience some things that were particularly painful: When we had Mother's Day, mothers were supposed to come down and spend a weekend. They were supposed to stay at a hotel that was in town. When I found out that my mother couldn't stay at the hotel, being a Black, I chose not to invite her to come down, because they said that she could come but she would have to stay in a dorm. Well, at that time no one stayed in the dorm... so I chose not to have her come down for that, to be exposed.

Jean did very well academically in college and

received exceptional recommendations from her student

teaching experience. She was named in who's who of

College students. She relates the following incident that

occurred during her search for her first teaching job:

So I tried in all these different places (to find $a j o b)$, and I wrote first and sent my resume. When they saw my list (of experiences) they called me and said, "Oh, it's beautiful. Yes, you're exactly what we're looking for." Then I'd go down, (for an interview), they'd see me in person . . . and their whole attitude changed. This was in 1952, and this suburban school was the last. I was really getting depressed by then. It was getting closer and closer to the time school was to open and I wasn't even hired. I found there was an opening there, and I talked with the principal. "Oh, yes," he said, "I'd love to have you. In fact," he said, "I have a teacher that's pregnant and so she will not be back next year." And he said, "I was wondering who I was going to get to fill this. I looked at your resume. You're exactly what we're looking for." He said, "Now I have to leave town, and I'll be gone about a couple of weeks, but as far as I'm concerned, you're hired." He said, "You can come to the school two weeks from now and I'll meet you there and. . . we'll have lunch together." so I borrowed my mother's car. I was so excited-maybe this man will be OK. Two weeks later I drove up. I went in the building. Nobody was there. So I called, and I said, "Anyone here?" - . (He came from down the hall) and said "May 
I help you?" Yes, I said "I'm Jean." You know what he said? "You aren't . . . you aren't." And he stood there. His face turned beet red. Then, he opened his mouth, and words wouldn't even come out. He finally said, "I tried to contact you, but she decided--the teacher that you were going to replace--she decided she wasn't going to quit after all." Now if you're pregnant, you're pregnant. You don't get unpregnant, do you? That was a blow. Oh, that hurt. So I remember driving home, just crying. I cried, yet I didn't want to let my mother know I was that hurt. Here she had worked, she and my daddy had worked so hard to get us through school and I felt like I was a disappointment to them.

Jean felt responsible for the racism she encountered, and felt that she had somehow failed her parents. The debilitating feeling of trying to break into a system over which you have no control is one recounted by other respondents. Jean's salvation lay in having a family and community to embrace her after being rejected in the larger world.

Many years later, after Jean had become an outstanding teacher and completed her master's degree and administrative credentials, she was appointed to her first principalship:

So I went into the principalship. Noon school was the first school that I went into. And again, the same old thing--prejudice, discrimination raised its ugly head again. They (the parents) were upset because they wanted a male. Of course, they wanted a White male. Well, instead they got a female and a Black. so they called a meeting right away at one of the homes. The first thing they said was, "This is nothing against you, but we did request a male." Now they never said "White male," but I really knew. "And we really feel that we've been shortchanged because we didn't get what we asked 
for." So I listened to all the things that they said and then they sat there and waited for me to respond to that. Well, I had no intention of responding to that. Then I said, "Well, what are some of the things you expect as far as what the children ought to learn?" And they named some things. I said, "what programs are you interested in?" Then I said, "Well, I'm pretty sure we can handle those things," and just completely skirted it (their disapproval), and they worked very well with me. I was at that school for two years and I really enjoyed it.

I recount the above passages in their entirety in order to illustrate the pattern of racism that has been a constant in Jean's life, beginning with her first year out of high school. While Jean experienced discrimination that was more overt than that encountered by some respondents, the dailiness of racism (often submerged in institutional policies and practices) is a fact with which all respondents contend. Jean's way of coping with racism was to plow through it, to develop rational strategies to meet irrational acts and concerns. She developed the ability to do this while maintaining good working relationships with parents and teachers over a 30-year career in education. "Despite the tiring agitation associated with constantly proving one's self, establishing and reestablishing credibility is essential" (Hall, 1988, p. 13). Like other respondents, Jean developed a way of coping that could realistically accomplish her own goals within institutional parameters. A study by Lykes (1983) described discrimination and coping in the lives of Black women who achieved success in 
the professions in the 1940 s and 1950s. She related that these women made quite conscious decisions about how to best cope with the institutional racism they encountered:

In some contexts effective coping may be directly or instrumentally confronting the identified problem. In other contexts flexibility in identifying alternatives may be more effective than a direct instrumental response. A realistic recognition of the external constraints affecting the outcome may interact with the predominant racial composition of the work place in which one identifies the constraints and may demand a more flexible rather than a more directly instrumental approach to the problem. (p. 84)

As hooks, (1984, 1989, 1990, 1993) and Collins (1989, 1990, 1991) asserted, Black women use their "view from the margins" and "outsider within" status to assess institutional dynamics and to plan their strategies for achieving their goals. Jean successfully developed ways of maneuvering within a system that frequently erected roadblocks.

\section{Audrey's story}

[Audrey]. I think what I bring to the legislative process is a commitment of working toward consensus as much as that is possible, or pointing out the possibilities of another way to try to do something. I believe that one of my strengths is bringing people together around a table, around an issue--people who might normally not sit down together to talk about an issue. And I think those of us who have been fortunate in our lives to have lots of different experiences, lots of contacts in different communities outside of our own, I think this is particularly true for lots of people of color. We come with that resource that additional resource and that advantage. 
I met with Audrey in her spacious apartment which overflows with books, magazines, and art, much of it with African or African American motifs, collected on her travels. There is a sense of calm that emanated both from the environment and from the woman. Audrey, in her midforties, has lived all of her life in a mid-size colorado City with a small African American population. An activist in the Black community since adolescence, she worked for several years as the director of an international organization whose mission is to foster peace and justice initiatives for disenfranchised people. Audrey was elected to the state legislature six years ago from a primarily white district. She is divorced and has one adult daughter.

with her mother, father, and two siblings, Audrey grew up in a stable, primarily African American neighborhood and recalls the community of her childhood:

I also have a real strong sense of that neighborhood being connected. As I got a little older and was in grade school, walking back and forth to school, I remember the Smith's who had a grocery store right on the corner. And, of course, as kids we'd run in there and get our candy. But the Smith's were the type of folks who you didn't just run in the store and out again. They'd always ask you, "How are you parents doing?" Or, "How's school going?" They would always say something that was encouraging, but also holding us accountable for our behavior as kids. And the memory of them is really very strong--the Smith family, that store, and that connection for the rest of the neighborhood kids, and the kind of encouragement we got from them. 
Audrey's father was a stern task master who demanded

that she and her siblings do well in school:

Coming home with grades that were below a B was not something you wanted to do. He would question, "Why is this a c? Why not a B or an A?" "You're gonna have to work harder." But the other message about working harder was that you're gonna have to be twice as good as white folks in order to succeed. That was a very clear message.

In addition to her mother and father, Audrey enjoyed a close relationship with both of her grandmothers:

My grandmother on my mother's side was very active in the community. She was very active in the Colorado Association of Colored women's clubs. She was a founder of the Harriet Tubman club, which was a literary group. She was always involved in something. I remember being at my grandmother's house . . . there were always these women in the house planning something. It might be their next tea or their next fund raiser, or whatever .. . and so I got to see that and to listen and be around that kind of activity. And my grandmother on my father's side, same thing.

Black women of Audrey's grandmothers generation were primarily domestic workers for white families. And while this work was low paying, low status, and physically draining, it did not diminish the care they extended to their families, or their stature within the community.

Black women's work took place within two distinct spheres that were at the same time mutually reinforcing and antagonistic. One workplace was centered in their own homes and communities, the locus of family feeling. Beginning in the slave era, the family obligations of wives and mothers overlapped in the area of community welfare, as their desire to nurture their own kin expanded out of the private realm and into public activities that advanced the interests of black peoples as a 
group. In contrast to this type of work, which earned for black women the respect of their own people, participation in the paid labor force (or slave economy) reinforced their subordinate status as blacks and women in American Society. (Jones, 1985, p. 3)

Audrey attended a selective girls high school outside of her neighborhood that both expanded her academic opportunities, and presented difficulties. Although Audrey's choice was to attend her neighborhood high school, her mother's wishes prevailed and she attended along with several others from her neighborhood, the accelerated high school:

But I had negative experiences that still just stay with me. I remember a vice-principal who chastised a group of Black students as we were walking down the hall one day who told us that we should lower our voices because the voices of colored girls were very loud, or words to that effect. "Shhh, be quiet!" I remember being told that...

I had an interest in nursing when I started the school but my counselor was directing me toward commercial foods or commercial clothing, mostly commercial foods. This counselor never said to me, "You're not going to get a job in these other areas," or anything like that, but I just remember a very firm directing toward these other areas. And I resisted that and, of course, my mother wasn't hearing any of that and was always at the school (advocating for Audrey).

But I was determined I was going to stay in these classes, I was going to graduate from these classes, and I did that. And it was interesting because my very first job, right out of high school, was at the telephone company as a records clerk, and I went back and let that counselor know that "I got that job." 
These high school experiences were meant to literally "silence" Audrey's voice. It was her mother's constant advocacy that enabled her to continue to risk the negative feedback she often received from teachers.

Audrey relates two other high school memories when her competence was questioned by teachers:

This was an English class, and we were doing these crossword puzzles one day. Remember I said I was a reader and I had an early interest in film and all of that, and there was one question about a film maker, and I knew that the response was Elia Kazan. And so I wrote that down, and the teacher questioned how I knew that, and he questioned me in front of the rest of the class as though somehow I wasn't supposed to know anything about Elia Kazan. And, again, that sticks with me even to this day. I don't recall that he accused me of cheating or anything, it was just his questioning of, "how do you know this?" . . . I think he was expressing his own surprise that I had that information and questioning where I possibly could have gotten it because in his mind and from his own expectations about me and who I was, this was supposed to be outside of my realm of information.

With her mother's encouragement, Audrey participated widely in school activities, but often felt out of place:

But what I remember about all these activities is that I was always one of maybe one of two or three Black women who were involved . . . So I always had this sense of being kind of under a microscope or on display. I don't know how to describe it, just odd or different. Not quite accepted, but I always felt the challenge of trying to belong or be a part of what I thought was there for everybody to participate in. And I know that I had friends who resisted all that, who just said, "that's a little white girl's thing, and we're not even going to bother". . . But I think I looked at those activities as opportunities to learn and do other stuff. 
Plus, I was being pushed, too, to take full advantage of it all (by her mother).

Collins $(1990,1991)$ referred to Audrey's feelings of being not quite a part of the dominant culture, as being an "outsider within." Outsider Within status is experienced by some people from marginalized groups who have partial access to the milieu, rewards and activities of the dominant culture, but are prevented from the privilege of full membership by virtue of their difference (i.e., race, gender, sexual preference, second language, class, or whatever makes them stand out from the dominant group). As an adolescent, Audrey experienced the "outsider within" state as alienation, however, collins points out that this status can also prove to be a place from which to develop a standpoint of resistance and self efficacy. Audrey's experiences as the "outsider within" were twofold. In addition to feeling "under a microscope," she was also aware of being somewhat removed from the other Black girls because of her choices to fully participate in school activities. Although it was not a part of Audrey's experiences in high school, some African American women report feeling ostracized or excluded when they begin to achieve outside of the usual parameters of the expectations for Black women. Fordham (cited in Talley-Ross, 1991, p. 33) reported that the African American woman who begins to achieve not only faces significant discrimination from white members of the 
dominant culture, but also is viewed suspiciously by members of her own culture who view her as "unblack" or "acting white."

I know about those high school leadership activities that, while my parents and folks in the community were real proud when those kinds of things happened for me. I think it was a dual thing going on--where I would feel kind of uncomfortable if I was being split off from the group in some way. And it's not so much that I recall my friends talking negatively about me doing these things, but something was going on during this time that was about a dual message. It was about striving but at the same time there was this down side to it, and $I$ know that it is something that is still going on today.

As described elsewhere in the study, "outsider within" status can also be cultivated as a special standpoint that allows one to understand social processes more fully and to contribute to a distinctive degree of insight about institutional structures and practices that are not always obvious to those at the cultural center. Audrey describes how, in later life this "view from the margins" has helped her work in the legislature:

I think what I bring to the legislative process is a commitment of working toward consensus as much as that is possible, or pointing out the possibilities of another way to try to do something. I believe that one of my strengths is bringing people together around a table, around an issue--people who might normally not sit down together to talk about an issue. And I think those of us who have been fortunate in our lives to have lots of different experiences, lots of contacts in different communities outside of our own, I think this is particularly true for lots of people of color. We come with that resource that additional resource and that advantage. 
So I know that is an important role that those of us who are people of color in these positions can play. But I think that we end up modeling something that other legislators can pick up on, and they too can learn how to ask these questions and play these same roles [To encourage inclusion and airing multiple viewpoints].

\section{Betty's Story}

[Betty]. So what you do is, you go ahead and do what it is that you want to do. And with my kids (in the gardening project), I try and tell them that people who generally are successful are people who are persistent. Not the brightest, not strongest, or anything else--if a person hangs in there...

I arrived at Betty's building in the heart of a low income Black community in Los Angeles and climbed three flights of dimly lit stairs to reach her sparsely furnished apartment. Shelves of books line the walls of the three "shotgun" rooms. In the middle room, a harp, which Betty began playing a few years earlier, shares space with a new computer being installed that sunday morning by a volunteer "computer whiz," an elderly Caucasian man interested in supporting Betty's work with children creating green spaces in their desolate community. Other musical instruments, folk and found art, multi-hued candles and mini-Alters adorn every surface, and announce that the woman who inhabits this space is one who marches to her own beat.

I first learned of Betty's work while listening to a national radio broadcast that featured her work with 
children creating gardens, pockets of beauty, on abandoned lots and neglected school grounds in the city. Two weeks before our visit, Betty had been honored at the White House for her commitment to, and success involving children in reclaiming and beautifying the desolate neighborhood in which she lives and works. Betty's work has reclaimed not only scores of vacant lots and derelict playgrounds, but in the process the lives of hundreds of children who create and maintain these oases of hope. Betty's long history of political activism in support of civil and human rights, blends with her love of nature and growing things to create this remarkable project in which she is passionately involved.

Betty's parents were both born in the south and each brought children from previous marriages to the union to which she and a sibling were born. Raised in Illinois, Betty remembers her parent's marriage as being difficult. "They broke up, came together, broke up, came together, and when they broke up the last time my father ended up with all the kids." Her father, a mechanic and jazz musician, "gave everything up (his music) and decided he'd rather raise his kids."

The person Betty remembers most as a mentor during her childhood was her Godmother, who for a while provided her with companionship and a model of hard work and self sufficiency: 
Mother's oldest and dearest friend, was a florist and a hairdresser and a business woman all the way. And she was the only woman that I was exposed to when I was younger that I value. I really liked her. . . because she didn't take anybody's nonsense. And she didn't take any stuff from any man. And she was totally independent . . . And as a little girl, eight years old, I would sit in her shop, and she had me wiring and picking and making ribbon roses (for corsages) and things like that. And so I kind of got, I guess, an introduction to a love of flowers or something from her. But I quickly learned that I liked the outdoor stuff much better than that.

Although Betty was a straight A student, she did not like school especially after her family "disintegrated when I was in the fourth grade." She was aware of unequal treatment in her school as early as kindergarten. Although students at the school had only Black students, children were separated by color:

The teachers were old, they were white, they were racist. The used offensive words . . . This kindergarten teacher I had made that (her racism) definitely clear even to the point of dividing the black kids by color--the light skinned ones they treated better than the darker ones, and that type of thing.

While school was a continual disappointment, Betty frequented the library and "read voraciously."

In the local library I could sit down and read in the adult book section. I couldn't take the books home, but since I didn't run around and cause trouble with anything, I think I fascinated my librarian. She would just let me sit there and read. So I read things like Richard Wright and James Baldwin and a whole lot of other stuff before I got into junior high school. 
Unlike the other respondents in the study, Betty did not credit the adults of her childhood as having provided ongoing and meaningful support to her during her early years. When asked if there were other supporting influences in her early life, she answered:

No, no, no. Even with my godmother and my father . . I tend to look at myself as being my own product to a grand extent. And that's because there was never a lot of anything or anyone around. My father was very busy and had to work all the time just to keep everybody together.. . And I think that the other thing I learned very early was that information was everywhere . . . and I understood that power.

My mother wanted me to be a nurse, my father wanted me to be a doctor. . You can't live your life to please your parents or anyone else for that matter, and it just wasn't me.

I used to grow vegetables in the backyard. The school there had a program when I was growing up and a teacher who used to come to your house and see what your place and garden looked like.

They used to come by and grade that garden!

Betty has a deep connection with the natural world,

and "Mother Earth" is her constant teacher:

I am a very earth kind of person. I'm a nature centered person. So it's kind of . . . there's an understanding about a broader reality that comes to people who work with nature than maybe somebody who--not putting anyone down--who sits at a desk does not see. There is something when you are working with cycles, because you have to work with Mother Nature and you have to work by her rules and understand them.

\section{Carla's story}

[Carla]. So I have really made myself do things, and I'm so much more comfortable than I was. So I've had kind of a struggle to project myself, or to put myself in situations where I 
am seen as a leader . . . . I know people who come into these positions probably are easier with that (being seen as a major community leader) than I have been. But I've really tried to push myself.

- . I mean, I do think I have a level of comfort if I know that I'm representing the views of the community, whoever we are defining as a specific community . . . . I don't have a need to push myself too far ahead. I mean, I know there are some people that relish that. But that is not [important to her].

Carla arrived at my hotel room in Boston where she was attending a professional conference. She is a softspoken woman in her middle fifties who has held a variety of regional and statewide leadership positions in educational and mainstream civil rights organizations over the past two decades. She is now the Executive Director of a major philanthropic foundation in a large western city. Carla is married and has two adult children who no longer live at home.

Carla was raised in a mid-sized city with a small African-American population. She speaks wistfully of her childhood:

(I have probably) romanticized my growing-up some, because I think so fondly of growing up there--and of the people that influenced me. I came from a family of women. I lived with my grandmother and my mother and my aunt, and my uncle and another aunt lived next door. And our house was kind of the center of a lot of activity. I was very tied to the church and to a group of women-and men, but largely women-who were my mother's friends who really were very, very supportive of me. And I grew up as an only child, in a community that was nurturing and encouraging. I guess what we'd define as a working class community-people that really 
worked hard at whatever they did and really were role models for me. As you might imagine in the community in the ' 40 s and ' 50 s there were not a lot of Black professional people there. I mean I remember one lawyer and one physician, and I knew one social worker . . but it was really a working class, very tightly knit community.

Carla attended public schools that were racially mixed, "school was a place where we had almost evenly divided white students, Asian students, and African American students, particularly in high school. And so it was a good place." Although not an "exceptional" student, Carla enjoyed school, especially history and English classes and was an avid reader, who often borrowed books from the library. Carla was involved in extracurricular activities at school and in the community, but does not consider herself to have been a leader.

But I wasn't a leader. There were a couple of leaders in our school that were African

American, but I felt really that it was a school in which I participated a lot. Good school activities.

Carla was also active in church, and at the Phyllis Wheately (Named for an 18th Century African American woman poet) branch of the YWCA:

I grew up in the $Y$, and it was a very small $Y$. But the $Y$ secretary was a very important woman in our community . . . and it was the first place that I attended teas where women got together to raise money and had special programs. It was a very important place in our community, and I suppose probably more than the school, I was active at the $Y$.

Collins (1990) and Scott (1981) African American women sociologists reported that clubs, churches, and 
Black sororities have traditionally been important socializing opportunities for girls in the Black community. In these venues young Black women developed a voice, enjoyed opportunities for public speaking and encountered Black women role models. These were places where they could discover their strengths and talents, and be held in positive regard.

Growing up in a city with a small African American population, Carla was always interested in learning more about Black culture.

Well, I knew Harlem was on the other side of those mountains cause I read Lights and Years as a child. And, in fact, I did my eighth grade paper on Harlem, and I was determined that that's where I was going to go and live when I finished college, which I did.

Carla chose to attend a historically Black southern college when she graduated from high school. As a mother who has herself sent two children off to college, Carla expresses a sense of appreciation at her own mother's generosity as she encouraged her only child to leave home to go to a distant city, to the college of her choice. Carla relates the following anecdote about her mother, who died 10 years ago:

She also took me on trips, not too far (they could not afford it), but I remember visiting Canada and California. And you know, when I was nine she took me on a plane ride to Yakima, Washington, because she said, "This is the way people are going to travel when you're an adult, and I want to you to have this experience" ... When I think of it, I almost cry. She really was quite wonderful. 


\section{Katy's story}

Katy arrived more than an hour late for our appointment in her basement office located in a depressed section of Los Angeles, amid abandoned buildings and rubble filled vacant lots. She initially appeared reluctant to be interviewed, and we spent time in casual conversation as she (it seemed to me) decided what her level of participation would be. In order to make the interview less invasive and as relaxed as possible, I took notes by hand instead of using the tape recorder as I did during the other interviews. I later found out that katy has recently been "courted" by the mainstream media, and that she was suspicious of interviews that might misrepresent her words, or "steal" time that she might better use meeting the demands of her busy schedule. My own introduction to Katy's work came through a news article that appeared in the New York Times. Katy's manner warms after we have spoken more about the purpose of the study and it's potential for helping other Black women and girls understand more about their own capacity to assume leadership roles. By the end of the interview a sense of camaraderie had developed between us and we made a date to meet for an informal social time later that evening.

Katy is the Executive Director of a church sponsored nonprofit development corporation in one of the nation's 
poorest Black communities. The organization builds and manages housing for moderate and low income families, senior citizens, and the homeless. It provides a variety of support services for children, adolescents, and families, and spearheads economic development projects designed to strengthen the community.

Katy grew up in a southern state amid a strong extended family of uncles, aunts, and cousins. Although the only child of a single parent, the close proximity of her six girl cousins enabled her to develop strong sibling-like relationships that have continued into her adult life. Like Katy, her female cousins all were high achievers, went to college and graduate school and are in high profile professions around the country. In contrast, Katy states that her male cousins did not fare as well and did not achieve academically or professionally as well as the women did. Katy ponders these differences with her female cousins, but has come up with no answers to account for this.

Katy's family owned several businesses in the town and were involved as early as 1956 in the fight for civil rights for Blacks. Katy learned early that "we were to give back (to the community) and be a part of something" bigger than themselves.

As a small child Katy was an avid reader, making extensive use of the Bookmobile, because the public 
library was not open to Blacks. She was attracted to art and design at an early age, and would have enjoyed joining her family's construction firm. However, there was "no room for girls" in the business, and she eventually majored in landscape design and city planning.

Katy was active in her church from an early age and church involvement continues to be an important part of her life. She states that the church of her childhood was "the only institution that African Americans controlled," and speaks of its importance to her own developing sense of self during those years. Katy is keenly aware of the clearly drawn roles for men and women in her present church (men are the nominal leaders, while women are seen as the followers but perform most of the work). However, she sees the church as an important anchor in poor areas for establishing and building community, and for developing resistance to negative forces within the community, such as drugs and violence. She lives with the contradictions she faces as a woman with major leadership responsibilities in a male dominated church hierarchy, and manages to work around the obstacles, stating that, "understanding the culture of the church allows you to get things done." 
Summary

Although it was not a part of the original research design, the seven respondents were all in their forties and fifties. As African American sociologist Lightfoot (1994) asserted in her study of six highly accomplished, "privileged" African American men and women, mid-life seems to be a propitious time for reflection, for risk taking, for a willingness to expose past pains, as well as to celebrate survival and other accomplishments:
Not only do the middle years provide a wide- angle view of generational contrast, they are also a propitious moment for reflection and reinterpretation of a life story. After years of single-minded ambition, middle age can feel like a time to pause, a time for self-reflection and stocktaking, a time to reenvision the future. For these storytellers, I realized, it is also a time to take risks. Having hit their stride, discovered their strengths, developed a craft and found a voice, they become more daring - . This daring is reflected in the willingness of the six individuals to participate in the intense, demanding process required by this book. (p. 11)
While this study of African American women leaders is of a different scope from Iightfoot's (1994) study which involved intensive interviews over a one year period, there are similarities in the two studies. Throughout the interviews I was aware of the generosity of spirit that propelled respondents to dig deeply for the truth of their lives, even when it dredged up painful memories or unresolved conflicts. Like Lightfoot, I saw among the 
women a greater concern for responding with honesty than for projecting a polished mythical "leader's" image. 
CHAPTER V

DATA AND ANALYSIS

I looked up the road I was going and back the way I come, and since I wasn't satisfied, I decided to step off the road and cut me a new path. (Angelou, 1993, p. 22)

The purpose of this qualitative study was to learn more about leadership from the perspectives, norms, and values of a selected group of African American women leaders. In so doing, I developed a more inclusive view of the realities of leadership, and a better understanding of the impact of the interlocking status of race, gender and class on the pursuit, practice, and perceptions of leadership by Black women. In probing the confluence of the historical, personal and professional events of respondents' lives, I better understand the origins of their leadership, the barriers and supports they encountered, and the ways in which they have come to cultivate and conceptualize their leadership roles. In addition, I developed a more wholistic picture of leaders than is routinely reported in the literature by exploring the intricacies, tensions, and connections between respondents' personal lives, their professional activities, and their socio-political, and a cultural milieu. 
This chapter presents an analysis of the data obtained during interviews with the seven African American women leaders participating in the study. The seven include a high school principal, a senior level community college administrator, the executive director of a large philanthropic foundation, and an elected state official. Three non-positional leaders include a human rights activist who provides the leadership in a number of community activities including as an advocate for gay and lesbian rights, and two other community based workers, one of whom is the founder and director of a successful neighborhood revitalization project involving children and the other a director of programs that build and secure housing and job opportunities for low income and homeless people in one of the country's largest poor Black communities.

\section{Socio-Historical Influences}

It is important to locate this study in the social/political context of the 1960 s and 1970 s when all of the respondents came of age. With the exception of Jean who is 5-10 years older than the other respondents, the women all credited the civil rights movement as having been a major influence on them, their growing sense of definition as an African American, and their awakening as social activists. In varying degrees, all respondents 
were active in that struggle, and three of them directly link their leadership roles today to their activism during the civil rights movement, and to a lesser degree to the antiwar movement.

\section{Locating Myself as Researcher}

My interest in this study grew out of my own experiences as an African American woman who has worked in a variety of leadership positions during the past 18 years, most recently as an elementary school principal and for a philanthropic foundation in the Pacific Northwest. While still an elementary school principal, I began doctoral work in Educational Policy, Foundations, and Administration at Portland State University, and became aware of the lack of congruence between my own day-to-day leadership experiences and the descriptions in the literature of the world of educational leaders. Notably absent from this literature are critical analyses of the impact of race, gender, and class on the practice and conceptualization of leadership. In addition, there is little in the traditional literature that describes leadership within the context of the larger social world, and its limitations and issues. This study hopes to add to the literature a point of reference--that of African American women leaders--presently absent. 
Results

Using a Black Women's Standpoint and Black Feminist Epistemology as a guide (referenced in Chapter III), I followed the lead of respondents as to where our conversations took us. Although I did use probes, as appropriate, I did not attempt to standardize the questions, nor did I require discrete responses that would have made tabulation of the data more uniform. At times I learned as much from the context and emotional content of responses, as from the spoken words. Listening to each tape several times was an important step in this process.

After amassing in the interviews several hundred pages of rich descriptive data, it became my task as researcher to categorize, to sift, and to cull, deciding what to include and what to discard, what was important and what was peripheral, at least for the goals of this study. There were both similarities and differences in the respondents' lives, experiences, and perceptions of leadership, as will be noted. But the intent of the study was not to make rigid comparisons between them. Rather, I hoped to provide a beginning look at a variety of paths to leadership, and to expand the concept of leadership to include "ordinary leaders," of whom there are unknown numbers, already serving in every community. They consider themselves a part of, rather than apart from others, and see their leadership as an endeavor shared 
with others, for a common concern or cause. In interweaving their personal and professional lives, I wanted to present a profile of leaders as fully human, with both strengths and weaknesses, who set a leadership standard in their community. Finally, I wanted to provide snapshots of Black women's leadership that do not minimize the problematic nature of negotiating life in a society that denigrates the worth of Black women, but of folding these realities into the mix, making the contextual explicit.

The paradox of descriptive research is that while it serves well to magnify the dimensions of individual and group experiences, and enables one to achieve a depth of understanding rarely possible in quantitative research, the data do not necessarily generalize to large populations. This is particularly true of studies which involve small populations, such as this study on the leadership of African American women. Nevertheless, certain themes emerged in the study that seem to be supported by the findings of others (Collins, 1989, 1990, 1991; Etter-Lewis, 1991, 1993; hooks, 1984, 1989, 1990) investigating the historical, socio-political, and cultural conditions of Black women. Prominent among these themes are: the role of family and community in the construction of self-esteem and self-efficacy; experiences with racism and sexism; a leadership paradigm posited as 
an act of service and connectedness with others; and the concept of resilience which emerged as the overarching theme heard throughout the interviews. I explore these themes in the next section, and discuss the idea of resilience and its relevance to this study.

\section{Resilience}

Resilience research was introduced by child development researchers and other social scientists who wanted to change the focus of their research agenda from a deficit model (looking at what is wrong with children and their lives), to a model that focused upon the social and environmental factors that foster strength, resistance, and resilience in socially vulnerable children. specifically, researchers sought to isolate and to understand the factors that enabled some children living in negative situations including poverty, abandonment, racism, life with drug affected parents, etc., to survive childhood intact, and to become healthy and wellfunctioning adults. Resiliency studies compared emotionally healthy children with children from similar circumstances and comparable experiences, who exhibited major developmental and/or adjustment problems including criminal activities, drug abuse, violence, in childhood, and later as adults:

As the children studied in these various longitudinal projects grew into adolescence and 
adulthood, a consistent--and amazing--finding emerged: While a certain percentage of these high-risk children developed various problems, (a percentage higher than in the normal population), a greater percentage of the children became healthy, competent young adults. For example, Manfred Bleuler found that only 9 percent of children of schizophrenic parents became schizophrenic, while 75 percent developed into healthy adults. . Similarly, Michael Rutter's research on children growing up in poverty found "that half of the children living under conditions of disadvantage do not repeat that pattern in their own adult lives." (Garmezy cited in Benard, 1991, p. 2)

A profile of the resilient child is of one who: - . develops social competence including . . qualities of responsibility, flexibility, empathy and caring, communication skills, a sense of humor, . . ( who develops) good relationships with both peers and adults, (who develops) good problem solving skills including the ability to think abstractly, reflectively, and flexibly and is able to attempt alternate solutions for both cognitive and social problems, (and who develops) autonomy, a strong sense of independence.. - a sense of one's own identity and an ability to act independently and exert some control over one's environment.

(Bernard, 1991, pp. 3-4)

Historically and currently, the family, the school, and the community are the primary venues where resilient children are likely to connect with the people and participate in the experiences that help them to develop and maintain healthy and productive relationships. Benard (1991) described the "protective factors" that appear to insulate resilient children, build upon their inherent strengths, and mitigate the effects of harsh childhood experiences as: the presence of a strong non-exploitative relationship with an adult with high expectations for the 
child's behavior, and the involvement by the child in positive, esteem building activities at home, in school, or in the community which are recognized, appreciated and rewarded by adults.

Relevance of Resiliency Research to the Study of African American Women Leaders

Much like the children studied in the resiliency research, all respondents in this study grew up with one or more of the environmental and/or social "risk factors" outlined in the literature. All encountered racism throughout their childhood and into their adult lives; as a young child, one woman was abandoned by her mother, and two experienced sexual abuse as children. In young adulthood, one respondent was voluntarily committed to a mental institution, while two others described periods in which they experienced serious mental depression and were unable to cope with the demands of their daily lives.

I found that the resiliency research offered a useful theoretical framework for understanding the rebounding that enabled study participants to overcome hardship, develop a healthy sense of self, and to make substantial contributions as leaders in their communities.

It is interesting to note the parallels between Benard's (1991) concept of resilience and protective factors, and the elements which make up Collins' (1989, 1990, 1991) construction of a Black feminist epistemology. 
Both constructs note the central role that family and community play in helping children develop a standpoint of resistance to negative life experiences, and in the process develop a positive sense of self. In addition, both stress the importance of connectedness with others as a way of defining oneself. The following sections relate how respondents viewed the support of family and community in childhood, in early adulthood, and beyond.

\section{Childhood/Family and community}

The resiliency literature (Benard, 1991), the literature on Black women's standpoint (Collins, 1989, 1990, 1991) and literature on Black women's leadership (Chatman, 1991; Hall, 1988; Talley-Ross, 1991; Woodbrooks, 1991) speak of the importance of supportive adult involvement from family and community in developing a healthy sense of self, and "the courage to lead" (Hall, 1988). Audrey comments on the role that the adults in her community played in her early years:

And I was blessed. I think we who came through my neighborhood, those neighborhoods at that particular point in time were very blessed, because we had neighborhood, we had community. And it was a time when kids really were looked out after by the other adults, and there was a connection to church. And if we were harmed in some way in school---by that I mean if we heard negative messages at school--there was a place to come and talk about that and have that dealt with. I also have a real strong sense of that neighborhood being connected. As I got a little older and was in grade school, walking back and forth to school, I remember the Smith's who had 
a grocery store right on the corner. And, of course, as kids we'd run in there and get our candy. But the Smith's were the type of folks who you didn't just run in the store and out again. They'd always ask you, "How are you parents doing?" Or, "How's school going?" They would always say something that was encouraging, but also holding us accountable for our behavior as kids. And the memory of them is really very strong--the Smith family, that store, and that connection for the rest of the neighborhood kids, and the kind of encouragement we got from them.

Audrey's mother, as often happens in traditional

Black communities, continued to provide guidance and

support to her after her marriage at a young age, and the birth of her child:

And when, later in life as a young woman, after I left high school and was married young and was a teen mom, but had the opportunity to go back to school, back to college, it was my mother who encouraged me to do that and who said, "Don't worry about the child care and all of that because we' 11 make sure that those things get taken care of." She was letting me know that she'd step in and do whatever she needed to do to assist, but that school was an opportunity-going back to school--and getting more education was something that I should do. And when travel opportunities came along, she was the same way. Again, I was a young mother, and by this time I was single, separated, and when my first big travel opportunity came along, which was to go to Africa in 171, my first thought was, "Gee, I can't do this because I've got a five year-old, and there is no provision for her to go on the trip, so how am I gonna do this?" But my mother was just so, she was adamant: "Africa, you're going. And we'll make whatever arrangements we need to make." Which was interesting, because my father was very fearful about me going on that trip, and he didn't say, "don't go," but he kept throwing up all these things that might happen to me if I did go "way over there." so that was kind of interesting. 
Jean mentions the support of both parents, and notes that her father encouraged her and her sisters to attend college. She also points out that it was not the "norm" in her community for Black girls to attend college. Rather, they more often married young. However, she states that her father "never faltered" in his continuing belief that it was important for his daughters to achieve as much as they could:

Looking back at my life, the most important relationships, I think, were family. That's where I got all my strength--from my mother and father. - . my mother was a school teacher. My father was a railroad man . . . They both encouraged all of us to go to college.

It was interesting, because even though my father did not have a college education, his father before him did, and he encouraged my mother and encouraged us to go on to college. It wasn't easy for him at times, because when he was out on the railroad some of the waiters would say to him, Why are you working so hard to send your girls to college? You know all they're going to do is get married and have a bunch of children." But he never did falter. He encouraged us every step of the way to get an education and be self-sufficient.

Despite the closeness of her family, Jean understood that she would have to fight her own battles against racism. Sometimes this meant that she suffered her hurt alone:

I just didn't share a lot of it with my mother. It was pride. I just did not want to disappoint my parents. I knew they both worked hard to send us through college, and they always said that there were going to be obstacles out there, but if you apply yourself you could be successful. So I would fall back on that, and on my own strength. 
Jean's way of coping with the institutional racism and personal discrimination she encountered in college was to become a high achiever who excelled both in academic and extracurricular activities. She used these same coping mechanisms in her professional life, and, at a cost, became a highly respected school leader:

I was very determined to get as much experience in everything as possible, because I knew I was going to need some $k$ ind of leadership training when I graduated. I worked at the newspaper. I became the president of the dorm. I actually was also invited to join sororities, and I ended up being the president of the sorority. I ended up getting national recognition from who's who Among College students. I don't think there was anything I wasn't involved in somehow or other.

Betty's father worked hard and long hours to support his family, and had little help in doing this. However, she remembers that, "the encouragement to excel and do well-they basically came from my father."

Carla lived in what, in the broader culture, might seem to have been an "unconventional" family structure--a household with three women, and next door to other close relatives. However, this arrangement was common in the Black communities of her childhood, and would not have been viewed as unusual, or deficient, in any way. She believes that her ability to take risks, and the development of her leadership skills were rooted in these early family and community experiences:

I grew up as an only child in a family of three women in a very nurturing community. And yet, I went away across the country to school 
(college). When I finished school I went to Harlem to live. . . . Somehow, what I received was the ability to take risks and to think, "oh, this is a wonder, and I'm going to find out about it.. . I wasn't fearful. I just wasn't fearful. . . I often think, do you think my mother was frightened? You know what I mean: Her only child going off. And yet, you know, she encouraged me.. . I mean, it's a wonderful gift I've found that I received. And so when I thought about taking this job it was that sense, I think, of being able to take risks.

I really feel strongly that people really cared about me . . . the community had eyes and ears. - . I think I've been so lucky. I mean, I know there are limits. But I never felt limits. I mean, I just didn't feel that I had to operate within a certain spot.

Carla "never felt limits," and sees her community experiences as systematically imparting to her the

leadership skills she uses today:

I mean, I think people really, really cared, that I was an important person in my community. And it wasn't based on money or social status. It was based on the community's interest in me as a young woman. (At the African American YWCA) I mean, we were taught all kinds of skills --leadership skills, how to act. . . I mean, we knew we had to do certain things. Not that you, perhaps, need to know how to act at a tea, but there were certain social graces that we were taught. And yet we were also taught some about our history, and we felt, I think we were made to feel, we were part of a greater whole. And so I think that women need some of those basics, kind of a basic grounding, and certainly to know that people realiy care about them.

Carla was engaged in a variety of activities in school, in the choir at her church, and most important to her, in the YWCA:

I was also active in the local Phyllis Wheatley branch of the $Y$. And I was a member of the $Y$ teens, and we did a lot of activities in the 
community and around issues. I think that was one of the places that I was most active. But I grew up in the $Y$, and it was a very small $Y$ (and) very important . . . in our community. And I suppose, probably more than the school, I was more active at the $Y$.

The Black college she attended continued to nurture Carla and contributed to her sense of being embraced by a community: "Actually it was probably a good place for someone leaving home for the first time. But it was another place where people really pushed you."

Kim's mother left the family when Kim was a young child, and she went to live with her paternal grandparents. Despite the separation, Kim recalls a close knit community, a large extended family and many happy childhood memories. Her grandmother provided her with the stability she needed during this time:

[Kim]. And, you know, it's an interesting piece, because I don't remember a lot of the first two years that we were there in terms of my reactions to my mother being gone. But I do remember just the warm atmosphere and somebody who was clearly in charge--my grandmother, cooking every day. And there was really, really a lot of comfort that came from my grandmother. I can remember that she would put me over her knees, and I got a lot of comfort from kind of humming . . you know how kids are? You have that little mmm . . . And she would just jostle me on her knees, and I'd kinda go to sleep, or feel very comfortable, and get up and go play. She always made the time.. . She was 60 years old when we came.

The resilience literature (Benard, 1991) asserts that one of the ways in which children develop "protective factors" is by being involved in activities in which they 
feel success, that is noticed and encouraged by adults. Betty was interested in gardening even as an elementary school student, and speaks of the pride she had in the garden she created:

Yeah, even young I figured it out (love of nature). I used to grow vegetables in the backyard. The schools there had a program when I was growing up and a teacher who used to come to your house and see what your place and garden looked like. They used to come by and grade that garden!

\section{Summary of this section}

All of the respondents experienced some degree of nurturing and adult continuity during their childhood. While in two instances the major caretaker shifted, a responsible adult was always "in charge," if not constantly available. In addition, every respondent reported feelings of competence in one or more areas as a child. They were involved in school and community activities and excelled in some areas. All were avid and early readers, as reported in the next section, and were encouraged in this activity.

\section{Construction of Identity}

The construction of identity and the claiming of self is an ongoing process that begins when one becomes aware of one's "otherness," and for many, perhaps for most, continues throughout the life cycle. The theoretical framework of Symbolic Interactionism (Blumer, 1969) makes 
the assertion that what one knows as the "self" is a

social construction that perceives, evaluates, and acts on the basis of the ways in which interactions with others have shaped the person she sees herself to be:

The self is not seen lying inside the individual like the ego or an organized body of needs, motives, and internalized norms or values. The self is the definition people create through interaction with others of who they are. In constructing or defining self, people attempt to see themselves as others see them by interpreting gestures and actions directed toward them and by placing themselves in the role of the other person. (Bodgan Biklen, 1982, p. 35)

This theory of how one comes to know and claim one's "self" presents an interesting dilemma. For the African American woman, and for others whose gender, race, or other difference is so often associated in the collective public psyche with destructive and negative images, the construction of a positive sense of self necessarily involves a sifting process requiring that she both see herself and not see herself as others see her.

Evidence supports the claim that the first step in the process of conscious identity construction for African American women leaders (and it is a recurring first step) is to locate, reject and discard both conscious and more subtle negative views of self that have crept in through the cracks of vulnerability, and by the pervasiveness of the message. Then, the task (again, it is a recurring one) for African American women leaders, is to discover, 
invent, and cultivate those experiences, people, and habits of mind powerful enough to root out what is falsely negative, and to replace them with an awareness of what is potent, and life affirming, and personally true.

The following section discusses activities and experiences that appear to have helped respondents in developing a positive sense of self. They include: importance of reading, mentors and friends, finding a voice, religion/spirituality, and connectedness with others.

\section{Reading as a Primafy Influence}

All seven respondents were avid readers beginning in early childhood, and books were seen as pleasurable, as a means of gaining information about the broader world, and as a means of escape. This finding on the important role that reading played in the lives of successful Black women is consistent with one reported by Talley-Ross (1991) in her study of African American women in non-traditional professions.

Audrey mentioned early in her interview of fondly remembering her mother always reading, and making available magazines, newspapers, and books to Audrey and her siblings. She speaks of the recognition she received in school for being a good reader:

Again, because of my interest in reading, I can remember about third or fourth grade having a teacher who really picked up on that, and she 
was encouraging of my interest-encouraging me to read a variety of things. And I can also remember being selected to read aloud and to work with a group of other students who were having difficulty. I can remember being assigned that role.

Audrey experienced, "pride. Yeah, special, me being picked out and asked to do that."

\section{Identity as struggle and Definition}

The nature and the persistence of historical and contemporary negative images of African American women are embedded in the "taken for granted reality" of our social systems, media, and memories. It is not surprising then, that the act of deconstructing false and negative images is for African American women a conscious act of sifting though and rejecting those things that would diminish her. Each respondent has resisted being externally defined, and each has had help in doing this. As the following section relates, a variety of people and experiences influenced respondents' identity construction in ways both positive and painful. Having lived through the difficult, respondents' speak of lessons learned, and make little distinction between the "easy" lessons and the "hard" ones.

After graduating from an historically Black southern college, Paula went to the east coast to attend graduate school. Although she had been a good student in high school, and had done very well in undergraduate school, 
Paula had some misgivings about being in a primarily white university. During her first year, she proved to herself that she was able to compete with her peers:

And it was probably at that time, even though it was a struggle, where I began to feel really confident in science. Because the first year they gave me a Teaching Assistant's job. The TA worked under the professor . . . I think it was the second semester of my first year. I asked the dean, "May I teach a class and not work under the professor," and he said, "Yes." And it was at that time when I really felt legitimate. Because not only was $I$ in graduate school, I was doing everything equal to my white counterpart. I think it was through those years that I really felt [able to compete in the white world].

Another time when Paula began to change her view of self, occurred after her divorce. Because she had expected to remain married, and had not considered a life outside of marriage, her divorce was a critical turning point for her. Her family's strong message was that a successful life for a woman was based upon a successful marriage (even though her own mother had been divorced):

So it was significant to be able to define myself outside of the program that was planned for me [by her family]. And it's taken many years, and I feel very comfortable there, but clearly that was a major, major turning point. Because there was nothing there. There was no program, there was no agenda after divorce. - . I mean, the support was there, but it's like, "well, no, that's not a role you play out. That's not part of the program." so it was like I had to figure this thing out, and I think that's where the female friends came into play [her women friends were the people who were most helpful during this period of transition]. 
In part, Betty's definition of self has come from deciding how she did not want to live her life. In speaking of her mother and father, she remembers them both doing work that they didn't like. Betty is aware that they had few choices at the time, and did the work that was available to them, but she rejects for herself working just for survival.

My mother wanted me to be a nurse. That was her big thing, she wanted me to be a nurse. My father wanted me to be a doctor. You know, "No, don't be a nurse. Be a doctor." . . All that stuff just was not important to me. . . . I have three great loves in life. I love nature, period. So I don't like to say I love gardening, I'd rather just say I love nature. I love music, and I love art. So it (her work) had to be one of those three. I couldn't see putting the best of my life into something where I would not be a happy person.

Betty became politically active as a young student and came to view herself, her work, and her relationships with others through a political lens. These activities strongly advanced her awareness of self, and her activism has continued for three decades:

I'm a very political person. That didn't make them (her parents) happy either. And political in the sense that I would really do things--you don't just sit there and read books about it and go to meetings about it, but you actively do things. And so my political activism was (important) - . . I was very much influenced by the movements of the 160 s and the riots. I lived through a couple of them, you know. I've traveled, working with different organizations - defense of skokie (Illinois), and fighting the Klan in Orgo, California and those opposed to school integration ... I have mixed feelings about that period (in her life) . . but (I thought that) anywhere they have the 
nerve to try to hide behind their white sheets, you were supposed to be there.

Audrey credits a national invitational leadership program in which she was involved a few years ago with helping her to "find her voice," to develop a greater sense of self confidence, and to claim further legitimacy as a leader. For Audrey, learning to consciously take risks was an important part of this experience:

I think it really got started in a way where I was just really conscious of the risk taking, with the national leadership group experience. I think it (Her view of herself as a leader.) went to another level with this experience. Because I think throughout my life I have been a risk taker. I've been one who wanted to explore, wanted to do it a little differently, and I've done that. But I think this leadership experience helped me.. . take that to another level.

I think I found my voice through that. I think that was a part of it. And by that I mean I think that experience has helped me affirm my own thinking about the world, and my place in it and that my thoughts about issues have value and that they are to be shared. I mean I can't walk around with all this stuff inside. I have to put it out there someplace for people to do with whatever they will. And I think the legislative experience has been like rappelling (a rock climbing maneuver), that I didn't do when I was at the outdoor experience. But actually running for office and going and putting myself in that arena was the act of rappelling. And I understand that now.

Audrey's growing ability to take risks and her changing level of self awareness that resulted, is echoed by other respondents, who also acknowledge that risktaking is something that they have had to cultivate. Carol speaks of her "self-talk" related to risk-taking: 
You know, if it doesn't work, it doesn't. And I talk to myself. Are you at the age where things have to be certain?... Where you have to know where every little thing is? This is a risk, but you might as well give up if you can't take it.

Hamilton (cited in Hall, 1988, p. 11) asserted that learning to take risks is essential for African American women leaders, whom she believes have been taught to live cautiously:

Leaders must master the art of risk-taking and learn to seize every opportunity available to them, while enjoying feelings of uncomfortableness. . . Black women have not been encouraged to (take risks) and that is something that powerful leaders have learned at an early age. I think that Black women have been told to watch out! Be careful! Don't do it unless it feels comfortable. (p. 11)

\section{Mentors and Friends}

The primacy of the roles played by mentors and friends in the lives of African American women is mentioned in the literature (Collins, 1989, 1990, 1991; Hall, 1988; hooks, 1993; Lykes, 1983) as central to the development of a healthy construction of self. Friends and mentors help to guide, to give comfort, and to reflect back an image of worth, capacity, and hope.

Meyers (1980) found that an influence on black women's coping with racism and sexism was the feedback offered by those whose opinions mattered most to them, that is, other Black women. The Black women she interviewed were significantly more likely to compare themselves to other Black women than to white women and the view of black women described by many of them allowed for the possibility of self-esteem and pride. (Lykes, 1983, p. 81) 
Mentors and friends recalled by respondents as important allies were most often African American women, but included men and caucasian women:

In speaking of the president of the NAACP who served as her mentor, Jean recalls his advice when she entered college, and later upon graduation when she found that the school district had already hired its "quota" of Blacks for the year. Jean used this respected community leader as a sounding board, and as someone who would give her pep talks, and help her to remember that she and her activities and successes were not only personally important for her, but for the whole Black community. Because of his access to the city's white power structure, this mentor also frequently was able to find out information that Jean needed in order to successfully stay on her path:

He told me, If you really want to teach, I suggest you sign up as a substitute. What you can do . . . is don't give up. He understood all that discrimination and subtle prejudice that existed. He would say to me, "Remember, you're not down there to have a good time (college). You're down there for a career, and that alone is going to be different from the majority of people down there."

After Jean had successfully taught school for several years, she was noticed by someone in the community as being very talented, and was encouraged to become a school administrator:

[A Black woman college educator] was encouraging me to go ahead and get my Master's degree, which 
I did. She said, "You ought to try to do something besides teaching. You've got a lot of skills there. You've got some leadership (ability)."

Audrey describes a woman she considers as a mentor,

and a role model who continues to be her teacher:

I met Mrs. Brown maybe 15-17 years ago through the work I was doing with the Urban League and in the community. She'd always be at these different community meetings. And what I appreciated about her was that she would just stand up and say what you were thinking but might be afraid to say. She had a way of just cutting to the core of it. And because she was an elder, too, she was listened to in a different way than some of us who were younger. So I admired and still admire her courage and ability to just stand and say what needs to be said-and her energy. She's 70 years old, and she's always everywhere. And she has a love of the arts, and she loves people, all kinds of people. And she's one who is tolerant in the sense that she'll let you know if she's at a gathering of black folks and she hears people talking in a way that suggests that the only people on the planet are black folks: "Well, wait a minute. I go to a white church," she'll just kind of go through the list, and she'll say, "And look at me, I'm still Black. But I have all these other things going on in my life." And I just think her presence is such a healthy contribution to any gathering. I think I've learned from her that it's okay to have a healthy dose of paranoia. And that's what Mrs. Brown does in this community-she's a truth teller. She will say it in a way that you may not like, may be rough, raw, totally unpleasant, but you don't forget what she says and it gets you to thinking. The other thing that she has modeled, I think, is about women looking out after each other and helping each other. And when one woman succeeds at something, praising that, but also being constructively critical.

Although Betty has mixed feelings about whether she has had any true mentors, she remembers with great fondness a woman she knew during her early childhood. 
Mother's oldest and dearest friend was a florist and a hairdresser and a business woman all the way. And she was the only woman that I was exposed to when I was younger that I value. I really liked her. . . because she didn't take anybody's nonsense. And she didn't take any stuff from any man. And she was totally independent. . . And as a little girl, eight years old, I would sit in her shop, and she had me wiring and picking and making ribbon roses (for corsages) and things like that. And so I kind of got, I guess, an introduction to a love of flowers or something from her. But I quickly learned that I liked the outdoor stuff much better than that.

This woman who modeled independence and initiative for Betty continues to stand out for her as a person worthy of respect, but she does not consider her to have been in her life long enough to have been a mentor by Betty's definition.

Friends and mentors were mentioned by six of the seven women as having been important in providing them with advice, material support, acceptance, a model to aspire to, and as a mirror to reflect back their value as Black women. One respondent describes the role that her women friends have played in her life, and she, in theirs:

We could easily be crazy, we could be locked up someplace, we could be overdosing on some drug, we could be doing things that were just totaliy negative, but we've [friends] been blessed and fortunate to identify some of the pieces that work to create a life. And that's what we're trying to do (Black women leaders), that's what I'm trying to do. 
silence and Voice

Language too, shapes social reality and the dynamics of unquestioned power relationships. Standard English, the coinage for success in schools and for mobility in the workplace, locks people both in and out of the cultural mainstream, while voices traditionally tentative and muted (for example, those of women, and men of color, among others), must often be raised to be heard as legitimate contributors to the discourse.

For many, as hooks (1990) asserted, "language is also a place of struggle" (p. 146). Moving from silence to speech is a recurring theme in the everyday acts of those whose voices have been muted or erased. We are silenced by others, and we silence ourselves. Five of the seven respondents were consciously aware of the ways in which silencing occurred in their own lives. Paula reacted most forcefully when asked if there were ways in which she felt she had been silenced as an African American woman. It was a question she had not consciously considered before. She speaks of silence imposed in her family, in the workplace, and in her personal life that was gender related:

[Paula]. Absolutely. Yes. I've been kept in silence my whole life. Professionally, there's clearly a code of behavior, particularly if you get anywhere close to the "old Boy" network. - . I think the way the female thinks and does things is different from the male. I think we do respond a little bit more to our intuition. It's good, it's based on .. . something solid, 
but it is not pure reason. And if, in any way, you talk from that angle, then you're silenced.

And then, I think I imposed a silence on myself when it comes to the brothers (Black men). But it was a choice. I mean, you know, if I didn't -. . in the position I'm in, if I didn't impose that silence I think I would pay, the supreme price (of being isolated from Black men). . . And I didn't want to pay that price.

I think even in my family I was silenced because the males were dominant. My brother is highly successful. He's the star of the family. He just told me recently when we were growing up he could do no wrong and my sister and I could do no right in my mother's eyes. . . . We always had to be better. Whatever we did, it wasn't good enough. And I think that's a form of silencing.

Kim relates the extreme consequences of feeling unable to speak about her sexual orientation as a teenager and young woman.

Like when I talked earlier about coming to some realizations in college (about sexual orientation), the realizations were there a long time before, but I didn't have any words for them--about sexual orientation, whatever. Then you get to be 16 and your cousin calls you a name, and you shut down. And then you hide and - . you know, I dated a lot of guys. And it was like, "Why are you doing this to yourself?" Well, you can't say who you are. You cannot say who you are. And it's like maybe that's what the silence was, too. Not talking, because if I talk I might say who I am.

The cost of her silence propelled her towards a crisis that $\mathrm{Kim}$ experienced as a young woman:

When I was twenty-seven years old I spent--I don't remember anymore--four to six weeks in a mental hospital. And I remember sitting on the bed looking out the window thinking, "How did you get here?" And saying to myself, "You are going to figure out how you got here and you are never going back here again." I didn't have all 
the words I needed, I didn't have all the concepts I needed, but I saw the problem. I think that what I had been doing a lot of my life was just not saying who I was and trying to be a good daughter, a good person, without having to look if I'm good from my inside. Everybody else's version of good . . . So I think that was the beginning of it (breaking the silence). It was figuring out that $I$ was in the hospital because I would not say "no," and that I simply would not say it. And that if I wanted my life, I had to say it.

over two decades later, as a respected community leader, Kim again faced a choice between silence and speaking out, and exposure to she knew not what. But at this time, she was prepared to use her reputation as a leader in the community, and her voice as a powerfully insightful and principled woman, to speak out against what she considered to be a fundamentally dangerous and regressive measure:

When the anti-gay measure came and I read it, I realized several things. One is, I had respect in several places---several different communities. I had respect as somebody who had been an elected official. I had visibility. I had all this stuff, but if I simply stepped out (as a lesbian) it would at least cause some cognitive dissonance in some people's minds. - . I saw this, not just as an attack on me as a lesbian, but a whole anti-democratic step. And so I was there, again saying, "Uh uh, I gotta say who I am here."

Jean learned over the years that she needed to be very deliberate in how she expressed herself. As an "outsider within" (Collins, 1991), a part of the system, but as a Black women relegated to a place on the sidelines or margins, Jean was always aware of the potential 
consequences of both her actions and her words. While always an activist, she chose her battles and the ways in which she went about achieving her "goals for children" in a way that assured success:

I feel as a Black female administrator, you have to work twice as hard. You have to be very sensitive to the fact that you are not responding in an emotional manner, because they assume . - . first they're going to assume that being female you're going to overreact, and being a Black female you're definitely going to overreact. So you spend more time in trying to be logical, trying to weigh the right and the wrong, of what's going to be the best (strategy) in the long run. You try to look down to the future to see what's going to happen as a result of your decision, and I think we are almost forced to do that more so than the male.

The power of the adult over the child, males over females, Caucasians over all other races, the louder voice over the softer one, is so elemental a part of our taken for granted reality that it passes for normal until obvious extremes are reached, as in child abuse and domestic violence, lynchings and official repression of free speech by governments. But in each of these scenarios, those holding the balance of power are capable of silencing others, through either outright force, or subtle manipulation. In either case, the result of feeling sufficiently silenced, is to accept the proposition that one's right to speech is less than that of others, and in the process to relinquish one's right to be fully human. 
Audrey sees a pattern of silencing that she traces

back to her early relationship with her father, and to her subsequent personal and professional relationships with men.

Oh, I think, I know that some of what contributed to the silence was abuse-physical abuse, verbal abuse, at different points in my life. The relationship I have now with my father, for example, is not the relationship I had with him as a child. He was there, he was encouraging about school, he was a provider and all of that. But I spent a lot of time being afraid of my father, too, because his way of disciplining the children in the family was to be physical. Today they would call it child abuse. But then he was doing what he knew to do and what he had been taught to do. I know that now, but then something else was going on. And I know something about that experience also contributed to my choices of men, relationships, and that whole internal thing of somehow not being good enough or not quite doing it well enough to please somebody. And so the silencing piece. . On the one hand being disciplined at home by my father, because my mother was not the one who would do the physical piece-she might do the verbal thing from time to time-but I had this expectation, I think, that my mother... I think I developed a feeling that somehow my mother was an accomplice in this thing. She could have said or done something that would have relieved us of this pain. In fact, my brother left home because of this, the beatings.

My father had a friend who came into the house, and I know that something sexual, something happened there that I still cannot totally get a handle on. I just remember this man liking to bounce me and I think my sister, around on his lap. And I can't take it any further than that, but there are just feelings there about that, and that I was never able to talk about that with my dad or anybody and really get that cleared up.

And I think, too, some of that silencing by men or feeling that I could not speak truthfuliy in the presence of men carried over into other 
intimate relationships. It also carried over into some of my community work, and it affected roles I took on in the organization, telling myself, "I'm just comfortable being in the background."

Audrey describes one consequence of her becoming more vocal and a more independent thinker, as she began to expand her view of the world and of her place in it. During a conversation with a long time African American male political ally, she was chastised for speaking out on a political issue that he defined as "white folks business" that she shouldn't concern herself with:

It was like a piece (of myself) was being cut off. A piece of who I think I an and what I try to represent was being nullified. And that was just real painful. And, again, that experience goes back to some feelings I know I had when I was moving into these leadership roles in high school and feeling kind of split off from the group, and perceiving that people were looking at me differently or treating me differently perhaps.

Moving from silence to speech is an important concept for African American women who have traditionally served in the background, providing the labor, and often developing the plans and strategies for action, in different movements, but leaving the "leadership" to men. A contemporary look at this pattern is reported by Bryan (1988) in her essay on women's involvement in the civil Rights Movement. She described the major contributions of Fannie Lou Hamer, and Diane Nash, as "stalwarts of wisdom, endurance and ability . . they were aware of their influential powers (p. 60). However, these women and a 
great many others who worked on the front lines of the Civil Rights Movement, were not the ones whose voices from that time are remembered.

In addition, as cited in Chapter II, the use of language that is acceptable in the academy presents another set of issues for Black women academicians who want to speak in their authentic voices and have their work be accessible to all Black women, while conforming to what feels like the stilted and artificial (for them) language the academy requires for a successful academic life.

Finally, language is another social arena where an unwritten hierarchy of power exists. Those who feel without a voice, silenced, are most aware of the hierarchy, and those most privileged by it are the least aware of its existence. However, it is a dynamic readily observed in many classrooms, board rooms, and living rooms.

\section{Religion/Spirituality}

In the doctoral dissertation of Talley-Ross (1991), in which she interviewed African-American women in nontraditional professions, she reports the importance of church affiliation for 13 of the 17 study participants. In addition to the support the church provided them as children in developing oratorical and social skills, and in providing access to information, formal church-related 
activities remained a dominant part of their lives as adults. This finding was not seen in my study. Although six of the seven respondents reported that church had played a central role in their childhood lives, only one woman regularly attended church at the time of the study. However, all respondents had a self-defined "spiritual life" and expressed the need for connection with something "bigger than" themselves:

[Carla]. My family went to the local Presbyterian church, and I went to that church until I was about thirteen. And then $I$ went to the Baptist church because that's where all the kids were at. And so I sang in the choir, and I participated in other church activities. In fact, it was at the church--that was one of the places I was encouraged to go to my college because my minister went to it.

The values that move me through this universe are religious values . . . And I know that when I read (meditations) before I start my work, that it is really helpful to me throughout the day.

Although she no longer regularly attends church services, Carla still deeply identifies with the religious values learned in childhood:

There is something about the support . . The need to have something, a kind of higher spirit than me to hold onto. But I think that one's faith can really be a sense of support that's probably like no other. And I know that because whenever I go to church I feel real good . . . And I think religious values shape the way I think about things. I really feel that I want to treat others.. . I want to be treated the way I treat others . . . And that, I think, really does frame the way I look at my life and the way I treat other people. So I think that the values that move me through this universe are religious values. 
Betty has strong negative feelings about the value of traditional churches and religions:

And I've watched the role of the bigger churches, you know, in the community. And as far as I'm concerned, so what? The second thing about it is you cannot talk about religion and women's questions without talking about patriarchs. And most religion is patriarchal - - religion as it is taught is basically used as a measure to control people, period. Patriarchal religion creates zombies. It creates fanatics, you know, unquestioning, unthinking.. . That's what it's about. And we all know the richness of all the patriarchal churches. None of them are broke.

If you cannot look in the mirror and see the face--the reflection of the one Most High in your own face-you will never know power. How can you?

Betty does claim a rich spiritual life and speaks of the importance of a trip to Africa when she met women whose spiritual practices she embraces. She does not wish to talk about the details of these practices or of her initiation:

Well, they're spiritual women. It's a spiritualist thing. And they had met me the first time I was there and did not want me to go home. They kept saying to me, "Why can't you stay here. We have so much to teach you and we want to talk to you." And I didn't know why they wanted to talk to me in particular, but they had singled me out as somebody they wanted to.. - out of all of us that were there, they wanted to really talk to me.

And I was trying to connect with traditional healers there (Africa), I had my own mission. I was actually initiated in a women's spirituality rite on the second time.

Women's spirituality came through working with the earth because the earth is very giving and very nurturing and sustains every form of life. 
You know, watching the stars, watching the birds, watching the birds.. . everything that mother nature sends you is a sign, a renewal of life. . from a rainbow in the sky to the first buds of spring. The resurgence of life always.

When you asked me how working in the garden has inspired my spiritually, it's understanding that time is not really yours. (Mother earth) has taught me that it's not. And the little bit of breath I've got right now is only a microcosm in the overall . . . system of things. And I feel more like Johnny Appleseed planting seeds. And there are going to be mighty oaks I won't live to see grow, but that's not important. And that's what I want to do.

- . All of us are following a map, and that map rolls way, way back (to ancestors). And many people who have helped write this thing, put this thing together, we will never know their names. . . . But they were people who all had a vision and could see past the time in which they lived.

Audrey, who has not attended formal church services

for many years, relates a dream from the night before the

interview that she has just remembered:

It's interesting, when you said that [asked a question about her spiritual life] I realized I had a dream last night about church. It was at a local Baptist Church. I walked a long way to get there. There were obstacles on the way to getting there. My sister was with me when we walked in the door, and we made our way down the aisle looking for a seat. I'm looking for a place to sit and there are people either sitting right on the aisle and they're not making a move to allow me in, or it's a row and there is no one else sitting there and it's like, Gee, do I want to sit in this row all by myself? And I turn around and I look and I don't see my sister and I'm assuming, well I guess she sat down back there someplace. And then suddenly I'm in the front row. And I sit down, and I'm aware of this woman to my left who's looking at me. And I want to ask her, "Is it okay to sit in the front row?" But I decide I'm going to sit in 
the front row. And then at some point we ended up . - . There was a ceremony of some sort where everybody got up and we were to make this huge circle, and the circle was to go back down the stairs of the church and wind in and out of the rooms of the church, but we were all supposed to remain with our hands in one another's hands while we did this. And as I made my way through the different rooms, there were a couple of times when I'd get to . . . I'd realize I was standing by myself and there was no one else to hold on to, and I could go one way or the other, and at one point a woman came along, a woman, and I said, "Which way do I go?" And she said, "Oh, it's that way, honey." Yes, that's what this dream was about! And I kept going the way that these women-it was different women-told me to go. And we wound up back inside the church, and I wound up back in that front row, and one of the women had carried my purse. I had dropped it or something, and in this dream the woman is saying something like, "I carried this for you just to make sure that it was okay, or something like that." And at that point I was trying to . . . I had a sense of, Do I get up and speak now? And that's about where the dream left off. But it's amazing you asked me that question and that all comes back.

When asked what she thought the dream was about

Audrey replied:

I think one of the messages is about this journey that I'm on that is a spiritual journey. And that doors are still opening. That there are choices, there are choices that I'm going to be making, and some of those choices I'li have to make by myself and other times there will be folks helping to point the way, and I guess I can trust that when it happens. But there are going to be times when I have to do that by myself. I'm going to wind up back in the front row. - . And I can remember, too, I can remember looking back and trying to look for familiar people so I could be assured. And there weren't familiar people. And at one point I remember names being called off, and there were some names I recall. And I asked the woman next to me, "Are they calling the names of visitors now?" And she said, "No." 
[Kim]. It's very interesting. I would call myself a spiritual person, I would not call myself a religious person, although I respect what religion does for some people. I was brought up-I was christened Catholic, brought up Methodist-Baptist. I wanted to be an orthodox Jew when I was a teenager until I found out the orthodox Jews make women sit in the balcony. I didn't have the word "feminist," but I knew I didn't want to play. And then I was an atheist--it was, like, I don't believe in this. But the more I see of the world and the more I allow myself to feel that stuff, the more I know there's something beyond me. And that's what I call spirituality--that connection I have with all the other humans on the planet. And the connection I have with all the humans who were on the planet before me. And the humans that will be on the planet. I feel like part of the whole, and I don't do what I guess people would call praying. But I have this little place in my house (an altar) and yesterday I lit the candles--and I said "I need your help, 'cause I'm not doing this right."

I know I do not believe that it's necessary for anybody to be between me and whatever force I want to communicate with in this universe. I do not need a priest. Now I may need some people to help me think it out, or feel it out, or search it out, but I don't need a priest. I don't need anybody who says, "God says to you go do 10 Hail Mary's." I don't need that. So I guess I'd call myself spiritual.

Each of the seven respondents in my study spoke with passion about her spiritual life. Their beliefs are less doctrinaire or traditional than those of the women reported in Talley-Ross's (1991) study. It is perhaps a regional difference, for the participants in the earlier study lived in a southern state, where church going is as much a cultural and social, as a religious experience and an inseparable aspect of the expectations of community life. 
As in other areas of their lives, the respondents in my study appear to be defining their spirituality as they go along, rejecting what doesn't fit them, and exploring and incorporating what does.

\section{Connectedness with others}

Belenky et al. (1986), Collins (1989, 1990, 1991), and others describe connectedness with others as the powerful force that allows women to identify who they are, and who they are capable of becoming. Like the friends and mentors who play a major role in the construction of self during childhood and young adulthood, the ongoing act of connecting with others provides the women in this study with the grounding they need for renewal, for growth, and for survival.

[Carla]. I get a lot of calls from young African American women-sometimes men, but largely women who are trying to make career decisions, who are interested perhaps in philanthropy, which is a very closed field, who need support. And I'm trying very hard to be that (mentor) to other women. And I really put aside time, or I take the time, to have them come in and talk to me.

[Audrey]. And I guess the other thing I would add is that I just feel blessed about other women who are in my life. In a recent conversation we were sharing how much we get from other women we know, and particularly from Black women-that there are these conversations you're able to have that don't even have to have a lot of words in them because there is the nonverbal stuff that goes on. And how healthy that is right now, how important it is to have that right now, given everything else that's going on in the world. We could be crazy, we could be locked up someplace, we could be 
overdosing on some drug, we could be doing things that were just totally negative, but we've been blessed and fortunate to identify what some of the pieces are that work to create a life, and that's what we're trying to do, that's what I'm trying to do.

[Paula]. My female friends, and they're both Black and white, outside of my family probably would be my life's blood. Particularly females who have experienced success or dare to perceive themselves as an individual outside of definitions of marriage or through partnership with a brother. Some of them are married, some of them not. We have been able to give (to each other) a sense of identity, a sense of self the struggles, raising kids, particularly those who are single parents raising kids alone, we could talk, we could cry together.. . they just understood. As a woman you don't have to give the whole story, and they understand. They just understand.

[Kim]. I feel a certain ethical standard and a consciousness of the fact that I'm a model. I like that I know that. It doesn't mean that I won't ever get to do anything that's dumb, it just means that I get to know that when I do something that's dumb I'm still a model. I get to talk about it and tell people. I get to help people understand that we're all kind of human beings. I like that I love. And by that I mean feel connected to. And I don't know that there's anybody that I wouldn't try to effect that connection with. There are some people that frighten me in the world, but I think if you put me to it, I'd sit down and I'd try to work something out, I would. Unless the person was so far gone that you couldn't have a reasonable conversation.

Betty sees a need to become a greater ally with other Black women. In her community many women work on projects and activities but there are few formal opportunities to meet or work together:

One of the things I'm working on now is to try to set up some sort of network where we (Black women leaders) get to know each other. Because 
many times there's a bunch of us out here wheeling and swinging at, you know, a Goliath. only one problem is (if) you're on the left and $I^{\prime} m$ on the right, and somebody else is on the south, we really don't know (if) we've hit him. We need to be able to connect with each other. We need to form our own network. Networking is everything among ourselves. Let us not sit up and reinvent the wheel. If I have a piece of the puzzle that you need, I should be there to offer it to you--you know, whatever I can, whenever I can. We need to have more confidence (in) and respect for one another. . . . confidence and respect.

\section{The Reality of Racism and}

\section{Sexism}

Racism and, to a lesser degree, sexism are realities so interwoven with the daily existence of respondents' lives that they are usually recounted only as background information. However, some events stand out as being particularly painful. One of Kim's most painful adult experiences with racism occurred when she was involved in the campaign against a ballot measure that threatened the civil rights of gays and lesbians. Because she had been active in the gay and lesbian community and was well known and respected, she was surprised and angered at the ways in which nonwhites were excluded from having a voice in the campaign:

[Kim]. I did a naive thing. I went into that campaign and, knowing some of the people there, expected a certain camaraderie and expected a certain respect. This is probably the bigger dilemma because what $I$ saw in that campaign was racism, and I'm Black. But it was a campaign against an anti-gay measure. And I'm a lesbian. So what do I do? Do I stay? or do I go? And I go back and forth, still on that one. To stay felt 
like selling out. To leave felt like destroying the effort. Before we even got off the ground I had calls from several people asking me what I thought about the campaign, whether they should support it or should give their money--these were influential people. So I knew if I left those same influential people would be calling me up to ask me why, and I know me--I would tell them. And I still don't really know. Yes, I do know what I should have done--which was organize at the beginning. The only thing I can come to, is to go in with conviction and knowledge that I was gonna have to do more than simply talk about racism.

Like many other women of her generation, Jean was

told by her parents that she must be prepared to support

herself, and that getting an education was the best way to do this. Connected to this was the message that racism

was a fact of life that she had to learn to deal with.

You never know what's going to be out there for you in this world, and you live in a racist society and you'd just as soon face it, but don't use that as an excuse or a crutch. Just prepare yourself, so if anything happens, whether its job oriented or career oriented or in marriage--you don't know how your marriage is going to be--be able to take care of yourself and be independent. They were successful in that (message to their children) because we are all very independent.

Being prepared by her parents since childhood for encounters with institutional racism and personal prejudice helped Jean to develop a realistic, almost philosophical attitude about racism. She speaks of the frequency with which her decision-making as a Principal was challenged by teachers and parents when she made unpopular decisions based upon what she viewed as what was best for the child, or the program: 
Some parents have been resentful that a minority is trying to give them guidance about their child. . . . Sometimes when I finally did get something across to the parents based on, again, a hard decision that I've had to make, and they have finally agreed, when they left my office they have said racial names about me to my secretary, which she shared.

Although each of the respondents described the ways in which they were wounded by racism, all seven, in different ways, spoke of the pride they felt in being a Black woman who had, despite racism, made a contribution to her community, however she defined community. The sentiments behind Jean's words are echoed by others:

I would say that the very fact that I am a minority person and have grown up in an integrated society and have experienced discrimination and segregation in some form all my life--it has made me a very strong person, so I think in that respect (being a Black woman) has been an asset, because I was able to rise above those kinds of conflicts that we have. In terms of (being a Black woman) opening doors for me.. I had to do that on my own.

\section{The Leadership of Black Women}

The following selections, excerpted from the interviews, represent views on leadership that are sometimes the unique voice of one woman, and sometimes representative of themes heard in several interviews. The degree to which the respondents had consciously considered their roles as leaders prior to the interview is usually apparent. Some, when asked to speak about leadership in general terms, and of their own leadership in particular, 
gave eloquent and lengthy responses, having given much thought to the moral and ethical responsibilities of leaders, and about their own way of defining and exercising leadership. Two of the respondents, Audrey and Kim, had been involved in a year long national invitational leadership program, and had thought deeply and deliberately about the kind of leaders they aspired to become, and the tasks of leadership. This level of reflection is heard in their interviews. In other instances, the interview was the first time the respondent had articulated her thoughts on leadership or consciously defined her own role as a leader. These responses, although brief, are valued for what they are: a beginning effort by the respondent to claim her own authentic definition of her role as a leader and to separate the "doing" from the "reflecting upon." In every interview, the respondent dug deeply for the truth of her life and leadership.

What becomes clear in the dialogues that follow, is that leadership for these respondents is viewed not as something that is divisible from the core of who they are as human beings, but rather it is conceived of as a social contract expressing their deepest values and most profound commitments. Each respondent understands and articulates the relationship between how they live their lives and make personal choices, and the kind of leadership they 
want to provide. They are also aware that the degree to which they veer from the expectations of others, whether allies or critics, and "speak their own truth," will find them sometimes standing and speaking alone. And, to this end, most have decided that the price of being a "truth teller" is one that is part of being a leader, and it is a price they are willing to pay. Finally, what is also clearly related in the transcripts, is that all respondents, even community leaders who work almost exclusively in the Black community, see themselves as citizens of the world, a part of a human community that transcends race, gender, class, and nationality. Despite these commonalities, each respondent sees her own call to leadership in a way that is distinctly personal, as is expressed in the following section.

\section{Betty}

Betty works with children creating vegetable and flower gardens, reclaiming abandoned vacant lots and playgrounds, creating pockets of beauty in one of California's poorest Black communities.

My whole life has been a series of being involved with this, doing that, and totally reevaluating everything I'm doing... sometimes going in a completely different direction.

So what I want to do as much as I can in this incarnation in this particular lifetime is stop the machine [systems that rob people of rights, integrity and power]. You've got to be 
responsible for you own information [thinking for oneself].

In commenting on how she has grown into her

leadership role, Betty contrasts her life now with earlier

activist periods. She sees her project as being

"multinational," a metaphor perhaps, for her openness to

including people of any race who are committed to working

to further the project, and her ideals.

My favorite term for it is, input. You need input . . . So I started investigating stuff, and that was the first time I had listened . . The project is multinational even though it's located in this poor California neighborhood. People from all walks of life, all kinds of people who participate and work, and they're welcome.

Betty in speaking out about what she sees as negative

leadership in her Black community:

And a sister who just passed, a great black sister who will be revered, I believe, in generations to come-Audre Lorde . . . once said, "you cannot tear down a man's house using his tools." I think you cannot be anti-life because you're anti-you when you're anti-life. If it's somebody else's life that you're anti-it all circles right back. (Racism by Blacks.). . - It's not my vision of Black power. It's not my vision of Black identity, and it's not my vision of Black love. My Black power is so strong that it is not threatened by somebody else's stuff. It's not threatened by somebody else's culture, it's not threatened by anybody else's accomplishments. . . . I don't have to put somebody else's (culture) down to make mine seem like something.

Betty's revitalization project includes both boys and girls, but she is strongly committed to fostering 
independence and competence in young girls, and believes

that the leadership of women is crucial:

We need strong female leadership. Women, you see, understand what sacrifice is. They understand putting back their own personal needs-for the good of the whole. Women raise families.. . The woman's voice in terms of leadership in all levels--governmental, spiritual, I mean, everything-needs to be heard, and they need to be empowered all over the planet. Because that's the only thing that's going to save this place.

On power: Nobody likes to give it up, even if they're on the way to hell with it.

So what you do is, you go ahead and do what it is that you want to do. And with my kids, I try and tell them that people who generally are successful are people who are persistent. Not the brightest, not strongest, or anything else-if a person hangs in there.

\section{Carla}

Carla is the Executive Director for a major philanthropic foundation in a large western city.

The progressive foundation for which she works allows her to maintain authenticity as a leader because of the good fit between her goals, and the mission of the foundation:

It is a very progressive foundation, and it has funded for a long time the kinds of groups that I am very interested in supporting: small community based organizations that represent communities of color. I mean, we've had a strong focus on funding at the neighborhood level, and funding, even in our cultural grant making, "smaller" organizations. And so it was that profile of the foundation that really fit into my own personal values. And really supporting community leadership . . And 
because I came from a community where it was very important for people to work together to meet certain goals, working with a foundation that puts so much stress on community involvement was very important to me.

"staying in touch" as a leader is important to Carla, and she continues to read proposals that come to the foundation, and to attend meetings in the community. She describes her contact with the head of a Latino organization:

He said, "I'm really in a pinch, and I know that you often understand what we're trying to do here." I think that:s an important tie... that he can call me and get through to me and that I will listen. And sometimes I may not be able to help, but I am trying.

What Carla brings to her leadership role:

Well, I think that I bring a real sense of caring, and I think I represent a voice for some people who feel that they do not have a voice. I think a real grounding in certain values that - - You know, I often think about who will follow me when I'm gone. I don't think it will be a person that looks like me because I think there are not continuous opportunities for Black women or even Black men in positions like this - . And so I think that I have this little time, and what I want to bring most to this position is a sense of caring and commitment. But I do want people to feel they can come to me, and I want to be supportive of some efforts that I know that other leaders will not be. - . I guess I feel it's a special opportunity to serve as a resource for people in our community that don't always have that resource.

I could say I'm kind of a plodder. There's certainly smarter women than me, and quicker. But I am a hard worker. So I've never seen work as 9-to-5. I don't consider myself a mover or a shaker in that kind of pure sense. So I've had to really, I've tried to take on things that make me somewhat uncomfortable. (Taking risks) 
Kim

Nationally known as a human rights activist, Kim is a leader in several arenas, including the gay and lesbian rights movement in Colorado and nationally.

In addition to the national invitational leadership program that Kim attributes to helping her become reflective on her role as a leader, she is a talented writer and speaker, which comes through in her interview as she expresses her thoughts on leadership:

I think leadership is about responsibility. That's one thing. I think leadership is about being a conduit, that's another. I think that I have a combination of things that I believe in, that help me as I try to make a difference. And I'm not doing this for anybody else. This is about me. . . But in terms of doing the work, since I do believe in people and I do trust that they can somehow communicate, most of them, what they need, I think it's really important to talk to them.

Kim feels a commitment to mentoring the next generation of Black women leaders and actively works to do this:

Number one is that I can't do it all. Number two is other people need the experience. I'm not here to be the permanent fixture. I mean I'm gonna die one day. There are people with more energy. There are people with new thoughts. There are people with different approaches. And it's fine with me. It's like it's their turn. So if I don't relinquish some of that--and that's the other piece, is recognizing that, whether I think I have power or not, I do.

Because she is a powerful speaker and communicator of ideas, Kim has many speaking engagements throughout the 
country. She is aware both of her gifts, and of the danger of losing perspective on herself and her chosen work:

What I know is the biggest danger for me is getting to be the charismatic leader who is isolated from everybody else, and with that in mind, I just try to make a really good effort not to become that person.

Isolation--nobody to call you on anything, nobody to help you with anything, nobody to give you input. You're making it ali up (on your own), and all you get is kudos and kudos and kudos.

I think of myself more as a facilitator and conduit. . . I'm not trying to downplay any of the things that I do, because I think that I do have a knack for taking that thing that is kind of abstract and making it concrete. I think I also have a knack for juxtaposing the stuff out of your head with the stuff out of your heart and bringing those together for people. But I'm not sure that's what leadership is.

Kim further discusses her leadership:

You have the fortune, the gift, that was given to you. It's not yours even, it was given to you. School, language, the ability to hone ideas down to a graspable size. I have those-I didn't do those. . . . I mean there are some parts of me I think I created, but those things are as much a consequence of circumstance and perhaps luck, and so my responsibility is to use them.

Kim is aware of the tension that sometimes arises in

her community between Black men and women around

leadership:

I think that Black women have sometimes given over to Black men on this leadership issue, and I think it's time we stop doing that. We cannot help people grow by holding ourselves back. My not talking does not help somebody else talk! And I think that we abandoned them (Black Men) 
sometime in the sixties when we didn't make enough noise about behavior that was inappropriate and we said, "Well, let them be men." Now what do we expect of men? So we expect men to be jerks! We're here to tell them, "No, you can't be a jerk!"

So, I think that we have an important role to play in terms of, first of all, helping the men grow. And it's a hard role because its a critical role. Its a role that says, "No you may not do the same old manhood stuff. First we want you to do the personhood stuff." I think we also have a role, an important role, to play in terms of being visionaries and being wiliing to take the lead--what have we to lose?

Like Joseph (1994), Kim sees leadership as being the province of many "ordinary people," particularly Black women in her life with whom she talks with on a regular basis:

When I look at the people around, especially the Black women, and I just consider them--like, I don't see any difference between me and them, except that I'm more public. Maybe because I have more time. I'm just more out there, but when I talk to my friends and I talk to the people I know, we're thinking the same thing. so that means, to me, that we're all doing leadership in some way. And if we're talking about a difference of degree, that seems to me a difference in circumstance, and not necessarily character, intent, focus--it just seems like a different circumstance.

Kim sums up her thoughts on Black women's leadership:

And that's part of what we get to teach, whether we like it or not. It's called being a human being. Being aware of people around you. Being aware of yourself, and being aware of the dynamics of interaction and interdependence. 
Jean

Jean is a recently retired High school Principal in Colorado.

After describing the ways in which her leadership was challenged as a new principal in a primarily white school whose parents openly rejected her as their leader: "There are all kinds of challenges, and you work through them because as long as you have your goal on the children, I find it's a lot easier."

There are things that I am sure no other person (leader) would have to go through other than a minority. So when you know that feeling exists (racial name calling), you know feelings of other kinds also exist, because it's difficult for most people to see beyond the color of your skin until you've proved yourself over and over and over again.

Jean offers these thoughts to those who would be leaders:

First you have to be sure that's what you want to do . . . When you've made that step, then you have to be yourself, believe in yourself, and you have to be strong because there are going to be all kinds of things that are going to be thrown your way, that can give you high levels of stress and make you want to stop and turn back, or frustrate you, would say develop some outside interests along with humor... One thing is, you don't feel sorry for yourself.

On leadership and colleagues:

I have some colleagues that I feel have the same basic philosophy about children . . . They weren't there... to build up their ego. They were really in the educational arena for children, so those kinds of colleagues I was easily able to identify with because we could share programs together . . there were several 
colleagues that I really felt were very

dedicated, and could understand, not only the majority, but the minority children too, and the problems that they were having.

Jean's early retirement was prompted by her refusal

to compromise on issues related to the well-being of

children, and to a challenge to her autonomy as a

principal. Like other committed principals in her

district, she faced confrontations with the teacher's

union when trying to dismiss teachers she felt were

harming children. Also, like other principals, she found

an unwillingness by her district to "take on" the union to

dismiss teachers.

I enjoyed being a principal, but one thing I found was that the longer you're a principal the more responsibility they give you, and the more you're responsible for the end results, but you can't make the decisions. That's where I found a tremendous amount of conflict. . . But it became more and more difficult, and then $I$ thought, well, it's time to go while I still liked education, still felt good about education. It was time to go. It was a fulfilling job. I enjoyed it. If I were to do it all over again, even with what I've experienced (most of it was positive) . . . I would still go into education.

The support and respist that Jean earned as a

principal from the Black $\because$ umunity were important to her throughout her career.

I've felt that in being a teacher and an administrator that the Black community, I've felt that they've been very supportive. All the minority parents that I've worked with have shown a high degree of appreciation of the fact that they have a minority person on staff, and they felt that we could understand their problems. 
Jean feels that one of the primary ways she has exercised leadership is though modeling. She speaks of the changing dynamics between her and white teachers in a school early in her career: "So that's when I determined the only way I could change anything at all was through modeling. . . Now to model you've got to be able to do it."

Paula

Paula is a senior level community college administrator and a nationally known expert in science education in a mid-western city.

After many years of working her way up the administrative ladder to her present job as a high level administrator in a community college, Paula has begun to feel some degree of comfort with being in the spotlight as a leader. But, several times during the interview, her ambivalence breaks through as she remarks that she doesn't know if she is really a "leader."

But then at the federal level they begin to recognize you as a leader of some sort, it's just the way the politics go. And then again, I got called to serve on several committees, attending invited conferences, and planning - . and basically, I call them meetings of what the country perceives of as the leaders. I don't know that I'm one. But, again, this was not a design (her position as a leader). It was not politically arranged, because I'm really a private person. 
Paula defines leadership as that which enables her to realize her passions, that of making science accessible to everyone, and of empowering those with whom she works to do the same:

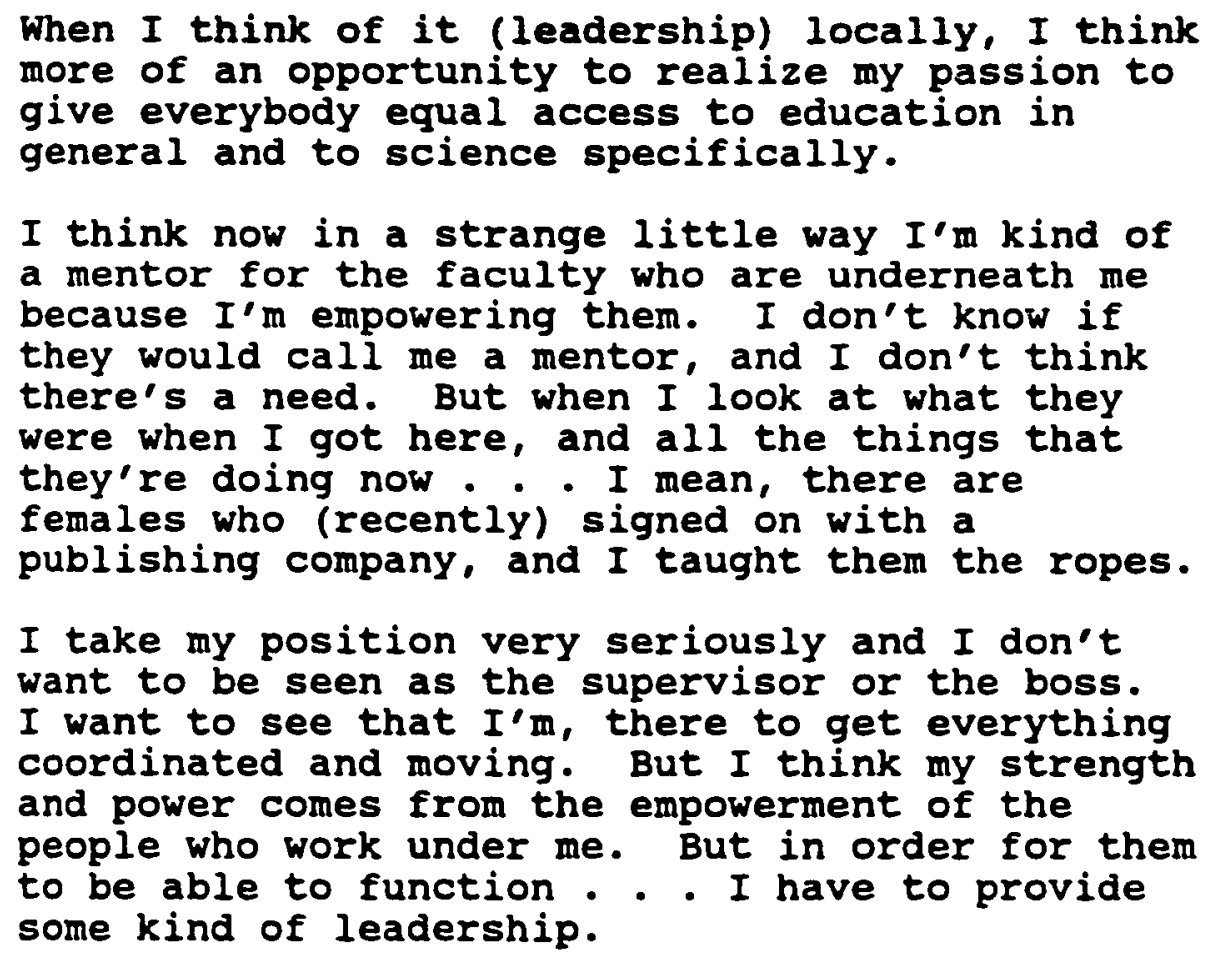

\section{Audrey}

Audrey is an elected official in colorado. Audrey is the other woman who was involved in the national invitational leadership program mentioned earlier. Although she was an experienced and successful leader when she entered the program, the challenging experiences and the validation she felt in being invited to join this program with other high profile leaders, was a turning point for her. As a result of the experiences 
in the program, she became increasingly able to take risks and to branch out into new areas of leadership. As she saw fewer limitations, her view of herself as a citizen of the world, and as a person with untapped potential evolved, and with this, a reassessment of the roles and expectations that others had for her:

[Audrey]. I see myself as an actor in the world and not just in a narrow piece of it.

But I found it, over a period of time, harder and harder to relate to people who in a collective sense were identifying their everyday reality and existence around just race. That box is just so hard for me to be in, and to act out of, and to respond to all the time. And I also came to see it as unhealthy in an emotional-mental health sense. So it's been painful in some ways to have to change relationships, or the way in which I relate to certain people, but it has also been the healthiest thing I could do for myself.

Audrey creates her definition of leadership from the totality of her experiences as a Black woman:

I suppose a lot of people externally would see it (her leadership) as empowerment and political positioning. I think the summary of it would be, because I happened to be born black and a woman I've had some incredible experiences in my life that have shaped who I am. I know a lot of those experiences have been around travel to other places, they've been because I wanted to be connected and learn about people outside of my own community. I've always had this sense of not wanting to be constrained and rebelling against that in the best way I knew how at the time, but always rebelling against that. I'm doing it now in different forms. But I think in doing that, too, there have been times in my life where I felt like there was more than one me. And I particularly feel that now. I think that one of my struggles right now is wanting to make sure that people also appreciate that I am multidimensional and that it isn't necessary to 
call me by my title to get my attention. The title is something that comes along with the role, and it has its place, but it's not who I am. And that realization is something that I've come to as well. I didn't come to it all of a sudden. It's been a process.

As Audrey has redefined herself as a leader, she has also developed an appreciation for simple living. She sees a connection between living a life not focused on material things, and in her sense of freedom from many of the pressures and ethical dilemmas often faced by politicians. She lives without an automobile, without debt, without want, on a very moderate income:

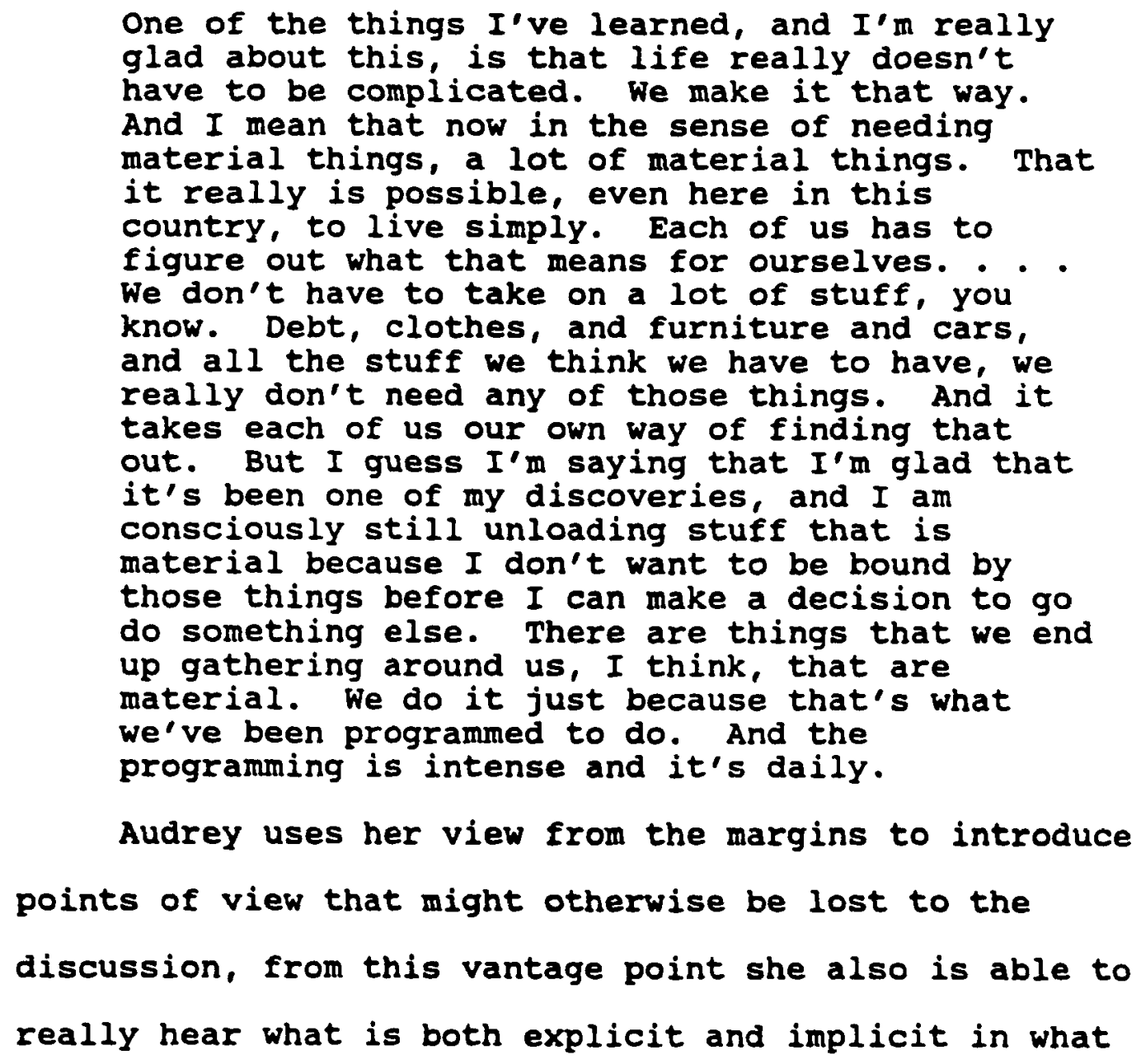


others say, and to help weed out the distractions that

hinder good decision making.

I think what I bring to the legislative process is a commitment of working toward consensus as much as that is possible, or pointing out the possibilities of another way to try to do something. I believe that one of my strengths is bringing people together around a table, around an issue--people who might normally not sit down together to talk about an issue. And I think those of us who have been fortunate in our lives to have lots of different experiences, lots of contacts in different communities outside of our own, I think this is particularly true for lots of people of color. We come with that resource, that additional resource, and that advantage.

Audrey is conscious of the ways in which a view from the margins can be used as an advantage in broadening the parameters of discussions and decision making:

So I know that is an important role that those of us who are people of color in these positions can play. But I think that we end up modeling something that other legislators can pick up on, and they too can learn how to ask these questions and play these same roles (working for inclusion, parity, consensus).

Central to Audrey's emerging leadership paradigm is

the responsibility to share leadership, and to pass it on. She has done this with young women in her community, in a conscious way.

My pulling back (from a leadership role in an organization she helped to found) was happening at a time when I was recognizing how important it is-you can be a catalyst, but you don't always have to be there and be the one who's doing it all. We have to pass these roles on to other people in the community so that they get the experiences and it's ongoing, ongoing, ongoing. 
That Audrey views her leadership as inseparable from

her life was shown above as she simplified her life while

taking on new leadership responsibilities. It is also

seen in the attention she gives to her personal and

spiritual health:

I think another important thing is taking time for myself that is quiet time, that is time to just really reflect and be quiet and think about what I want to do and how I want to do it--to be less busy all the time. Because there was a period when I was just going all the time. It was this meeting, that meeting, getting on a plane, going here, going there. And it was also a time when I was not as healthy physically, emotionally. It's interesting to me these last two or three years I haven't had a bad case of anything. I mean, I've had a cold here and there, but I haven't had (any real illness) - . I don't know, I've just felt more vital, more in control of my own life and what I want to do with it than I ever have in my life. It's more self-directed, I think, than other-directed or (always responding to) other people's

expectations. But I think it's because I make time to be quiet, and I make time to listen to music and go for walks, and spend time with friends. So I'm not always out there (as a public person).

In closing, Audrey talks about what it means to be an authentic person, an authentic leader:

And I guess all I'm trying to say is that I'm becoming more comfortable with myself every day, and learning that, or knowing that you don't have to mend your appearance or amend who you truly are in order to operate in any of these arenas. And I think a part of that affirming that I'm talking about has to do with my own personal truth-that my life experiences are to be trusted. They're mine. I've learned something through them, and it's okay to share those things. And they may be understood, misunderstood, or something in between, but the way you really stretch and grow is by putting it [one's own thoughts, ideas, points of view] out 
there, which also helps people get a better sense of who you are too... (It's) Very risky. Very risky.

\section{Summary}

In Chapter V, I analyzed the data and presented the experiences and reflections of study participants in their own words. Although they are all acknowledged leaders within their communities, and some have achieved national recognition for their leadership, each of the women is a self-proclaimed "ordinary person." As Joseph (1994) stated, diverse cadres of ordinary people are needed to provide the leadership required to meet the economic, social, and spiritual needs of the twenty-first century. As the transcripts reveal, being an "ordinary" leader is not equated with being without special talents, skills, or insights, rather, it is a way of inscribing a set of values about the definition and tasks of leadership: of connectedness, of responsibility, and of ethical commitment. In discussing the professional and personal meaning of their lives, respondents are seen contextually, as real people who appear aware of the infinite variety and complexities of human experience.

Echoes of Black Feminist epistemology are heard throughout the transcripts, as is the dominant theme of resilience. The crucial role of supportive adults and communities in a healthy construction of self is 
highlighted, as is the centrality of having mentors and friends, and a spiritual life. Finally, the emerging definition of leadership orbits around the central concept of connectedness. 


\section{DISCUSSION, CONCLUSIONS, AND RECOMMENDATIONS}

As I play and replay the interview tapes, I am aware of the pauses that also hold volumes of meaning. Each respondent gropes for the precise words that will communicate the truth of her experiences, perspectives, and passions--each weaves together the strands of remembrance and of conscious reflection. It is a struggle for even the most articulate to tell the story of the life that has brought her here. Each woman is aware that the combination of the words "Black," "woman," and "leader" represents for many a source of cognitive dissonance, an anomalous concept, a jolted reality. Most are frequently reminded by the responses of others to their leadership that for Black women to "step outside of the box" is itself a sign of leadership, and also a gesture of defiance. Respondents allude to the ways in which they are "making it up as they go along." As Bateson (1989) has cogently expressed in another context, these women are not so much discovering the contours of their lives and leadership, as inventing them--creating both meaning and direction from their own mix of personal experience (including negative and intermittently debilitating ones), 
cultural legacies, intuitions, skills, and moral and ethical commitments. In the process, they develop new constructions of leadership: "for what we search for does not exist until we find it-both past and the future are raw material, shaped-and reshaped by each individual" (p. 16).

\section{Restatement of Purpose of study}

The purpose of this qualitative study was to develop a contextual view of leadership from the perspectives, norms and values of a selected group of African American women leaders. In so doing I hoped to develop a more inclusive view of the realities of leadership and a better understanding of the impact of the interlocking status of race, gender, and social class on the practice, pursuit and perceptions of leadership by these women.

Unlike traditional leadership studies that posit the norm of leadership as white and male, (or occasionally in more recent studies as white and female) this study is grounded in Black women's standpoint, and places Black women's experience at the center of analysis. By this I mean that the data are presented as legitimate and coherent expressions of Black women's experiences and thought, and not in relationship to its divergence from, or conformity to, white or Black male, or white female experience. 
Review of Research Questions

1. At the intersection of race, gender, and class, how do African American women leaders describe their lives and leadership?

2. What are the similarities and differences in the personal and professional life experiences of African American women leaders?

3. Which educational, social, and experiential opportunities appear to foster leadership development in African American women?

\section{Emergent Themes}

The four major themes that emerged from the data were: resiliency, encounters with racism and sexism, reading as a primary influence, and construction of a positive sense of self. Discussion of these themes follows.

\section{Resiliency}

The overarching theme of resilience characterized respondents' ability to cope with, adapt to, and survive, difficulties in their lives and environments. Most centrally, all respondents dealt with ongoing incidents of racism, which they generally became aware of in early childhood, and continued to encounter throughout their adult lives. In addition, two of the respondents were 
sexually abused as children, and at least two had endured periods of serious emotional distress that required medical treatment. In spite of these and other "risk factors," study participants became healthy, high functioning adults, demonstrating the resiliency that Benard (1991) described. Her studies investigating the ability of some children to bounce back, to survive and to thrive after facing many or continuous adverse or stressful life events described the "protective factors" that appeared to account for the resiliency of these children.

Similar to those involved in the resiliency studies, six of the seven women in my study enjoyed a combination of positive adult relationships, and involvement in school and community activities for which they received recognition from adults. The one respondent who did not receive ongoing and active adult support became a political activist at an early age and as a teenager and young adult identified strongly with leaders of the activist Black power wing of the civil Rights Movement. This respondent does, however, remember one friend of her mother's as being a role model.

\section{Racism and sexism}

As mentioned above, all respondents related ongoing encounters with racism. In addition, all report instances of sexism, although this was not as easy to discern except 
in encounters with other African Americans, when gender discrimination was more evident. For example, one respondent who was clearly the most experienced and qualified for a job to head her city's branch of a national civil rights organization, was passed over in favor of a Black male who would be able to continue the organization's tradition of Black male leadership.

\section{Reading as Primary Influence}

All seven respondents were avid readers beginning in early childhood and they spoke of the multiple purposes that reading served in their lives including: as a source of pleasure; as a means of gaining information about the broader world; and as a means of escape. This finding is consistent with one reported in an unpublished dissertation by Talley-Ross (1991), a study of African American women leaders in nontraditional professions where nearly all of the 17 participants were avid readers as children.

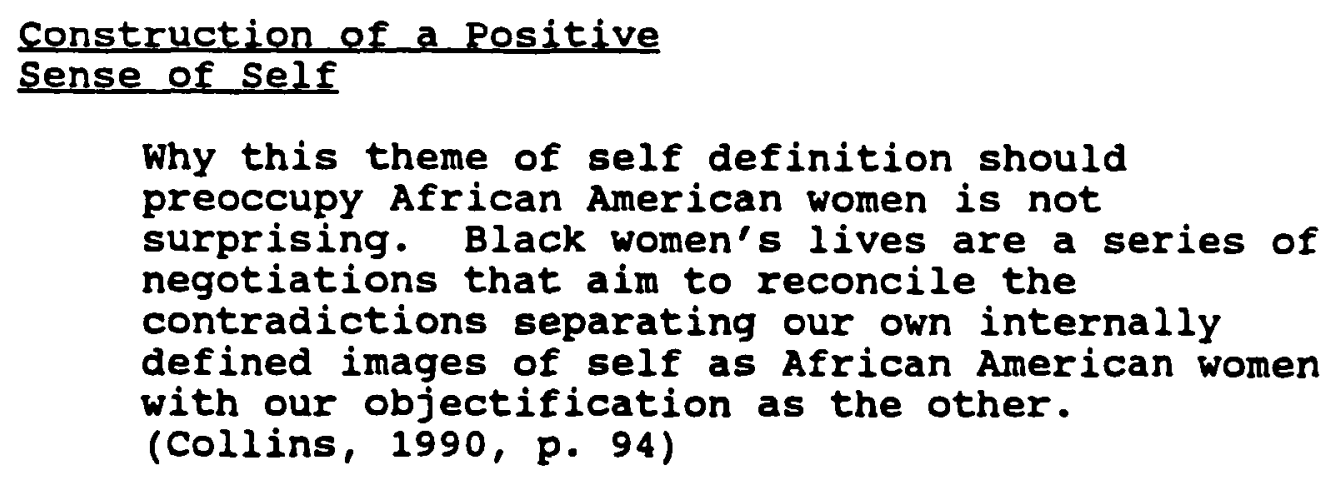


It is no surprise that in a society where most images depicting Black women are negative, developing a positive sense of self is for Black women a continuing process requiring an ongoing stance of vigilance. Throughout the interviews respondents spoke of critical experiences in their lives, and of the people who have most influenced the ways in which they have come to define themselves. All seven respondents alluded to the fact that they are still "becoming": integrating new experiences; rejecting negative images of Black women; challenging racist and sexist encounters; welcoming new challenges; taking risks; becoming discouraged, refueling, and starting over again. Among the experiences respondents said contributed to their positive development of self over time were: the support of family, mentors, friends, and others who expressed a belief in them and in their work (b) a spiritual life or spiritual beliefs and (c) a sense of purpose or mission as a leader concerned with the well being of others. In addition, two of the women mentioned the contribution made by a national invitational leadership program in which they were involved for one year. Along with an outdoor wilderness experience and many opportunities for dialogue and debate with a diverse group of leaders from throughout the state, the program offered these women a time for reflection and for solidifying their intentions and goals as leaders. 
Another respondent mentioned the central role that being a mother played in how she identified herself and her accomplishments. In seeing her adult daughters become confident, capable, "good people," she felt able to measure the "real accomplishments" of her adult life. Finally, as respondents successfully met challenges and accomplished visible goals, their sense of efficacy and direction as leaders increased and became another positive dimension of how they saw themselves.

\section{Methodological Discussion}

First, there is the ontological question. What is the form and nature of reality and, therefore, what is there that can be known about it? Second, there is the epistemological question. What is the relationship between the knower and the would-be-knower and what can be known? Third, there is the methodological question. How can the inquirer (would-beknower) go about finding out whatever he or she believes can be known? (Guba \& Lincoln, 1994, p. 108)

I began this study with the question of why the traditional organizational and leadership literature failed to capture (or even allude to) the reality that I experienced as an African American woman in an educational leadership position. My search led me to studies by and about women (Belenky et al., 1986; Gilligan, 1979, 1982 ; Schmuck, 1980, 1982, 1986; Shakeshaft, 1982, 1986, 1987a, 1987b) who explicated the limitations of using the "scientific" method in doing educational and social sciences research, and exposed the limited view of reality 
represented by the positivist paradigms that dominated the literature. Subsequently, I discovered a growing body of scholarship by African American women across disciplines, investigating the lives and experiences of Black women (Collins, 1990, 1991; hooks, 1984, 1989; Jones, 1985; Jones Montenegro, 1983, 1988) that not only more closely represented my own experiences, but importantly, provided me with a theoretical framework which helped me to make sense of my often alienating and confusing experiences as a leader.

In the course of conducting this study, I have gained a new appreciation for both the promise and the limitations of competing research methods, and for the dimensions of reality they explicate. In applying a postpositivist lens to the study, the evidence suggests that all knowledge (with the possible exception of some areas of physical science) is situated in the social, personal, and historical conditions of both the researcher and the respondent, and that the truth garnered from any research study, is necessarily a partial truth. The value of research studies in education and the social sciences, including this study, lies not in the extent to which they represent universal experience, but rather in the degree to which they provide another framework, a different voice, to the discourse on human experience, and perhaps 
to human survival. (I am indebted to a recent discussion by Yvonna s. Lincoln at Portland state University that helped me to concretize these ideas.)

Having said this, I believe that this study on the leadership of African American women begins to capture voices and record experiences which can contribute positively to more inclusive dialogues on leadership. The women in the study use their experience on the margins (hooks, 1984) to critique their world, and in so doing contribute a perspective on leadership that incorporates their historical and cultural legacies and their individual experience. Black women's historical resistance to being defined by the negative views of others (Collins, 1989, 1990; Etter-Lewis, 1991, 1993; Jones, 1985; Mitchell, 1988), along with the experience of being perpetual "outsiders" (Collins, 1989, 1990; hooks, 1990; Lorde, 1984), provides a backdrop for the ways in which respondents have come to think about and to define their leadership. Therefore, Afro-centric Feminist Epistemology (Collins 1989, 1990) proved to be a useful framework for me in understanding the dimensions of Black women's leadership in general, and specifically for the leadership of study participants. Throughout chapters IV and $v$ the transcripts reveal the ways in which the respondents' thoughts and experiences corresponded with the ideas expressed in these basic claims: 
(1) There are two types of knowing knowledge and wisdom. Living life as Black women requires wisdom since knowledge about the dynamics of race, gender, and class subordination has been essential to Black women's survival. AfricanAmerican women give such wisdom high credence in assessing knowledge. Knowledge without wisdom is adequate for the powerful, but wisdom is essential to the survival of the subordinate. (Collins, 1989, pp. 758-759)

Thus, concrete experience as a criterion for credibility frequently is invoked by Black women when making knowledge claims.

(2) The use of dialogue with other members of a community is important for new knowledge claims --Dialogue implies talk between two subjects, not the speech of subject and object. It is a humanizing speech, one that challenges and resists domination. (hooks cited in collins, 1990, p. 212)

Dialogue promotes connectedness rather than separation and is an essential component of the knowledge-validation process for Black women. (Collins, 1989, p. 763)

Dialogue promotes the discovering of common truths, and the validation of self.

(3) The ethic of personal accountability--Not only must individuals develop their knowledge claims through dialogue and present those knowledge claims in a style proving their concern for their ideas, people are expected to be accountable for their knowledge claims. (Collins, 1989, p. 768)

(4) The ethic of caring--The ethic of caring suggests that personal expressiveness, emotions, and empathy are central to the knowledge validation process. Ideas cannot be divorced from the individuals who create and share them. Talking with the heart promotes connection, builds trust and a common level of presence. (Collins, 1989, p. 765) 
The ethic of caring suggests that personal expressiveness, emotions, and empathy are central to the knowledge-validation process. (Collins, 1990, p. 215)

Thoughts on Developing

Leadership Potential in

African American Girls

As a final question, I asked respondents about their thoughts on young Black girls growing up in today's climate of low expectations, violence, and an uncertain future. They expressed their observations, insights, and concerns. Specifically, I wondered what they believed to be important factors in fostering the next generation of Black female leadership.

Paula believes that the most important task of adolescence and young adulthood is to become inner directed, to find one's own path. In her role as "other mother" to many of her friends children, she practices acceptance, and counsels independent thinking:

I'd tell them there's absolutely nothing wrong you can say. I will not condemn you for anything. I know what it is to try to struggle through to figure out who you are when you're young. So the message that I would give them is, know yourself and determine what do you, what do you want? Because very often we're living our lives for other people,

And then I'd say, "It's okay to take [a risk]. Experience it. And then go for it." You might have to compromise, you might have to make a few adjustments, but when you know what you want you're centered, you're focused. And then you don't have to give up anything you really don't want to give up. And you can probably have more of what you want. 
But keep asking yourself what do you want? And not in a selfish way, but in a way where you can love yourself. I don't think you can be loved any more than you love yourself. So if you never get in touch with yourself, you don't know what you want. What makes you think anyone else is going to know? Particularly a brother?

Because I think that's when you can get the most. And then you don't have to be so angry or disillusioned or upset, or feel like you're not going to get your day. It may sound real simple, but I think that's the answer. And then the other thing . . . is to get educated.

Like Paula, Kim expresses the importance of young women becoming self-directed, and independent thinkers, who learn to take risks and to accept responsibility for their own actions. She also urges them to take on ever greater challenges. When asked what young Black women should pay attention to, Kim replied:

Right now one thing that comes to mind is health--their own health. And that's not just physical health, although I think that's an important part. Emotional, spiritual, psychological. By that, I mean trying to find the places where they can be comfortable in the world. Pay attention to themselves, learn to watch their own behaviors. Learn to watch what you do.

Now I don't think that you can go through life without sacrifice, but I think you have to choose and be conscious of the fact that you're giving something up and what it is--your reasons for that. I think I would tell young women to pay attention to their own needs. Women often say, "Well, I want what you want," or, "Oh, it doesn't matter to me." Pay attention! What do you want? Now there will be times when it doesn't matter. But what do you really want right this minute?

Pay attention to education. Pay attention to relationships, that's important. I don't mean romantic relationships, that's only one kind. But I think that people need to figure out what 
they want from their relationships and what they get. Some of them are already established, and out of what they get, what do they want to change? Pay attention to your own power, your own impact on the people around you. Recognize that, that it's true. You are not helpless; you are not a victim. You are able to talk to people around you. Pay attention to your own fears and see how they restrict you and decide on whether you are going to leave them in place or act in spite of them. Because I believe that is pushing the edge.

Oh! And pay attention to victories! Pay attention to victories and good things, write them down.

In the large city in which she lives, Carla sees many young Black women who seem without direction. Through her work she has supported programs for young African Americans. She believes that strong children, and strong leaders can only develop within strong communities, such as the one that she knew as a child.

Well, you know, I think I look at young women sometimes on the street that are engaged in conversation or hollering up the street, and I think, "Oh, God . . ." If they had a sense of themselves, you know, they would see life differently. They would walk taller. So I think we need to give them a sense of themselves and their connection to our history. I think that is so important. They do not know their glory, and I think they need to be grounded in who they are in order to be prepared to step forward. And I think that's one of the things that the $y$ gave me. And so I think that women need some of those basics, kind of a basic grounding, and certainly to know that people really care about them.

But I think that for kids now . . there don't seem to be enough places for them to be able to be. They can't run, in some cases, to the $Y$ on Saturday: Or the church is not open that day. But I think we need to reinvent that community. 
As the only respondent whose work is now primarily

with young men and women, Betty has given much thought to

what young women need in order to survive and prosper:

More than anything they need to know that they are valuable because they don't get that from anywhere.

They have no self-esteem, or understanding of, you know, what a woman is. They can't define themselves outside of a relationship to a man or their family . . . you know, that makes you nobody. In terms of being able to view yourself as something other than an appendage, they don't have [the ability to do that]. Or to see themselves as a beautiful person, a powerful person, a creative person. You know, that's sad. And there's no mechanism set up which will give them that.

Speaking of her vision for young women Betty describes the following:

There would be programs for the nymphs, the young girls. They need to have women's training - -what a woman is, what it is to be a woman, to have pride in being a woman. And they need to have outlets that are good. I [want] them to be exposed to everything from art and music to the martial arts, you know--they need to know how to defend and take care of themselves. Women are attacked every three seconds around here.

And they need to see their face and in it the light of greatness, particularly young black females. . [to] know their true history. Who are our heroines? That's who we are. And they've got to know where they came from. you think you came from nuthin' you [feel as though] you ought to be acting like nuthin'.

The focus on self knowledge, self efficacy, and exposure to a variety of experiences is a thread that runs through the comments cited above. Respondents acknowledge the difficulties facing young Black women and offer their 
ideas about the responsibilities both of the adults within the community and of young women themselves in creating a future in which they can survive and lead. These comments also provide a bridge for the development of a Black women's theory of leadership which follows.

\section{On a Beginning Theory of Black Women's Leadership: A Paradigm of Connected Leadership}

After reading and reflecting upon the transcripts and related literature over a period of several months, I began to see the emergence of a Black women's leadership paradigm that embraces a set of behaviors and assumptions built upon connectedness with, and responsibility for others. In addition, the model serves as a corrective to the problem of separation of private self from public/leadership self, and posits leadership as embedded and interwoven in one's daily acts and life. The model assumes the basic validity of the Afro-Centric Feminist Epistemology cited above, to Black women's leadership. The Beginning Theory of Black Women's Leadership: A Paradigm of Connected Leadership includes the following assertions:

1. Leadership is posited not as the precious right and responsibility of the few, but rather as "ordinary" and situational, rooted in real world contexts and multiple realities. Leadership is "ordinary" in that it 
is seen as a congruent expression of self in action. It is based upon the wisdom gained through life lived at the juncture of race, gender, and class.

2. Leadership is contextual--a social construction, influenced by social, cultural, and historical contexts (Astin \& Leland, 1991, pp. 7-8). Black women's leadership is rooted in their historical and cultural conditions.

3. Leadership is interdependent, and involves collective effort. Leadership empowers others, is "power with, rather than power over" (Astin Leland, 1991, pp. 7-8). Leadership is shared, rotated, and cultivated in others, particularly in young people.

4. Leadership is inclusive. In a culturally pluralistic society, leadership embraces and is representative of the diverse peoples of the society.

5. African American women leaders bear the responsibility of being "truth tellers," of taking unpopular stands and sometimes standing alone. (Historically taught not to "air dirty laundry in public," some speak of the conscious effort it always takes for them to confront controversial issues, particularly in the Black community.)

6. Leadership means learning to live with, and to manage change in tumultuous times. Equilibrium or homeostasis is not a guaranteed result of effective 
leadership. (When it is not possible to act, a leader can still provide a sense of clarity and direction.)

7. Leadership involves risk-taking. (Many AfricanAmerican women have been taught to be cautious. However, stepping outside of what is known and secure, is a task of leadership.)

The Paradigm of Connected Leadership challenges the existing leadership literature in several ways. As seen in Chapter III, the traditional literature has described leaders and leadership in a number of ways: the trait theory posits that effective leaders are born to lead, while the situational theory purports that leadership can be taught. Proponents of organizational theory look to hierarchical roles and to the discrete skills and competencies needed to operate complex organizations. Others see leadership as primarily the formal or informal exercise of power. More recently, leaders have been charged with providing moral leadership, and with an ethical responsibility for followers. Taken together, these models present historical and contemporary leadership themes generally presented in the literature. What is absent from each is a contextual view of leadership that explores the social, environmental, and personal conditions of leadership and that addresses the question of "who leads?" This study challenges some basic assumptions about past models of leadership (i.e., 
hierarchical, white, and male) and posits leadership as diverse, contextual, interdependent, and situational. The study introduces African American women leaders, and develops a leadership paradigm built upon the concepts of connectedness, and service.

\section{Discussion}

In selecting respondents for this study I looked for women who appeared to be consciously constructing new leadership paradigms as evidenced by the ways in which they went about their own leadership activities and decision making processes. In practice, although none used the term, most respondents viewed themselves in Greenleaf's (1994) words as "servant-leaders." That is, they saw themselves as leaders with the ability to make a positive difference in the service of others in their community. It is important to understand that the word "servant" as used here bears no resemblance to the kind of servitude historically imposed upon Black women. The leaders in this study were fully aware of their personal value, and of their skills and gifts--they understood their power, and their ability to affect change within their communities. Their paths were chosen by them, and not mandated by others. And therein lies the critical distinction between past negative associations of service, and the self-defined commitments of respondents who serve 
by choice and with intentionality. In addition, as the transcripts reveal, most respondents speak of the importance of self-care, of giving and receiving nurture from family and friends, of cultivating a spiritual life, of seeking health and of being whole. They do not see themselves as "selfless," without personal needs or without frailties, and they describe the conscious steps they take to avoid being seen either by themselves or by others as "superwomen." They unanimously reject the notion of service as martyrdom.

In analyzing the transcripts, I faced the researcher's inevitable challenge of deciding how to represent judiciously and with clarity, the data collected. In relying heavily upon the women's own voices in chapters IV and V, I aimed to present the passages that best characterized the essence of the interviews--the experiences, thoughts, commitments, personalities, that seemed to best capture individual respondents. I am satisfied that I have accomplished this. However, I am also aware that even as I developed the most consistent and compelling themes, other data might as well have been a focus. For instance, as illustrated in many passages, the painful experiences of racism and sexism bracketed the existence of each respondent, and came through clearly as they related their stories. As the researcher, it was my decision to follow the lead of the respondents by not 
becoming mired in the pain of the past or of the present, but rather to acknowledge it, and to then move on. As I have reflected upon this, I believe that over time the respondents achieved a delicate balance in this regard: they neither deny the residual pain of their life experiences, nor do they embrace it too tightly. Rather, they keep it at an instructive distance, using it to continually learn from, but not to clutter their paths or direction, or impede their effectiveness. That each woman has developed a satisfying and productive life despite the persistence of racism and sexism as givens in their lives, is a part of the story about African-American women that is too rarely heard. The voices heard in this study speak neither of martyrdom, nor of defeat, but rather of the capacity of ordinary women to play the hand they've been dealt with uncommon finesse.

\section{Summary}

In listening to the voices of the women in the study, one hears the multi-dimensionality of their experience, and the individual meaning they ascribe to their lives and leadership. While they share many areas of commonality as the emerging themes have demonstrated, the ways in which they differ are also of great interest. For it is in their difference from one another that they confound the stereotypes of Black women, it is in their individual 
stories that one discerns their uniqueness. And while they celebrate their connectedness, they also experience the joy of being whole and separate, of being sufficient unto themselves. Kim makes explicit what other respondents expressed in different ways:

Today, I am the five year old forever alone. I am the arrogant, tough acting, frightened girl of twenty who believed she already knew, or could know . . everything. I am the self righteous woman of thirty. I am the woman of half a century who knows so much less than those young girls but understands and loves so much more.

I always know that I am all of the songs my Grandmother sang to me, I am all of the stories she did tell. Today I know that I am part of every song that was ever sung. Today I know that I am part of every story that ever was told. Today, I know that I am joined forever to all others, a mendicant for solace, a supplicant for love, craving reconciliation of life and spirit.

Today I know that I am one of a billion, billion, billion miracles in this, my universe. Today I know that out of those bililions of miracles, I am the only miracle that is me. (Kim, personal communication, February 1995)

\section{Limitations}

The limitations outlined in chapter III generally proved to be relevant as I conducted the study. In limiting the number of respondents to seven, I recounted the experiences and thoughts of only a small cohort of African American women leaders. Also, because they were not randomly selected, and all are in their forties and fifties, it is difficult to generalize their experiences 
to other populations. In addition, although my shared status with respondents enabled me to ascertain nuances, and to understand on a deep level the meaning of the data, it may have prevented me from discerning some things to which I was "too close" to see or hear. Another limitation of the study was that I did not probe for the ways in which respondents who were positional leaders exercised the positional power they had over subordinates, specifically in bureaucratic settings. Finally, an unanticipated limitation of the study was that the modified open-ended interview protocol I used did not elicit much specific information on the role of social class in the lives and leadership of respondents. Because social class and race in Black communities have been interwoven in ways not clearly explicated in the literature, this is an area that will require further and more targeted investigation in future studies.

\section{Recommendations for Educational Policy, Foundations and Administrative studies}

1. The contributions, experiences, and points of view of a diverse group of leaders, in particular women and men of color should become a part of the core curriculum (not an "add on" or "optional" reading assignment). The inclusion of these experiences will provide a more varied and representative view of leadership tasks and perspectives. 
2. Every effort should be made to contextualize all leadership studies. The social, cultural, economic realities of the "real world" should become an explicit part of the leadership discourse. With a better understanding of the context of leadership, students will develop a more relevant and comprehensive view of leadership.

3. Alternative modes of identifying and certifying educational leaders that consider personal and cultural strengths should be explored. For example, experienced community leaders might substitute documented "life experience credit" for some university coursework.

4. Non-degree leadership programs should be made available for experienced leaders who would benefit from opportunities to exchange ideas with other leaders, to reflect upon their leadership, and to develop thoughtful plans for action.

5. Opportunities should be made for African American women leaders to share their experiences with African American girls and young women, and with others who would benefit from this contact.

6. This study should be shared with African American women leaders in order to validate the experience of their lives and leadership, and to "leaders in waiting", to inform, to teach, to encourage. 
I consider the latter two of these recommendations as my continuing responsibilities as the researcher.

Identifying and cultivating leadership for the twenty-first century demands a greater understanding of the established and nascent leadership that presently exists in many communities. Future studies should report on the lives and leadership of those whose stories are unrepresented in the literature, particularly leaders in minority communities. In order to do this it will be necessary to reframe the questions, and to exhibit appropriate skepticism about past taken-for-granted notions about the nature of leadership. In addition, future studies should engage the leaders themselves in reflecting upon, and describing the meaning of their leadership. In the telling, and the respectful listening to a diversity of stories, may lie a contextual understanding of leadership equipped to address a multitude of problems facing humankind as we approach the coming "uncertain century" (Morse, 1994). 


\section{REFERENCES}

Adair, J. (1994). Leaders for tomorrow. In $\mathrm{W} . \mathrm{J}$. Reckmeyer (Ed.), Leadership readings (Section 1 ) (pp. 1-6). Stanford, CA: Stanford University, American Leadership Forum.

Agar, M. H. (1985). Speaking of ethnography. Sage University Paper series on Qualitative Research Methods (vol. 2). Beverly Hills: Sage.

Amodeo, L., Emslie, J. (1985, April 10-13). Minority women in administration: An ethnographic study. Paper presented at the 69 th annual conference of the National Association for Women Deans, Administrators, and Counselors, Milwaukee, WI.

Angelou, M. (1993). Wouldn't take nothing for my journey now. New York: Random House.

Argyris, C., \& Schoen, D. (1974). Theory into practice: Increasing professional effectiveness. San Francisco: Jossey-Bass Publishers.

Astin, H., \& Leland, C. (1991). Women of influence, women of vision. San Francisco: Jossey-Bass Publishers.

Bachrach, P., \& Baratz, M. (1962). Two faces of power. The American Political Science Review, 56(4), 947952 .

Bateson, C. (1989) . Composing a life. New York: Atlantic Month Press.

Belenky, M. F., Clinchy, B., Goldberger, N., \& Tarule, J. (1986). Women's ways of knowing: The development of self, voice, and knowledge. New York: Basic Books, Inc.

Benard, B. (1991). Eostering resiliency in kids: protective factors in the family, school, and community. San Francisco: Far West Laboratory for Educational Research and Development. 
Bethel, S. M. (1994). A leader has high ethics. In W. J. Reckmeyer (Ed.), Leadership readinas (Section 2) (pp. 1-16). Standard: Stanford University, American Leadership Forum.

Biklen, S. K. \& Brannigan, M. (Eds.). (1980). Women and educational leadership. Lexington, MA: D. C. Heath \& Co.

Blumberg, A., \& Greenfield, . (1986). The effective principal. Boston: Allyn and Bacon Inc.

Blumer, H. (1969). Symbolic interactionism: Perspective and method. Englewood cliffs, NJ: Prentice-Hall Inc.

Bogdan, R. C., Biklen, S. K. (1982). Qualitative research for education: An introduction to theory and methods. Boston: Allyn and Bacon, Inc.

Bolman, L. G. \& Deal, T. E. (1988). Modern approaches to understanding and managing organizations. San Francisco: Jossey-Bass Publishers.

Brewer, R. (1993). Theorizing race, class and gender. In S. M. James A. P. A. Busia (Eds.), Theorizing Black feminisms (pp. 13-29). London: Busia.

Bryan, G. (1988, Fall). Her story unsilenced: Black female activists in the civil rights movement. SAGE, $5(2), 60-64$.

Burgos-Sasscer, R. (1990, July 8-11). The changing face of leadership: The role of hispanics. Paper presented at the annual International conference on Leadership Development of the League for Innovation in the Community College, "Leadership 2000," San Francisco, CA.

Callahan, R. E. (1962). Education and the cult of efficiency. Chicago: University of Chicago Press.

Chatman, c. (1991). Personal perspectives of maior factors that influenced the educational personal and professional development of senior level black women. Unpublished doctoral dissertation. Greensboro, University of North Carolina.

Cleveland, H. (1980, May/June). Forward to basics: Education as wide as the world. Change, 12(4), 18-22. 
Cleveland, H. (1982). The leadership of followers, and vice versa. Journal of General Education, $34(3)$, 181-188.

Collins, P. H. (1989). The social construction of Black feminist thought. Sighs: Journal of Women in culture and Society, 14(1), 745-773.

collins, P. H. (1990). Black feminist thought. New York: Routledge.

Collins, P. H. (1991). Learning from the outsider within: The sociological significant of Black feminist thought. In M. Fonrow \& J. Cook (Eds.), Beyond methodelogy (pp. 35-59). Bloomington: Indiana University Press.

Davitz, J. R., \& Davitz, L. L. (1977). Evaluating research proposals. New York: Teachers College Press.

Deal, T. (1986). New images of organizations and leadership. Peabody Journal of Education, 63 (3). $1-8$.

Delpit, I. (1987). Skills and other dilemmas of a progressive black educator. Equity and Choice, $3(2)$, 9-14.

Denzin, N. (1978a) . The research act. New York: McGill.

Denzin, N. (Ed.). (1978b). Sociological methods: A sourcebook. New York: McGraw-Hill Books.

Denzin, N. (Ed.). (1979). studies in symbolic interaction. Greenwich, CT: Jai Press Inc.

Denzin, N., Lincoln, Y. (Eds.). (1994). Handbook of qualjtative research. Thousand Oaks, CA: Sage Publications.

Doughty, R. (1980). The black female administrator: Woman in a double bind. In S. Biklen M. Brannigan (Eds.), Women and educational leadership (pp. 165-174. Lexington, MA: D. C. Heath Co.

Douglas, J. (1985). Creative interviewing. Beverly Hills: Sage Publications.

Dumas, R. G. (1979, April). Dilemmas of black female leadership. Journal of Personality and Social Systems, $\underline{2}(1), 203-215$. 
Dunlop, D., \& Schmuck, P. (Eds.). (1995) - Women leading in education. Albany: State University of New York Press.

Dwyer, D. (1984, Fall). Forging successful schools: Realistic expectations for principals. Educational Horizons, $63(1), 3-8$.

Dwyer, D. (1986. Fal1). Frances Hedges: A case study of instructional leadership. Peabody Journal of Education, 63(1), 9-86.

Edson, A. R. (1988). Pushing the limits: The female administrative aspirant. Albany, NY: SUNY Press.

Erikson, E. (1985). Childhood and society. New York: W. W. Morton.

Etter-Lewis, L. G. (1991). Black women's life stories: Reclaiming self in narrative texts. In $S$. Gluck \& $D$. Patai (Eds.), Women's words: The feminist practice of oral history (pp. 42-58). New York: Routledge.

Etter-Lewis, G. (1993). My soul is my own. New York: Routledge.

Feldman, S. (1979). Nested identities. In N. K. Denzin (Ed.), studies in symbolic interaction (pp. 399-418). Greenwich, CT: Jai Press, Inc.

Foster, w. (1984). Toward a critical theory of educational administration. In $T$. J. Sergiovanni \& J. E. Corbally (Eds.), Leadership and organizational culture (pp. 240-257). Urbana-Champaign: University of Illinois Press.

Foster, W. P. (1988). Educational administration: A critical appraisal. In D. E. Griffiths, R. T. Stout, \& P. B. Forsythe (Eds.), Leaders for America's schools (pp. 68-81). Berkley, CA: McClutchan.

Freedman, M. (1980). Prophets, chiefs, commissioners, and queens: The moral and institutional context of leadership. In S. Biklen \& M. Brannigan (Eds.), Women and educational leadership (pp. 27-34). Lexington, MA: D. C. Heath Company.

Frierson, H. (1990, March). The situation of black educational researchers: Continuation of a crisis. Educational Researcher, 19(2), 12-17. 
Gardner, J. w. (1990) . On leadership. New York: The Free Press.

Gardner, J. พ. (1994). Building community. In W. J. Reckmeyer (Ed.), Leadership readings (Vol. 5, pp. 1-20). Standard: Stanford University, American Leadership Forum.

Giddings, P. (1984). When and where I enter. New York: Bantam Books.

Giddings, P. (1988) . A conversation with Jonnetta B. Cole. Atlanta GA: Sage.

Gilligan, C. (1979, November). Woman's place in men's ife cycle. Harvard Educational Review, $49(4)$, $431-446$.

Gilligan, c. (1982). In a different voice. Cambridge: Harvard University Press.

Glaser, B., \& Strauss, A. (1967). The discovery of grounded theory. Chicago: Aldine Publishing.

Gluck, S., Patai, D. (Eds.). (1991). Women's words: The feminist practice of oral history. New York: Routledge.

Goetz, J. P., Lecompte, M. D. (1984). Ethnography and qualitative design in educational research. Orlando: Academic Press, Inc.

Gosetti, P., \& Rusch, E. (1995). Reexamining educational leadership: Challenging assumptions. In D. Dunlop P. Schmuck (Eds.), women leading in education ( $\mathrm{Pp}$. 11-35). Albany: State University of New York.

Greenfield, T. B. (1988). The decline and fall of science in educational administration. In D. E. Griffiths, R. T. Stout, \&. B. Forsythe (Eds.), Leaders for America's schools (pp. 131-157). Berkley, CA: Mcclutchan.

Greenfield, พ. (1986). Moral, social and technical dimensions of the principalship. Peabody Journal of Education, 63(1), 130-149.

Greenleaf, R. K. (1994). The servant as leader. In $W$. J. Reckmeyer (Ed.), Leadership readings (Section 7) (pp. 4-22). Stanford: Stanford University, American Leadership Forum. 
Guba, E. \& Lincoln, Y. (1994). Competing paradigms in qualitative research. In $N$. Denzin \& $Y$. Lincoln (Eds.), Handbook of cualitative research (Pp. 65-137). London: Sage Publications.

Hall, N. (1988) - Courage to lead. St Paul: University of Minnesota, Humphrey Institute.

Halpin, A. W. (1960). Ways of knowing. In R. F. Campbell \& J. M. Lipham (Eds.), Administrative theory as a quide to action (pp. 3-20). Chicago: The University of Chicago.

Harding, S. (1986). The science question in feminism. Ithica, NY: Cornell University Press.

Haven, E., Adkinson, P. \& Bagley, M. (1980). Minorities in educational administration: The principalship. Annandale, VA: J. W. K. International Corp.

Hine, D. (Ed.). (1993). Black women in America: An historical encyclopedia. Brooklyn: Carlson Publishing.

hooks, b. (1984). Erom margin to center. Boston: South End Press.

hooks, b. (1989). Talking back. Boston: South End
press.

hooks, b. (1990). Yearning: Race, gender, and cultural politics. Boston: South End Press.

hooks, b. (1993). Sisters of the yam. Boston: South End Press.

Hull, G., Scott P., Smith B. (Eds.). (1982). But some of us are brave. Old Westbury, NY: The Feminist Press.

James, J., \& Farmer, R. (Eds.). (1993). Spirit, space and survival. New York: Routledge.

James, S. M. (1993). Mothering. London: Routledge. In S. M. James A. P. A. Busia (Eds.). Theorizing Black feminisms (Pp. 44-53). New York: Routledge.

Jewell, K. (1993). Erom mammy to miss America and beyond. New York: Routledge Publishing. 
Jones, E. (1982, July). Minorities in school administration and problems in documentation. Arlington, VA: AASA.

Jones, E. \& Montenegro, X. (1983). Women and minorities in school administration: Strategies for making a difference (ERIC/CUE Diversity Series No. 85). New York: ERIC Clearinghouse on Urban Education.

Jones, E. \& Montenegro, X. (1988, August). Women and minorities in school administration. Washington, DC: American Association of School Administrators.

Jones, J. (1985) . Labor of love labor of sorrow. New York: Basis Books.

Joseph, J. (1994). Leadership for America's third century. In W. J. Reckmeyer (ed.), Leadership readings (Section 17) (Pp. 5-11). Stanford, CA: Stanford University, American Leadership Forum.

Kanter, R. (1981, Fall). Power, leadership, and participatory management. Theory Into practice, 20(4), 219-224.

Kincheloe, J., \& McLaren, P. (1994). Rethinking critical theory and qualitative research. In $N$. Denz in \& $Y$. Iincoln (Eds.), Handbook of qualitative research (138-157). Thousand Oaks, CA: Sage Publications.

Kohlberg, L. (1984). The psychology of moral development. San Francisco: Harper and Row.

Kouzes, J. M., \& Posner, B. Z. (1987). The leadership challenge: How to get extraordinary things done in organizations. San Francisco: Jossey-Bass Publishers.

Ladner, J. (1987). Introduction to tomorrow's tomorrow. In $S$. Harding (Ed.). Eeminism and methodology (pp. 74-96). Bloomington: Indiana University Press.

Lightfoot, S. L. (1983). The good high school. Portraits of character and culture. New York: Basic Books, Inc.

Lightfoot, S. I. (1994). I've known rivers: Lives of loss and liberation. Reading, MA: Addison Wesley Publishing Company

Lincoln, Y., \& Guba, E. (1985). Naturalistic inquiry. Newbury Park, CA: Sage Publications, Inc. 
Lomotey, K. (1987, July) . Black principals for black students: Some preliminary observations. Urban Education, 22(2), 173-181.

Lorde, A. (1984) . Sister outsider. Trumansburg, NY: Crossing Press.

Lovelady-Dawson, F. (1980, December). Women and minorities in the principalship: Career opportunities and problems. NASSP Bulletin, 64(440), 18-28.

Lykes, M. B. (1983). Discrimination and coping in the lives of black women: analyses of oral history data. Journal of Social Issues, 39(3), 79-100.

Lyons, N. P. (1983, May). Two perspectives: on self, relationships, and morality. Harvard Educational Review, 53(2), 125-145.

Maslow, A. (1970). Motivation and personality (2nd ed.). New York, : Harper and Row.

Mccracken, G. D. (1988). The long interview. University Paper Series on Qualitative Research Methods. Newbury Park, CA: Sage Publications, Inc.

Mitchell, J. (1988, Fall). Three women: Cultural rules and leadership roles in the black community. Sage;, 5(2), 9-19.

Montenegro, X. (1993). Women and racial minority representation in school administration. Arlington, VA: American Association of School Administrators.

Morse, S. W. (1994, winter). Leadership for the new millennium. In W. J. Reckmeyer (Ed.), Leadership readings (Section 17) (pp. 1-4). Stanford, CA: Stanford University, American Leadership Forum.

Mueller, K. \& Kendall, M. A. (1989, March 27-31). Capturing leadership in action: Portrajture as a collaborative tool. Paper presented at the annual meeting of AERA, San Francisco, CA.

Nielsen, J. M. (1990). Eeminist research methods. Boulder: Westview Press.

Noddings, N. (1984). Caring. Berkeley: University of California Press. 
Oakley, A. (1981). Interviewing women: A contradiction in terms. In H. Parlee M. Brown (Eds.), Doing feminist research (Pp. 30-61). London: Routledge.

olesen, V. (1994). Feminism and models of qualitative research. In N. Denzin \& Y. Lincoln (Eds.), Handbook of gualitative research (pp. 158-174). Thousand Oaks, CA: Sage Publications.

Ortiz, F. (1980a, April 7-11). Career change and mobility for minorities and women in educational administration. Paper presented at the annual meeting of the AERA, Boston, MA.

Ortiz, F. I. (1980b, April 7-11). The structure of educational administration in public school organizations. Paper presented at the annual meeting of the AERA, Boston, MA.

Perinbanayagam, R. S. (1985). Signifying acts: Structure and meaning in everyday life. Carbondale: Southern Illinois University Press.

Perkins, C. O. (1988). The pragmatic idealism of Mary McLeon Bethune. Atlanta, GA: Sage (Vol V, No 2, pp. 30-36).

Piaget, J. (1981). Intelligence and affectivity. Palo Alto, CA: Annual Reviews Inc.

Regan, H. B. (1990, Summer). Not for women only: School administration as a feminist activity. Teachers College Record, $91(4), 565-576$.

Rutherford, C. (1992, winter). African American women and typical female low wage jobs: Is litigation the answer? Yale Journal of International Law, 17(1), 211-223.

Sarason, S. (1971). The culture of the school and the problem of change. Boston: Allyn and Bacon.

Schein, E. (1985). organizational culture and leadership. San Francisco: Jossey-Bass Publishers.

Schmuck, P. (1980). Changing women's representation in school management: A systems perspective. In $S$. Biklen and Brannigan (Eds.), Women and educational leadership (pp. 239-260). Lexington, MA: D. C. Heath and Company. 
Schmuck, P. (1982). Sex equity in educational leadership: The oregon story. Newton, MA: Educational Development Center.

Schmuck, P. A. (1986, February). Gender and education: culture, character, and concepts. Unpublished manuscript. Invited Lecture, University of South Florida.

Schoen, D. (1983). The reflective practitioner. New York: Basic Books.

Scott, P. (1981, February 21). Some thoughts on black women's leadership training. Paper presentation Wellsley College, Wellsley, MA.

Shakeshaft, C. (1982, March). Aramework for studying schools as work settings for women leaders. Paper presented the annual meeting of the AERA, New York.

Shakeshaft, C. (1986, Spring). A female organizational culture. Educational Horizons, 64(3), 117-122.

Shakeshaft, c. (1987a, April). organizational theory and women: Where are we? Paper presented at the annual meeting of the American Educational Research Association, Washington, DC.

Shakeshaft, C. (1987b). Training school administrators: The making of the man in the principal's office. Teacher Education Quarterly, 14(2), 59-67.

Shakeshaft, C. \& Hanson, M. (1986, Winter). Androcentric bias in the "Educational Administration Quarterly." Educational Administration Quarterly, $\underline{22}(1), 68-92$.

Shakeshaft, C., \& Nowell, I. (1984, Winter). Research on theories, concepts, and models of organizational behavior: The influence of gender. Issues in Education, 2(3), 186-203.

Smith, C. H. (1980, March). The peculiar status of black educational administrators in the university setting. Journal of Black Studies, 10(3), 323-334.

Smith, D. (1987). The everyday world as problematic. Boston: Northeastern University Press. 
Standfield, J. (1994). Ethnic modeling in qualitative research. In N. Denzin \& Y. Lincoln (Eds.), Handbook of qualitative research (pp. 175-188). Thousand Oaks, CA: Sage Publications.

Stewart, J. (1978). Understanding women in organizations: Toward a reconstruction of organizational theory. Administrative science Quarterly, 23(2), 336-350.

strauss, A. (1982). Social worlds and legitimation processes. In $N$. K. Denzin (Ed.), Studies in symbolic interaction (PP. 171-190). Greenwich, CT: Jai Press Inc.

Strauss, A., Corbin, J. (1990). Basics of qualitative research. Newbury Park, CA: Sage Publications.

Talley-koss, N. C. (1991). The African American woman practicing in non traditional professions: A life history approach. Unpublished Dissertation. University of South Florida, Tampa.

Terry, R. (1985) - Leadership: A preview of a seventh view. Unpublished paper.

Thomas, J. (1993). Doing critical ethnography. Newbury Park, CA: Sage Publications, Inc.

Tietz, I., \& Shakeshaft, c. (1982, March 21-23). Toward a reconstruction of organizational theory: Androcentric bias in A. H. Maslow's theory of human motivation and self-actualization. Paper presented at the Annual Meeting of the AERA, New York.

Valentine, P. \& McIntosh, G. (1990, December). Food for thought: Realities of a women-dominated organization. The Alberta Journal of Educational Research, 36(4), 353-369.

Valverde, L., \& Brown F. (1988). Influences on leadership development among racial and ethnic minorities. In N. J. Boyan (Ed.), Handbook on research on educational administration (pp. 143-152). New York: Longman.

Vaz, K. (Ed.). (1995). Black women in America. Thousand Oaks, CA: Sage Publications.

Wall, C. (Ed.). (1991). Changing our own words. New Brunswick, NJ: Rutgers University Press. 
White, E. (Ed.). (1990). The black women's health book. Seattle, WA: Seal Press.

Willy, C. (1994). Unpublished address to American Leadership Forum, Yamhill, Oregon.

witherell, C., \& Noddings, N. (1991). Stories lives tell: Narrative and dialoque in education. New York: Teachers College, Columbia University Press.

Wolcott, H. (1973). The man in the principal's office: An ethnography. New York: Holt, Rinehart, and winston.

Woodbrooks, c. (1991). The construction of identity thought the presentation of self. Unpublished doctoral dissertation. Ohio State University, oxford, Ohio.

Yeakey, C. C., Johnston, G. S., Adkison, J. A. (1986, Summer). In pursuit of equity: A review of research on minorities and women in educational administration. Educational Administration euarterly, 22(3), 110-149.

Yukl, G. (1989). Leadership in organizations. Englewood cliffs, NJ: Prentice Hall, Inc. 
APPENDIX A

LETTER TO PARTICIPANTS 
Gloria A. Gostnell

2327 N.E 16th Ave

Portland, Oregon 97212

(503) $287-7350$

Dear

I am a doctoral student at Portland State University in the Department of Educational Policy, Foundations, and Administration. Within a week or so I will be calling you to ask if you would be willing to participate in my dissertation study titled: Portraits of African American Women's Leadership: Constructing Realities, Shifting Paradigms.

The subject of this dissertation is of importance to me personally and grew out of my awareness that little of the literature required in my course work in organizational theory and leadership addressed the impact of race, class, or gender on organizational reality . In short, my reality was missing. While the literature on women and leadership has increased during the past decade, studies describing the contextual experiences of women of color remain infinitesimal.

It is my belief that the stories of African American women leaders bave much to add to the literature, and that the study could be of potential benefit to young women of color and to others outside of the cultural mainstream. I am enclosing information from my prospectus to tell you more about the project. I hope that you see the merit of the study and will agree to take part.

\section{Study Particulars:}

(1) Participants will be asked to fill out a Participants Profile (15 minutes) and to take part in a face to face audio-taped interview of approximately two hours. A follow up telephone interview ( 30 minutes or less) will give participant and interviewer an opportunity to expand or clarify the transcript.

(2) All interviews are confidential. Identifying data i.e., name, context, etc. will be masked to assure anonymity for the women involved in the study.

(3) Participants will see a draft of the study before it is submitted in final form and will have an opportunity to clarify, amend, or delete information at this dime.

(4) Participants who wish will be given a copy of the final study.

I will call you in a few days to see if you will be able to participate, and to answer any questions you might have.

Sincerely,

Gloria A. Gostnell 
APPENDIX B

\section{PARTICIPANT PROFILES}


9. Who were the wage earners ia your boumebold? What work did they do?

10. Describe your formel edncation, inchation degrees and dates awardad.

11. Which beat decribes the stodent body of ectools atteaded by you?

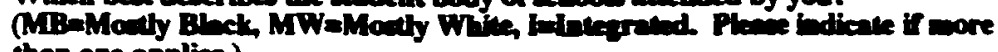
then one applies)

Elewentary. Junior Iigh High Sebool College

12 Which beas deacribes the rece of mout of yoar cuachers?

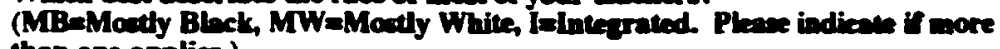
than one applies.)

Elementary. Junior High Dith School College

13. What is your present work?

Is this a paid position?

How may hours a week do you typically epeed at this work?

13. Lint the three pocitions you beld prior to your present position.

14. Liet your involvement in comennity setivities or in ofher ectivities important to you.

Please wee the back of thi pase for any additional information that would belp me to gain a fuller pieture of your tife. 
APPENDIX $C$

INTERVIEW SCHEDULES AND PROBES 


\section{INTERVIEW SCHEDULE}

THE LEADERSHIP OF AFRICAN-AMERICAN WOMEN: CONSTRUCTING REALITIES, SHIFTING PARADIGMS.

As I mentioned in my letter, the purpose of this interview is to gain an understanding of what your life is like 25 an African American woman leader in your community. For the purpose of this study I define leader as someone who exerts influence in her community to achieve defined goals.

I am interested in exploring with you the personal and professional experiences that have shaped the person that you are today. I would like to start off by asking you to describe your childhood and memories that stand out most for you.

(Probe) From Belenky, et. al (1986)

-What stands out for you in your life over the past few years? What kinds of things have been important? What stays with you?

-Tell me something about what your life is like right now. What do you care about. think abour?

-Is the way you see yourself now different from the way you saw yourself in the past? What led to the changes? Have there been any ocher turning points?

-Looking back over your life what relationships have been really important to you? Why? 
QUESTIONS RELATED TO BLACK WOMENS STANDPONT, OUTSIDER WITHIN, CONTROLLING IMAGES

- As a child what messages do you remember getting about youncelr? From your family? Your school? Who was your favorike adult? Why?

- Are there ways in which being a Black Woman bas been a diadranatage in your profecsional life?

- Are there ways in which being a Black Woman has beed an edvantage?

-What qualities do you most valee sbont yourselr?

-How would you describe your spiritual or religious life?

- Many Black women writers have written about the many ways in which they have been silenced and the process of finding their voice. Are there ways in which yoe hove felt (feel) sileseed? What has beet inportant in helping you to and your voice.

Last Qweation:

What would you say to young Black women asking your advice about what they stould pay attention to in bailding their own lives? 
From Astin \& Leland (1991)

(1) Socinl Contert and Ineses:

Critical incident:

Beckground- Family, childhood, edrention

Values \& commitoments

Involvement in eccial isases

(2) Leadership

Identifies antecedents: childhood, sdolescent, and college experiences; specific roles; and extent of participation

Obtain personal attributes, positive and negative;

-Styles and strategies ased in varions leaderalip

contexte, expecially in bring abont change; and

Critieal eveats in developing eurreat bederahip style

Mentors and Role Models:

- descriptive assesameats and

-ascesumeat of power and infloence available and exercised.

(3) Peer and Work Relationships

- Eramines internetion and commoniention with same and opposite gender work associntes quality of internction

sense of personal acceptance and contribution in varied contexts

- nature of sepport, extent and foeus of discussions quality of wortring relationships

-Reveals comparisons with opposite-gender leadership styles and effectiveness:

-networking and the need for and availability of colleagneship and support sroups or individuals

and signifieant peers whose leadership has brought about change.

(4) Perronal and Professional Development

\footnotetext{
-Inspects costdemands and benefital sativinctions of leadership experiences;

-iruntuntiondobatacles in bringing about objectives or changes; -supportive or facillitating foctors;

and specific alteratioas or abandomment of plans and

objectives.
} 
-Reviews personal support athl, partmer/goonse, friends, and extent of shared commiturents to issees or activities; -relationship of personal life to profescional responabilities : onature of visibility and demandomeomplementary and or competing;

-replenishment, sources for rechnging (Le. beinure, recreation ectivities, socinl life

eppiritual and/or religions involvement)

- Eealth, energs keveh personal eeeds for time, schedule;

-Scrutinizes professional agenda, career plans and appirations from present situation;

issues or activities that seem attrective or challenging; roles that might be played in the fature;

-talents, experiences, comnitments that might be societal -resources 
APPENDIX D

RESEARCHER NOTE 


\section{Researcher Note}

Because as the researcher, I share similarities of race, age, and leadership status with respondents in the study, I thought it important to understand to the degree possible, the experience of respondents as they went through the interview. I decided to experiment with interviewing myself, and went through the process, answering on a tape recorder the questions which I had asked participants to respond. While a somewhat artificial process (me interviewing myself), the exercise enabled me to become more aware of the emotional demands on participants made by the interviewing process in general, and especially when they explore exploring painful or unresolved past experiences. I conducted this experiment mid-way through the interviews and would recommend it to other researchers.

The experiment did not lead me change the way I conducted the remaining interviews, the protocol was eliciting useful data. However, it did help me to appreciate the vulnerability of these respondents, and of others who agree to take part in research studies, and to further my appreciation of my ethical responsibility as a researcher to the respondents. 